\title{
3D Cancer Models: Depicting Cellular Crosstalk within the Tumour Microenvironment
}

\author{
Teresa Franchi-Mendes ${ }^{1,2}$, Rodrigo Eduardo ${ }^{1,2}$, Giacomo Domenici ${ }^{1,2}(\mathbb{D})$ and Catarina Brito $1,2,3, *(1)$ \\ 1 iBET—Instituto de Biologia Experimental e Tecnológica, Apartado 12, 2781-901 Oeiras, Portugal; \\ mtfmendes@gmail.com (T.F.-M.); rodrigomeduardo33@gmail.com (R.E.); giacomo.domenici@ibet.pt (G.D.) \\ 2 Instituto de Tecnologia Química e Biológica António Xavier, Universidade Nova de Lisboa, Av. da República, \\ 2780-157 Oeiras, Portugal \\ 3 The Discoveries Centre for Regenerative and Precision Medicine, Lisbon Campus, Av. da República, \\ 2780-157 Oeiras, Portugal \\ * Correspondence: anabrito@ibet.pt
}

Citation: Franchi-Mendes, T.; Eduardo, R.; Domenici, G.; Brito, C. 3D Cancer Models: Depicting Cellular Crosstalk within the Tumour Microenvironment. Cancers 2021, 13, 4610. https://doi.org/10.3390/ cancers 13184610

Academic Editors: Vítor Gaspar and João F. Mano

Received: 2 August 2021

Accepted: 8 September 2021

Published: 14 September 2021

Publisher's Note: MDPI stays neutral with regard to jurisdictional claims in published maps and institutional affiliations.

Copyright: (c) 2021 by the authors. Licensee MDPI, Basel, Switzerland. This article is an open access article distributed under the terms and conditions of the Creative Commons Attribution (CC BY) license (https:// creativecommons.org/licenses/by/ $4.0 /)$.
Simple Summary: The tumour microenvironment is composed of multiple non-cancerous cells that communicate with the tumour cells, influencing their behaviour and impacting the progression of the disease and the response to therapy. To better understand the disease and try to predict the response of patients to therapy, there has been an effort to develop experimental strategies that could represent this complex human tumour microenvironment in a dish (in vitro). In this review, we describe the importance of each cell type and review the in vitro approaches recently developed for cultivating together the different cell types (co-culture) in a three-dimensional configuration to better represent the architecture of the tumour and cell interactions (3D models). We describe and compare the different studies and outline perspectives on the 3D modelling strategies and their potential impact in cancer research and anticancer drug discovery.

Abstract: The tumour microenvironment plays a critical role in tumour progression and drug resistance processes. Non-malignant cell players, such as fibroblasts, endothelial cells, immune cells and others, interact with each other and with the tumour cells, shaping the disease. Though the role of each cell type and cell communication mechanisms have been progressively studied, the complexity of this cellular network and its role in disease mechanism and therapeutic response are still being unveiled. Animal models have been mainly used, as they can represent systemic interactions and conditions, though they face recognized limitations in translational potential due to interspecies differences. In vitro 3D cancer models can surpass these limitations, by incorporating human cells, including patient-derived ones, and allowing a range of experimental designs with precise control of each tumour microenvironment element. We summarize the role of each tumour microenvironment component and review studies proposing 3D co-culture strategies of tumour cells and non-malignant cell components. Moreover, we discuss the potential of these modelling approaches to uncover potential therapeutic targets in the tumour microenvironment and assess therapeutic efficacy, current bottlenecks and perspectives.

Keywords: 3D cell models; tumour microenvironment; heterotypic interactions; cell communication; immune infiltrate; cancer-associated fibroblasts; tumour-associated endothelial cells; tumour spheroids; hydrogels

\section{Introduction}

Recapitulative disease models are important experimental tools, particularly in the oncology field in which new drugs fail in clinical trials more than in any other area [1]. During the drug development pipeline, more than $95 \%$ of the anticancer agents will not reach the market [1]. Therefore, ongoing research on experimental cancer modelling aims 
at achieving better predictions of drug efficacy by increasing the translational potential of the models employed [2].

Tumours are composed of heterogeneous populations of tumour cells, as well as nonmalignant cells and non-cellular elements, such as extracellular matrix (ECM) and soluble factors secreted by the different cell types [3]. The non-malignant cellular components and non-cellular elements constitute what is defined as the tumour microenvironment (TME). The role of the TME in tumorigenesis, tumour progression, invasion and metastasis has been acknowledged over recent decades and is today unquestionable [4-7]. Moreover, the TME has been increasingly implicated in the modulation of drug response and resistance [8-11]. Therefore, the use of therapeutic agents targeting TME-mediated signalling or TME composition has been proposed $[3,4,12]$, such as the drugs that inhibit matrix metalloproteinase (MMP) activity [12], disrupt angiogenesis [13] or immunomodulators (e.g., immune checkpoint inhibitors) [14].

The cellular elements of the TME may vary within different cancers and consequently the ECM and other non-cellular components. In solid tumours, non-malignant cells can be recruited locally (tissue-resident) and systemically $[8,15]$ and comprise mainly fibroblasts, endothelial cells (EC), and innate and adaptive immune cells $[8,16]$. Mesenchymal stromal cells (MSC), adipocytes and other bone marrow-derived cells have also been reported [3]. In addition to direct cell-cell contacts between tumour cells and the different TME cell types and amongst the latter, the main TME mediators are soluble factors (such as cytokines, chemokines, proteases, and other enzymes involved in remodelling the ECM) and exosomes. Moreover, the importance of the bidirectional communication between cells and the ECM, as well as of ECM remodelling, has been increasingly acknowledged, as recently reviewed in detail by Werb and co-workers [17], amongst others [18,19]. The ECM functions not just as physical structural support but also regulates local concentrations of soluble factors and cell-cell interactions, in addition to ECM-cell direct interactions [18,19]. ECM is also a guiding scaffold for chemotaxis and tumour cell invasion [20]. ECM can regulate important cellular processes such as proliferation and migration, through activation of different signalling pathways (e.g., ERK and AKT) [21]. Tumour ECM composition is usually characterized by increased deposition of collagens, especially fibrillar types, as well as fibronectin and tenascin [22-24]. Moreover, ECM fibres present an aligned orientation that facilitates cell migration $[25,26]$. Enzymes related to ECM remodelling play a major role in cancer development, such as the MMP and lysyl oxidases (LOX). MMP are proteolytic enzymes that mediate matrix degradation, facilitate migration and invasion, promote angiogenesis and release ECM trapped growth factors [27-29]. LOX enzymes are responsible for collagen crosslinking, increasing matrix stiffness and are associated with enhanced tumour growth and progression [30]. Increased ECM stiffness is typically linked to tumour aggressiveness [31]. The recognition of the importance of the ECM in regulating developmental and oncogenic processes prompted research on biomaterials that can mimic the properties and dynamics of the ECM and development of scaffold-based 3D models [32-35].

In this review, we address the strategies developed to model the TME, with an emphasis on in vitro 3D co-culture approaches and their relevance for oncology research and anticancer drug discovery. We describe 3D TME models, including scaffold-embedded models, depicting each of the main non-malignant cell components, as well as co-culture strategies in which different TME cell components have been combined. Emphasis is put on the major findings in addressing the molecular crosstalk with tumour cells and effect on drug response. Advantages and caveats of 3D TME models will be discussed, as well as current needs and future perspectives.

\section{Three-Dimensional Cancer Models}

Most cancer research and testing of drugs targeting the TME has been performed in syngeneic and xenograft mouse models, as reviewed extensively [36-38]. Although the majority of oncology research has been performed with monocultures of tumour cell 
lines, co-culturing of non-malignant TME cell types with tumour cells has been proposed and considered critical for depiction and evaluation of the interplay between tumour and TME components [39,40], increasing the clinical translation potential of the findings [41]. Co-culture approaches in 2D are widely used to study the crosstalk between tumour cells and TME components, either through direct cell-cell interactions or through paracrine signalling, making use of culture well inserts for compartmentalization of cellular components [42,43].

Although 2D methods are the most extensively used in the field due to their simplicity, three-dimensionality increases the level of recapitulation of the tumour tissue $[44,45]$. Differences in 2D and three-dimensional (3D) cultures have been demonstrated; specifically, 3D culture cell-cell interactions, cell-ECM interactions, and, consequently, cell polarity, gene expression and signalling pathways affecting proliferation, amongst other characteristics, present a greater resemblance to tumour cells in vivo [46-49]. Different 3D culture strategies, namely spheroids and matrix-embedded cultures, including organoids, have been extensively explored.

\subsection{Spheroids}

Multicellular tumour spheroids are spherical self-assembled aggregates of cancer cells that constitute a relevant and versatile tool [50-54]. Spheroids can be integrated with other platforms, such as embedding in scaffolds or culture in microfluidic systems [45,51,55], and their production can be easily scaled out and scaled up [56,57]. Spheroids can mimic tumour features observed in vivo, such as cell-cell and cell-ECM interactions and physicochemical gradients, with gene expression patterns closer to the original tumours than 2D cultures [50]. Particularly, spheroids with hypoxic and necrotic areas recapitulated more closely in vivo tumour gene expression profiles and exhibited the highest resistance to chemotherapy when compared to smaller and normoxic spheroids [58]. The main limitations regarding spheroids are related to the simplified architecture and ECM; autologous ECM is built up along culture time, limited to the components produced by the cell types constituting the spheroid [59,60]. Multiple methods can be used to obtain cell spheroids, namely gravitybased systems, in low adherence surface systems or agitation-based systems, such as spinner vessels and shake flasks; these methods have been extensively reviewed in recent years and a detailed description can be found, e.g., in the work of Rodrigues et al., 2020, and Costa et al., $2016[45,50]$.

\subsection{Tumour Organoids and Other Scaffold-Based Models}

Patient-derived organoids have become an important tool in cancer research. These are 3D epithelial structures established from tumour tissues that self-organize and proliferate embedded in a matrix [61]. Importantly, organoids have been shown to sustain tumour cell heterogeneity and genetic properties of the original tumours over a series of passages [61-64]. This ability of propagation of epithelial malignant cells in vitro allowed for the establishment of biobanks for different types of cancer from multiple patients $[65,66]$. Moreover, organoids from metastatic gastrointestinal cancers were used in a co-clinical setting to assess drug response [67]. However, organoid technology still faces several challenges, from heterogeneous efficiency in derivation of organoids from distinct tumour types and individual patients [45] to difficulties in integrating vasculature, stromal and immune cells [45]. Nonetheless, preliminary successful co-cultures have been reported very recently $[68,69]$.

One of the major limitations of organoids is the use of a reconstituted basement membrane extract (BME) secreted by a mouse sarcoma, commonly termed Matrigel [70]. Matrigel is a highly complex mixture, rich in type IV collagen, laminin, heparan sulphate proteoglycans and growth factors [70,71]. Matrigel or other brands of BME have been widely used to model the tumour matrix in vitro and in vivo but the animal origin, batch to batch variability, non-defined composition and presence of growth factors limit model reproducibility and introduce confounding factors [70,72]. 
Among the natural scaffolds, collagen I and fibrin have also been extensively used in cancer research [73]. An ideal scaffold should provide adequate environmental cues for cellular processes and ECM interactions while having a defined composition and being reproducible [45].

Artificial scaffolds, namely poly(ethylene) glycol(PEG)-based hydrogels and synthetic alternatives to Matrigel, are being extensively explored, as they allow for customized control of scaffold properties [74-76] but require deep knowledge on the interactions defining the TME that is still pending [77].

\subsection{Microfluidic-Based 3D Models}

Microfluidics involve the use of microchips usually designed with a different number of chambers and lateral channels, with a fluidic flow [78]. These microdevices allow high spatial controllability but also require highly specialized skills and are usually low throughput and can only support short-term culture [79]. Fluidic shear stress needs to be finely tuned as high shear stress is reported to affect cell viability [80]. Recently, 3D bioprinting has been gaining momentum, as it allows for controlled cell distribution and can contribute to generate more complex models with higher reproducibility [81]. Nonetheless, in this case, the scaffold (bioink) choice is a crucial step [45,82].

\section{Three-Dimensional Double Co-Cultures Incorporating Non-Malignant Cell Components of the Tumour Microenvironment}

\subsection{Fibroblasts}

In the tumour milieu, fibroblasts acquire an activated phenotype described as cancerassociated fibroblasts (CAF), a heterogeneous cell population, that represent the main stromal component of solid tumours [83,84]. This activated phenotype is mediated through multiple factors within the TME, mainly transforming growth factor $\beta$ (TGF- $\beta$ ), but also fibroblast growth factor 2 (FGF-2) and platelet-derived growth factor (PDGF), paracrine factors secreted mostly by tumour cells [83]. Despite the lack of a consensus CAF molecular signature [84], $\alpha$-smooth muscle actin ( $\alpha$-SMA) is described as a hallmark of the transition from fibroblasts to activated fibroblasts [85]. CAF produce bioactive molecules, such as ECM proteins, cytokines and growth factors, which influence tumour progression, invasion and drug resistance to different anticancer compounds [11,86-88] (Figure 1). In fact, CAF are one of the major producers of ECM and ECM remodelling mediators [19].

In recent years, CAF-targeting therapeutic agents have been proposed. These drugs can act by targeting CAF-derived factors (IL-6 or C-X-C motif chemokine ligand 12, CXCL12, inhibitors), or reverting their activated phenotype through TGF- $\beta$ blocking, or directly targeting CAF subsets, such as fibroblast-activation protein (FAP) positive populations [89-92].

Several authors have described the isolation of fibroblasts from tumours followed by in vitro culture. It is safe to say that CAF are the non-malignant cellular type for which more protocols for isolation and culture are available. Multiple studies with fibroblast co-cultures are reported in the literature, although the majority employed fibroblast cell lines (Table 1). Regarding 3D co-cultures, fibroblasts are also the TME cell component more often incorporated, typically employing cell embedding, in a variety of biomaterials. 


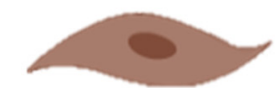

Fibroblast

- Activated phenotype (CAF)

- Variable source

- Heterogeneous phenotype and functionality

- ECM deposition and remodelling

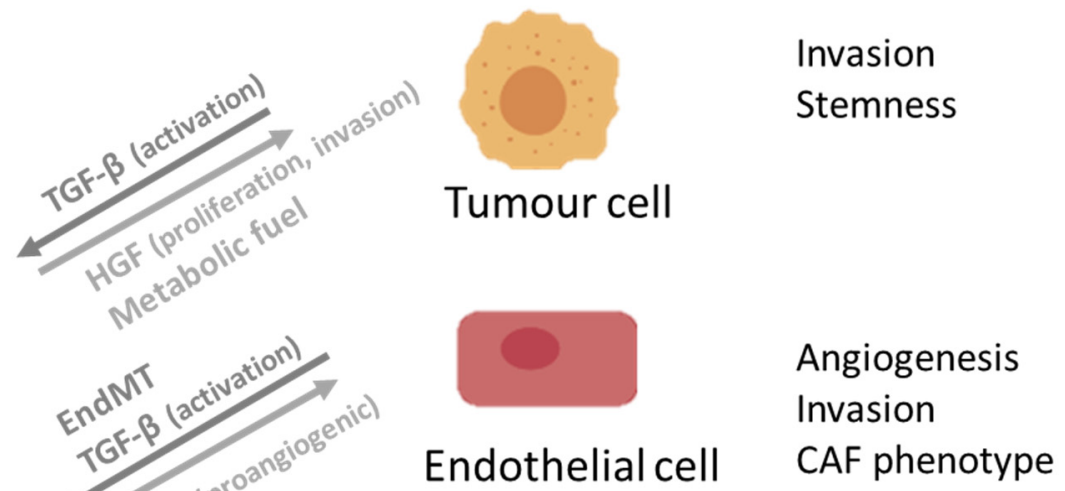

Endothelial cell CAF phenotype

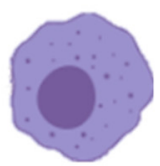

$\mathrm{M} 2$ polarisation Immunosuppression

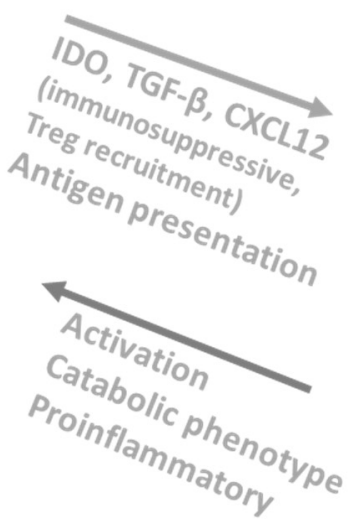

\section{Macrophage}

CCL2, IL-6,

IL-10, M-CSF

(immu nosuppressive, recruitment)

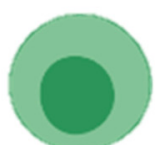

T lymphocyte

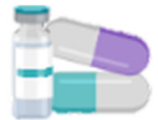

Drug resistance

Aggressiveness

\section{Chemotherapy}

Figure 1. Schematic representation of cancer-associated fibroblasts' (CAF) phenotype, their interactions and reciprocal effects on tumour cells and other non-malignant cells of the tumour microenvironment, and effects of chemotherapy $[11,19,86,88,93]$. Image created with BioRender. CAF: Cancer-associated fibroblast; CCL2: C-C motif chemokine ligand 2; CXCL12: C-X-C motif chemokine ligand 12; ECM: Extracellular matrix; HGF: Hepatocyte growth factor; IDO: Indoleamine 2,3-dioxygenase; IL-6: Interleukin 6; IL-10: Interleukin 10; M-CSF: Macrophage-colony stimulating factor; TGF- $\beta$ : Transforming growth factor $\beta$.

Table 1. Examples of studies developing and employing 3D co-cultures of tumour cells and fibroblasts.

\begin{tabular}{|c|c|c|c|c|c|}
\hline \multicolumn{2}{|c|}{ Tumour Cells } & \multirow{2}{*}{$\begin{array}{l}\text { Fibroblast } \\
\text { Source }\end{array}$} & \multirow{2}{*}{$\begin{array}{l}\text { Platform and } \\
\text { Matrix }\end{array}$} & \multirow{2}{*}{ Main Outcomes } & \multirow{2}{*}{ Ref. } \\
\hline Cancer Type & Source & & & & \\
\hline \multirow{2}{*}{ Colorectal } & $\begin{array}{l}\text { Human cell line } \\
\text { (HT-29) }\end{array}$ & $\begin{array}{l}\text { Human cell line } \\
\text { (CCD-18Co) }\end{array}$ & $\begin{array}{c}\text { Collagen I } \\
\text { Microfluidics }\end{array}$ & $\begin{array}{c}\text { Increased spheroid size but decreased cell } \\
\text { proliferation in co-culture; } \\
\text { lower sensitivity to paclitaxel in } \\
\text { co-culture }\end{array}$ & [85] \\
\hline & $\begin{array}{l}\text { Human cell line } \\
\text { (HT-29) }\end{array}$ & $\begin{array}{l}\text { Human cell line } \\
\text { (CCD-18Co) }\end{array}$ & Transwell & $\begin{array}{l}\text { Fibroblast activation and } \\
\text { increased tumour cell migration and } \\
\text { proliferation in co-culture; } \\
\text { no resistance to 5-FU in co-culture }\end{array}$ & [94] \\
\hline
\end{tabular}


Table 1. Cont.

\begin{tabular}{|c|c|c|c|c|c|}
\hline \multicolumn{2}{|c|}{ Tumour Cells } & \multirow{2}{*}{$\begin{array}{l}\text { Fibroblast } \\
\text { Source }\end{array}$} & \multirow{2}{*}{$\begin{array}{l}\text { Platform and } \\
\text { Matrix }\end{array}$} & \multirow{2}{*}{ Main Outcomes } & \multirow{2}{*}{ Ref. } \\
\hline Cancer Type & Source & & & & \\
\hline & $\begin{array}{l}\text { Multiple human } \\
\text { cell lines } \\
\text { (HCT116, } \\
\text { Caco-2) }\end{array}$ & $\begin{array}{c}\text { Human } \\
\text { primary } \\
\text { (CAF and NF) }\end{array}$ & $\begin{array}{l}\text { Collagen with } \\
\text { nylon mesh }\end{array}$ & $\begin{array}{l}\text { Increased signs of tumour cell } \\
\text { invasion and } \\
\text { enrichment in pathways involved in } \\
\text { hypoxia, ECM, EMT and angiogenesis; } \\
\text { no differences between CAF and NF }\end{array}$ & [95] \\
\hline & $\begin{array}{l}\text { Murine cell line } \\
\quad(\mathrm{CT} 26)\end{array}$ & $\begin{array}{l}\text { Human } \\
\text { primary (CAF } \\
\text { and NF) }\end{array}$ & Collagen & $\begin{array}{c}\text { Increased signs of tumour cell invasion in } \\
\text { co-culture with CAF in comparison with } \\
\text { co-culture with NF or tumour cell } \\
\text { monoculture }\end{array}$ & [96] \\
\hline \multirow{4}{*}{ Lung } & $\begin{array}{l}\text { Human cell line } \\
\text { (A549) }\end{array}$ & $\begin{array}{c}\text { Human } \\
\text { primary } \\
\text { (CAF and NF) }\end{array}$ & Collagen & $\begin{array}{c}\text { Increased signs of tumour cell invasion } \\
\text { and no differences in tumour cell } \\
\text { proliferation in } \\
\text { co-cultures with CAF }\end{array}$ & [97] \\
\hline & $\begin{array}{l}\text { Human cell } \\
\text { lines } \\
\text { (HCC827, } \\
\text { NCI-H1975 and } \\
\text { NCI-H1437) }\end{array}$ & $\begin{array}{c}\text { Human } \\
\text { primary }(\mathrm{CAF})\end{array}$ & $\begin{array}{l}\text { Spheroids in } \\
\text { collagen I and } \\
\text { Matrigel }\end{array}$ & $\begin{array}{l}\text { Increased signs of tumour cell } \\
\text { invasion and } \\
\text { decreased drug resistance to EGFR } \\
\text { inhibitor in co-cultures }\end{array}$ & [98] \\
\hline & $\begin{array}{l}\text { Human cell } \\
\text { lines (PC-9 and } \\
\text { HCC } 827)\end{array}$ & $\begin{array}{l}\text { Murine cell line } \\
\quad(\mathrm{MRC} 5)\end{array}$ & Transwell & $\begin{array}{l}\text { Increased drug resistance to EGFR } \\
\text { inhibitor in co-cultures }\end{array}$ & [99] \\
\hline & Human cell line & $\begin{array}{l}\text { Murine cell line } \\
\text { (WA-mFib) }\end{array}$ & $\begin{array}{c}\text { Transwell } \\
\text { Gelatine } \\
\text { microspheres }\end{array}$ & $\begin{array}{l}\text { CAF activation measured by } \alpha \mathrm{SMA} \\
\text { Enhanced tumour cell invasion }\end{array}$ & [100] \\
\hline \multirow{5}{*}{ Breast } & $\begin{array}{l}\text { Human cell line } \\
\text { (MCF-7) }\end{array}$ & $\begin{array}{l}\text { Human } \\
\text { primary } \\
\text { (dermal NF) }\end{array}$ & $\begin{array}{l}\text { Spheroids in } \\
\text { alginate } \\
\text { microcapsules } \\
\text { Spinner flasks }\end{array}$ & $\begin{array}{c}\text { Loss of tumour epithelial phenotype, } \\
\text { deposition of ECM proteins and increased } \\
\text { proangiogenic potential in } \\
\text { co-cultures }\end{array}$ & [101] \\
\hline & $\begin{array}{l}\text { Murine cell line } \\
\quad(\text { EMT6) }\end{array}$ & $\begin{array}{l}\text { Murine cell line } \\
\text { (NIH3T3) }\end{array}$ & $\begin{array}{l}\text { Silk } \\
\text { fibroin }\end{array}$ & $\begin{array}{c}\text { Acquisition of CAF phenotype in } \\
\text { co-culture, with decreased proliferation } \\
\text { and signs of EMT; } \\
\text { Enhanced resistance to doxorubicin in 3D } \\
\text { vs. 2D monocultures than in } \\
\text { co-cultures vs. monocultures }\end{array}$ & [102] \\
\hline & $\begin{array}{l}\text { Human cell } \\
\text { lines (BT474, } \\
\text { T47D, MCF-7 } \\
\text { and SKBR3) }\end{array}$ & $\begin{array}{l}\text { Human primary } \\
(\mathrm{CAF} \text { and } \mathrm{NF})\end{array}$ & Spheroids & $\begin{array}{l}\text { Fibroblast infiltration dependent on } \\
\text { tumour cell line }\end{array}$ & {$[103,104]$} \\
\hline & $\begin{array}{l}\text { Human cell } \\
\text { lines } \\
\text { (UACC-893, } \\
\text { BT20, } \\
\text { MDA-MB-453) }\end{array}$ & $\begin{array}{c}\text { Human } \\
\text { primary } \\
\text { (foreskin NF) }\end{array}$ & $\begin{array}{c}\text { Rotary } \\
\text { suspension }\end{array}$ & $\begin{array}{l}\text { Cancer cell invasion into fibroblast core; } \\
\text { Deposition of ECM proteins }\end{array}$ & [105] \\
\hline & $\begin{array}{l}\text { Human cell } \\
\text { lines } \\
\text { (MDA-MB-231 } \\
\text { and } \\
\text { MCF-7) }\end{array}$ & $\begin{array}{c}\text { Human } \\
\text { primary (breast } \\
\text { CAF and skin } \\
\text { NF) }\end{array}$ & Spheroids & $\begin{array}{c}\text { Increased tumour cell proliferation and } \\
\text { migration in co-culture with CAF but } \\
\text { not NF; } \\
\text { Increased } \alpha \text {-SMA in CAF co-cultured with } \\
\text { MDA-MB-231; } \\
\text { NF not activated by MDA-MB-231 } \\
\text { or MCF-7 }\end{array}$ & [106] \\
\hline
\end{tabular}


Table 1. Cont.

\begin{tabular}{|c|c|c|c|c|c|}
\hline \multicolumn{2}{|c|}{ Tumour Cells } & \multirow{2}{*}{$\begin{array}{l}\text { Fibroblast } \\
\text { Source }\end{array}$} & \multirow{2}{*}{$\begin{array}{l}\text { Platform and } \\
\text { Matrix }\end{array}$} & \multirow{2}{*}{ Main Outcomes } & \multirow{2}{*}{ Ref. } \\
\hline Cancer Type & Source & & & & \\
\hline & $\begin{array}{l}\text { Human cell } \\
\text { lines (T47D, } \\
\text { MDA-MB-361 } \\
\text { and } \\
\text { MDA-MB-231) }\end{array}$ & $\begin{array}{c}\text { Human } \\
\text { primary } \\
\text { (dermal NF) }\end{array}$ & Spheroids & $\begin{array}{l}\text { Similar tumour growth in mono and } \\
\text { co-cultures; } \\
\text { No differences between mono and } \\
\text { co-cultures in sensitivity to } \\
\text { combination of chemotherapy and } \\
\text { radiotherapy }\end{array}$ & [107] \\
\hline & $\begin{array}{l}\text { Human cell line } \\
\text { (MCF-7) }\end{array}$ & $\begin{array}{l}\text { Murine cell line } \\
\quad(\mathrm{MRC}-5)\end{array}$ & Spheroids & $\begin{array}{l}\text { Increased tumour cell growth in } \\
\text { co-cultures, with formation of } \\
\text { necrotic spheroid cores. }\end{array}$ & [108] \\
\hline & $\begin{array}{l}\text { Human cell line } \\
\text { (MCF-7) }\end{array}$ & $\begin{array}{l}\text { Murine cell line } \\
\qquad(3 \mathrm{~T} 3)\end{array}$ & $\begin{array}{c}\text { PET } \\
\text { scaffold } \\
\text { Microbioreactor } \\
\text { with } \\
\text { agitation }\end{array}$ & $\begin{array}{l}\text { Increased resistance to tamoxifen, } \\
\text { oxaliplatin and cisplatin in co-cultures }\end{array}$ & [109] \\
\hline & $\begin{array}{l}\text { Human cell } \\
\text { lines } \\
\text { (MDA-MB-231 } \\
\text { and } \\
\text { MCF-7) }\end{array}$ & $\begin{array}{l}\text { Human cell line } \\
\text { (HTB-125) }\end{array}$ & $\begin{array}{l}\text { Collagen I } \\
\text { Microfluidics }\end{array}$ & $\begin{array}{l}\text { Increased signs of tumour cell invasion, } \\
\text { collagen deposition and stiffness in } \\
\text { co-culture }\end{array}$ & [110] \\
\hline & $\begin{array}{l}\text { Murine primary } \\
\text { mammary } \\
\text { tumour cells }\end{array}$ & $\begin{array}{l}\text { Murine primary } \\
\qquad(\mathrm{CAF})\end{array}$ & $\begin{array}{l}\text { Organoids } \\
\text { Matrigel }\end{array}$ & $\begin{array}{c}\text { Co-culture increased signs of invasion } \\
\text { through release of TGF- } \beta\end{array}$ & [111] \\
\hline & $\begin{array}{l}\text { Human cell line } \\
\text { (MDA-MB-231) }\end{array}$ & $\begin{array}{l}\text { Human } \\
\text { mammary } \\
\text { fibroblasts } \\
\text { (HMF) }\end{array}$ & $\begin{array}{l}\text { Spheroids } \\
\text { Alginate and } \\
\text { Collagen I }\end{array}$ & $\begin{array}{l}\text { Increased tumour and fibroblast invasion } \\
\text { through alginate and collagen mixed gel } \\
\text { than collagen only matrix } \\
\text { Invasion potentiated by CXCL12-secreting } \\
\text { fibroblasts }\end{array}$ & [112] \\
\hline \multirow{4}{*}{ Pancreatic } & $\begin{array}{l}\text { Human cell line } \\
\text { (Capan-1 and } \\
\text { Paca-3) }\end{array}$ & $\begin{array}{l}\text { Murine cell line } \\
\text { (MRC-5); } \\
\text { human } \\
\text { immortalized }\end{array}$ & $\begin{array}{l}\text { Collagen I and } \\
\text { Matrigel }\end{array}$ & $\begin{array}{l}\text { No alterations in tumour cell proliferation; } \\
\text { Modulation of adhesion molecules }\end{array}$ & [113] \\
\hline & $\begin{array}{l}\text { Human cell line } \\
\text { (Patu8902) }\end{array}$ & $\begin{array}{l}\text { Human } \\
\text { immortalized }\end{array}$ & $\begin{array}{l}\text { Spheroids } \\
\text { Bioprinting }\end{array}$ & Generation of heterotypic spheroids & [114] \\
\hline & $\begin{array}{l}\text { Human cell line } \\
\text { (PT45) }\end{array}$ & $\begin{array}{l}\text { Human } \\
\text { primary (CAF } \\
\text { or normal) }\end{array}$ & $\begin{array}{l}\text { Microcarriers } \\
\text { Spinner flask }\end{array}$ & $\begin{array}{l}\text { ECM deposition in co-cultures with NF } \\
\text { and CAF; } \\
\text { NF acquired activated phenotype }\end{array}$ & [115] \\
\hline & $\begin{array}{l}\text { Human cell } \\
\text { lines (PANC-1, } \\
\text { AsPc-1, BxPC-3, } \\
\text { Capan-1 and } \\
\text { MIA PaCa-2) }\end{array}$ & $\begin{array}{l}\text { Human } \\
\text { primary }(\mathrm{CAF})\end{array}$ & Spheroids & $\begin{array}{c}\text { Spheroids more compact in } \\
\text { co-culture, with } \\
\text { collagen deposition; } \\
\text { Higher gemcitabine resistance in } \\
\text { co-culture than tumour monospheroids }\end{array}$ & [116] \\
\hline $\begin{array}{l}\text { Lung } \\
\text { Colorectal } \\
\text { Esophageal } \\
\text { Pancreatic }\end{array}$ & $\begin{array}{l}\text { Patient-derived } \\
\text { xenografts }\end{array}$ & $\begin{array}{c}\text { Human } \\
\text { primary (CAF) }\end{array}$ & BME & $\begin{array}{l}\text { Drug resistance to different } \\
\text { chemotherapeutics in co-culture }\end{array}$ & [87] \\
\hline $\begin{array}{l}\text { Lung, breast, } \\
\text { pancreatic }\end{array}$ & $\begin{array}{l}\text { Human cell } \\
\text { lines (e.g., A549, } \\
\text { MCF-7, Panc1) }\end{array}$ & $\begin{array}{l}\text { Murine cell line } \\
\text { (MRC5); } \\
\text { Human } \\
\text { primary (CAF) } \\
\text { and cell lines }\end{array}$ & Spheroid & $\begin{array}{l}\text { Increased proliferation in co-cultures; } \\
\text { Differential secretion of cytokines } \\
\text { depending on the tumour cell line; } \\
\text { Decreased drug sensitivity to targeted } \\
\text { therapy in co-culture for lung tumour cell } \\
\text { lines, but not for breast cancer cell lines }\end{array}$ & [117] \\
\hline
\end{tabular}


Table 1. Cont.

\begin{tabular}{|c|c|c|c|c|c|}
\hline \multicolumn{2}{|c|}{ Tumour Cells } & \multirow{2}{*}{$\begin{array}{l}\text { Fibroblast } \\
\text { Source }\end{array}$} & \multirow{2}{*}{$\begin{array}{l}\text { Platform and } \\
\text { Matrix }\end{array}$} & \multirow{2}{*}{ Main Outcomes } & \multirow{2}{*}{ Ref } \\
\hline Cancer Type & Source & & & & \\
\hline & $\begin{array}{l}\text { Human cell line } \\
\quad(\text { HepG } 2)\end{array}$ & $\begin{array}{l}\text { Murine cell line } \\
\quad(3 T 3-J 2)\end{array}$ & $\begin{array}{l}\text { Spheroids } \\
\text { Collagen }\end{array}$ & $\begin{array}{l}\text { Higher drug resistance to doxorubicin in } \\
\text { co-cultures }\end{array}$ & [118] \\
\hline Liver & $\begin{array}{l}\text { Murine and } \\
\text { human primary } \\
\text { mammary and } \\
\text { breast tumour } \\
\text { cells }\end{array}$ & $\begin{array}{l}\text { Murine and } \\
\text { human primary } \\
\text { (CAF) }\end{array}$ & $\begin{array}{l}\text { Transwell } \\
\text { Organoids } \\
\text { Matrigel }\end{array}$ & $\begin{array}{l}\text { Co-culture increased organoid growth but } \\
\text { not organoid number } \\
\text { In response to sorafenib, regorafenib or } \\
\text { 5-FU, less organoid growth inhibition } \\
\text { in co-cultures }\end{array}$ & [119] \\
\hline Prostate & $\begin{array}{l}\text { Human cell line } \\
\qquad(\mathrm{BPH}-1)\end{array}$ & $\begin{array}{l}\text { Human } \\
\text { primary } \\
\text { (CAF and } \\
\text { NF) }\end{array}$ & $\begin{array}{l}\text { Fibroblast } \\
\text { produced } \\
\text { matrix }\end{array}$ & $\begin{array}{l}\text { Increased signs of migration and } \\
\text { invasion in co-culture }\end{array}$ & [120] \\
\hline $\begin{array}{l}\text { Salivary } \\
\text { gland } \\
\text { adenoid } \\
\text { cystic } \\
\text { carcinoma }\end{array}$ & $\begin{array}{l}\text { Human cell line } \\
\text { (ACC-M) }\end{array}$ & $\begin{array}{l}\text { Human } \\
\text { Primary and cell } \\
\text { line (HFL1) }\end{array}$ & $\begin{array}{l}\text { BME } \\
\text { Microfluidics }\end{array}$ & $\begin{array}{l}\text { Increased signs of invasive phenotype in } \\
\text { co-cultures with CAF, but not with NF } \\
\text { MMP inhibitor blocked } \\
\text { CAF-induced invasion }\end{array}$ & [121] \\
\hline Ovarian & $\begin{array}{l}\text { Human cell line } \\
\text { (OVCAR5) }\end{array}$ & $\begin{array}{l}\text { Murine cell line } \\
\quad(\mathrm{MRC}-5)\end{array}$ & $\begin{array}{l}\text { Matrigel } \\
\text { Bioprinting }\end{array}$ & $\begin{array}{c}\text { Generation of co-cultures with } \\
\text { different sizes } \\
\text { and cell densities }\end{array}$ & [122] \\
\hline $\begin{array}{c}\text { Breast } \\
\text { Pancreatic }\end{array}$ & $\begin{array}{l}\text { Cell lines } \\
\text { (murine } 4 \mathrm{~T} 1 \text { and } \\
\text { human } \\
\text { MDA-MB-231 } \\
\text { and Panc-1) }\end{array}$ & $\begin{array}{c}\text { Murine and } \\
\text { human cell lines } \\
\text { (3T3, BJ-hTERT) } \\
\text { and human } \\
\text { primary (CAF, } \\
\text { NF) }\end{array}$ & Spheroids & $\begin{array}{c}\text { Increased } \alpha \text {-SMA and collagen } \\
\text { in co-culture; } \\
\text { Decreased penetration of } \\
\text { nanoparticles in co-culture }\end{array}$ & [123] \\
\hline $\begin{array}{l}\text { Breast } \\
\text { Lung }\end{array}$ & $\begin{array}{l}\text { Human cell } \\
\text { lines (MCF-7, } \\
\text { SKBR3, A549) }\end{array}$ & $\begin{array}{l}\text { Human primary } \\
\text { (CAF from } \\
\text { chemo-sensitive } \\
\text { or } \\
\text { chemo-resistant } \\
\text { tumours) }\end{array}$ & Transwell & $\begin{array}{c}\text { Increased drug resistance in co-cultures } \\
\text { with CAF isolated from } \\
\text { chemo-resistant tumours }\end{array}$ & [93] \\
\hline $\begin{array}{l}\text { Breast } \\
\text { Lung }\end{array}$ & $\begin{array}{l}\text { Human cell } \\
\text { lines (T47D, } \\
\text { MCF-7; H1299) }\end{array}$ & $\begin{array}{l}\text { Murine cell line } \\
\text { (MRC5) and } \\
\text { human NF }\end{array}$ & Spheroids & $\begin{array}{l}\text { Fibroblast localized preferentially in the } \\
\text { inner part of the spheroids; } \\
\text { identification of specific compounds that } \\
\text { inhibited fibroblast migration }\end{array}$ & [124] \\
\hline $\begin{array}{l}\text { Breast } \\
\text { Colorectal }\end{array}$ & $\begin{array}{l}\text { Human cell } \\
\text { lines (MCF-7 } \\
\text { HCT-116) }\end{array}$ & $\begin{array}{l}\text { Primary } \\
\text { (human dermal } \\
\text { NF) }\end{array}$ & $\begin{array}{l}\text { Spheroids } \\
\text { Microfluidics }\end{array}$ & $\begin{array}{l}\text { Imaging and quantification of tumour cell } \\
\text { spheroid invasion into fibroblast spheroid }\end{array}$ & [125] \\
\hline
\end{tabular}

BME: Basement membrane extract; CAF: Cancer-associated fibroblast; ECM: Extracellular matrix; EGFR: Epidermal growth factor receptor; EMT: Epithelial to mesenchymal transition; MMP: Matrix metalloproteinase; NF: normal fibroblasts; PET: Polyethylene; 5-FU: 5-Fluorouracil; $\alpha$-SMA: alpha-smooth muscle actin.

\subsubsection{Models with Normal Fibroblasts}

Aiming to mimic tumour-stroma cell interactions in initial stages of tumorigenesis, many authors resourced to normal fibroblasts. Kim et al. have proposed a proximity coculture model, using a transwell system for co-culture of spheroids of a human colorectal cancer cell line (HT-29) and a normal colon fibroblast cell line on a collagen gel [94]. The authors reported activation of fibroblast towards a CAF phenotype in 3D but not in 2D co-cultures, with increased expression of $\alpha$-SMA. Interestingly, a reciprocal interaction between the two cell types was demonstrated, with higher migration of the tumour cells in 3D co-cultures, which has been associated with epithelial to mesenchymal transition (EMT) mediated by TGF- $\beta 1$ [94]. The same team later designed a microfluidic chip in 
which spheroids of HT-29 cells and normal colon fibroblasts were embedded in type I collagen, placed in separate channels at a microscale distance [85]. In this setting, fibroblasts also acquired phenotypic traits of CAF. Reciprocally, in co-cultures, tumour cells revealed increased migration, decreased proliferation and consequently reduced susceptibility to paclitaxel relatively to monocultures, compatible with EMT [85].

Froeling et al. used co-cultures of pancreatic cancer cell lines and non-tumorigenic stromal components: immortalized pancreatic stellate cells (isolated from normal pancreas tissue and considered the tissue resident fibroblasts) or a normal lung fibroblast cell line (MRC-5) [113]. Tumour spheroids were cultured over stromal cells plated on gels of collagen and Matrigel [113]. The authors have not addressed the phenotype of fibroblasts upon co-culture but observed phenotypic changes in tumour cells in co-cultures with both types of fibroblasts, such as the expression of molecules related to adhesion (E-cadherin, $\beta$ catenin and Ezrin), but not altered proliferation. Inert biomaterials have also been proposed to set up co-cultures of tumour cells and fibroblasts. Dondajewska et al. used co-cultures of a murine breast cancer cell line and a murine fibroblastic cell line in a natural inert scaffold made of silk fibroin [102]. Regarding the fibroblast phenotype, gene expression analysis suggested a transition to a CAF-like phenotype. They observed lower proliferation rates of tumour cells in $3 \mathrm{D}$ vs. 2D and co-cultures vs. monocultures. Moreover, monocultures displayed higher resistance to doxorubicin in 3D as opposed to in 2D, whereas differences between mono- and co-cultures were less pronounced.

Cell encapsulation in inert hydrogels has also been explored for the generation of co-cultures of tumour cells and fibroblasts. Fang et al. used a microfluidic device with prostate cancer cells and normal prostate stromal myofibroblast cells (WPMY-1) co-cultured in two separate layers of alginate microcapsules to study paracrine interactions between the two cell populations [126]. As a proof-of-concept, the authors evaluated the shedding of E-cadherin byMMP, known to be deregulated in several cancers, including prostate cancer, and they found increased levels of shedding in co-cultures compared to monocultures [126]. In another approach, our team employed alginate microcapsules to co-culture a breast cancer cell line (MCF-7) with human dermal fibroblasts [101]. Deposition of ECM components, such as collagen I, as well as of secreted soluble factors, was detected in the microcapsules after two weeks of culture, compatible with transition to a CAF-like phenotype [127]. Moreover, tumour cells showed increased migration and angiogenic potential when in co-cultures [101]. This strategy was applied to lung cancer cell lines [56] and the feasibility of including other TME cell components has also been demonstrated with monocytic cells [128], which will be covered in Section 4.1.2.

The effects of in vitro-activated fibroblasts on promoting proliferation of tumour cells and resistance to chemotherapy remains to be clarified, as contrasting results have been reported in different $3 \mathrm{D}$ co-culture setups, and the underlying mechanisms have not been elucidated. The model design criteria, e.g., source of fibroblast and tumour cell lines, ECM composition, distance between cells, interspersion of tumour cells and fibroblasts, and time of co-culture, will impact the local distribution of tumour- and fibroblast-derived soluble factors and ECM, modulating fibroblast activation and their reciprocal effect on tumour cells.

\subsubsection{Models with CAF and Non-Malignant Epithelial Cells}

Several studies have explored the effect of CAF in tumorigenic events, employing normal epithelial or benign tumour cells. Holliday et al., in 2009, developed a model of the breast cancer microenvironment that included luminal, myoepithelial cells and fibroblasts isolated from malignant or normal tissue, embedded in collagen I gels [129]. Once CAF were added to the aggregates formed by luminal and myoepithelial cells, a change in cellular organization occurred, with disruption of the basement membrane, leading to a change in the model architecture; this phenomenon was not observed with fibroblasts derived from normal tissue [129]. This disruptive effect was mostly abrogated with inhibitors of MMP or hepatocyte growth factor (HGF) receptor (c-MET), in accordance with other studies re- 
porting the contribution of CAF-derived mediators to tumour progression $[130,131]$. Using Matrigel-embedded co-cultures, Shekhar et al., in 2001, also observed that CAF isolated from breast tumour tissue can stimulate the growth of non-tumorigenic and preneoplastic breast epithelial cell lines, while fibroblasts isolated from normal breast tissue induced the opposite effect [132].

Overall, these studies point to the ability of CAF to disrupt the normal epithelial cell architecture and phenotype, independently of the hydrogel in which cells were embedded, possibly linked to enhanced ECM deposition and altered ECM composition from CAF. Clark et al., in 2013, isolated CAF and normal fibroblasts from patient tissue and cultured them in 2D for two weeks in the presence of ascorbic acid to stimulate the secretion of $\mathrm{ECM}$, prior to seeding on top a cell line representing a human benign prostatic hyperplasia (BPH-1) [120]. The authors observed changes in morphology and migration of the BPH-1 cells when in co-culture with CAF, compatible with a more invasive phenotype [120]. It would be interesting to characterize the composition of the secreted matrix and compare it to the ECM composition of the parental tumours from which they were isolated.

\subsubsection{Models with CAF and Tumour Cells}

Jacobi et al. explored 3D co-cultures for evaluation of drug response in lung adenocarcinoma cell lines with distinct (epidermal growth factor receptor) EGFR profiles [98]. HCC827 cells, which harbour an EGFR mutation associated with clinical response to gefitinib, were co-cultured as spheroids with fibroblasts isolated from lung cancer tissues, within a scaffold of collagen I and Matrigel. The authors reported that HCC827 cells presented a higher invasive phenotype in the 3D co-culture than in monoculture. Moreover, once exposed to gefitinib (EGFR inhibitor) HCC827 exhibited higher drug sensitivity in heterotypic spheroids than in homotypic spheroids, whereas in 2D HCC827 cells were resistant to the drug. Increased drug sensitivity in 3D was associated with reduced signalling activity of Her family members, which might be due to increased gene expression and activation of members of the tumour necrosis factor-alpha (TNF- $\alpha$ ) pathway in 3D.

Other authors have also reported increased sensitivity to inhibitors of Her family members in tumour cell spheroids relatively to 2D cultures [133-135]. Nonetheless, the data are in opposition to findings by Wang et al. and Choe et al. [99,136], which reported increased anti-EGFR resistance in lung epithelial cancer cells co-cultured in 2D with CAF, mediated by stromal-derived HGF. Curiously, in double co-cultures of EC and tumour cells, no changes in drug sensitivity/resistance were observed, possibly due to the absence of a source of HGF [99]. It would be interesting to assess the production of HGF by fibroblasts within the 3D co-culture format proposed by Jacobi et al. and to understand how the presence of the ECM may affect the concentration of HGF in the extracellular milieu and the proximity of the tumour cells, given the role of ECM in regulating HGF/c-MET signalling [137].

Dolznig et al. generated multicellular tumour spheroids from colon adenocarcinoma cell lines and co-cultured them with CAF isolated from colon adenocarcinoma samples or normal fibroblast cell lines, all within a collagen gel stabilized with a nylon mesh [95]. The authors observed differences in cell-cell junctions and after four days of co-culture with CAF or normal fibroblasts and an invasive tumour cell phenotype, not found in tumour homotypic spheroids, even after 11 days of culture [95]. They reported a significant upregulation of gene sets involved in hypoxia, ECM deposition, EMT and angiogenesis in co-culture, in agreement with data obtained from patient samples [138]. On the other hand, Liu et al. observed prominent tumour cell invasive behaviour in co-cultures of a salivary gland adenoid cystic carcinoma cell line (ACC-M) with CAF isolated from an adenoid cystic tumour but not with a normal fibroblast cell line (HFL-1) [121]. In this study, the authors built a microfluidic device in which both cell types were embedded in BME (Cultrex) and patterned in two separate but connected chambers [121]. Moreover, this CAF-induced invasion was blocked by a MMP inhibitor [121]. 
In accordance with this, Attieh et al. also found differences between CAF and normal fibroblasts in inducing a tumour cell invasive phenotype, and this was linked to the collagen remodelling capability and fibronectin deposition by CAF. The authors generated tumour spheroids of mouse intestinal cancer cells (CT26) and embedded them in collagen I, together with CAF or their normal counterparts (both isolated from patients' samples) [96]. Horie et al. also reported an increased potential of CAF relatively to normal fibroblasts to enhance invasion of tumour cells, in a very similar set-up of co-culture embedded in collagen [97]. A lung cancer cell line (A549) was co-cultured with CAF or normal fibroblasts isolated from tumour and healthy lung tissue, respectively.

\subsubsection{Models with Different CAF Subsets}

The invasive prone co-culture phenotypes depending (or not) on fibroblast type emphasize the need for further studies on the heterogeneous nature of fibroblasts and their activation states. CAF heterogeneity has been identified in patient samples from different cancer types, namely, breast, pancreatic, gastric or colorectal cancers $[93,139]$.

$\mathrm{Su}$ et al. identified different CAF subsets in patient samples, and linked one of them to chemoresistance [93]. Particularly, CAF were isolated from chemo-sensitive or chemoresistant tumours and co-cultured in a transwell setting along with breast or lung cancer cell lines. The authors reported alleviation of growth inhibition of tumour cells when cocultured with CAF from chemo-resistant tumours compared to CAF from chemo-sensitive ones [93]. In vivo, these CAF from chemo-resistant samples were identified as a specific subset expressing CD10 and GPR77 and secreting IL-6 and IL-8, which correlated with cancer stem cell enrichment. When IL-6 and IL-8 secretion was abrogated, the chemoresistance effect induced by CAF to cisplatin or docetaxel was not observed. Importantly, this CAF subset was correlated with worse prognosis in patient samples and was not distinguishable from other CAF in the expression of conventional markers, such as $\alpha$-SMA, FAP or collagen I [93].

Herrera et al. found heterogeneous populations of CAF derived from primary colon cancer patients $(n=15)$. The authors classified CAF based on their ability to promote migration of a colorectal cancer cell line in a 3D setting and established a CAF promigratory signature, but the mechanisms underlying CAF heterogeneity have not been addressed. Nevertheless, this CAF signature was validated in Gene Expression Omnibus (GEO) database (accession number GSE51257, NCBI) and related to categorization of tumour progression risk in patients [140].

CAF heterogeneity is not only reflected in their phenotype but also function, as demonstrated with the identification of immunosuppressive, ECM secreting or antigen-presenting CAF, among others [141]. Another cause of CAF heterogeneity relies on their origin, as CAF can be recruited locally (tissue-resident cells), from adipose tissue or bone marrow. It has also been reported that CAF can be originated through epithelial or endothelial to mesenchymal transition $[142,143]$. A deeper understanding of the CAF-activation mechanisms is needed and has been attempted through the use of proteomics and single-cell RNA sequencing, aiming at identifying not only therapeutic targets but also putative prognostic biomarkers [141,144-146]. Importantly, in 2020 a consensus statement on CAF definition and biology has been issued. This was an effort to tackle the challenges of CAF heterogeneity and therapeutic targeting, and reinforcing the need for assay standardization [83]. In fact, CAF plasticity can augment modelling complexity and the impact of the culture format on tumour cell and CAF behaviour becomes clear-direct or indirect co-culture, proximity between the two cell types, tumour cells organized as 3D spheroids or as single cells, biomaterial composition, etc. It is therefore of paramount importance that the models employed for biological interrogation or drug assays are well-defined and properly characterized, including the phenotype of the fibroblast component.

In summary, in vitro models based on 3D co-culture of tumour cells and CAF lead, in general, to a more invasive tumour cell phenotype, signs of EMT and higher drug resistance, which are features that can resemble the tumour progression in vivo. As mentioned earlier, 
proliferation levels are still a matter of debate, as contradictory observations have been found. All these studies highlight the important role of co-cultures in the discovery of CAF-secreted factors, such as ECM and soluble growth factors, and their role within the TME. Although most of the studies on drug challenge of tumour cell and fibroblasts cocultures employed standard-of-care chemotherapeutics, co-cultures can also help clarify the therapeutic potential of CAF-targeting agents.

\subsection{Endothelial Cells}

Angiogenesis is a recognized hallmark of cancer progression [16,147] and EC have been implicated in drug resistance processes [148] (Figure 2). Tumour blood vessels present several characteristics that differ from the regular ones, such as excessive branching, increased permeability and lack of pericyte coverage $[16,149]$. Moreover, tumour-associated EC are distinct from regular EC in terms of morphology, gene expression and metabolism, with tumour-associated EC exhibiting increased proliferation or loosen intercellular junctions $[16,149,150]$. These features augment the complexity of in vitro tumour modelling.

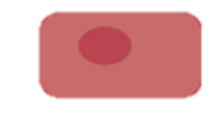

\section{Endothelial cell}

- Disorganized vascular network

- Chaotic blood flow

- Low perfusion

- High permeability

- High IFP

- Hypoxia

- Highly glycolytic

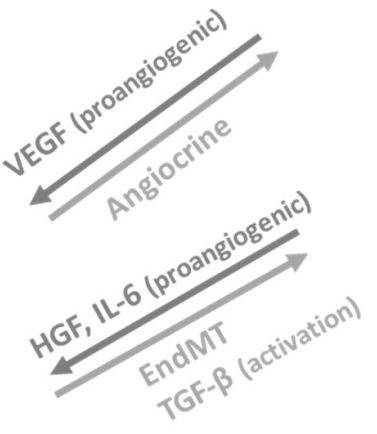

$$
\underset{\text { TEM recruitment }}{\text { VEGF, MMP (proangiogenic) }}
$$

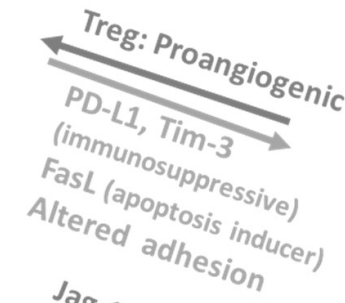

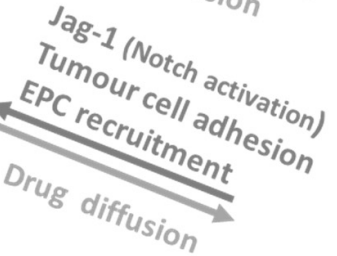

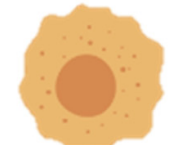

Angiogenesis

Metastasis

\section{Tumour cell}

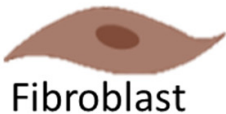

Angiogenesis

Invasion

CAF phenotype

\section{Angiogenesis \\ Tumour growth \\ Tumour invasion}

\section{Macrophage}

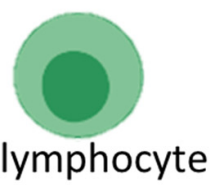

T CD8+: exhaustion, apoptosis

$T$ reg: increased infiltration Immunosuppression

Drug resistance Promotion of CSC Metastasis

\section{Chemotherapy}

Figure 2. Schematic representation of the characteristics of tumour-associated endothelial cells, their interactions and reciprocal effects on tumour cells and on other non-malignant of the tumour microenvironment, and effects of chemotherapy on them [16,148,150]. Image created with BioRender. CAF: Cancer-associated fibroblast; CSC: Cancer-stem cell; FasL: Fas ligand; EPC: Endothelial progenitor cell; EndMT: Endothelial to mesenchymal transition; HGF: Hepatocyte growth factor; IFP: Interstitial fluid pressure; IL-6: Interleukin 6; Jag-1: Jagged-1; MMP: Matrix metalloproteinase; PD-L1: Programmed death ligand 1; TEM: Tie expressing monocytes; Tim-3: T-cell immunoglobulin and mucin domain-3; TGF- $\beta$ : Transforming growth factor $\beta$; Treg: Regulatory T cell; VEGF: Vascular endothelial growth factor. 


\subsubsection{Heterotypic Spheroid Approaches}

Heterotypic tumour spheroids are a versatile and simple 3D co-culture approach to incorporate EC [151]. Upreti et al., in 2011, generated heterotypic spheroids of a murine mammary tumour cell line combined with a murine EC line to assess the response to ionizing radiation or chemotherapy [152]. Firstly, the spheroids were generated by plating the tumour cells and, on day three, the EC were added. The EC were reported to infiltrate the spheroids towards the core, resulting in larger and more compact 3D structures than the tumour cell monocultures, which started to disintegrate after eight days. The presence of EC sensitized the tumour cells to chemotherapy. On the other hand, upon exposure to radiation, tumour cells in heterotypic spheroids had higher proliferation rates than in monotypic spheroids, suggesting a resistance mechanism that was not studied further.

Chiew et al., in 2017, also employed a heterotypic spheroid approach, with tumour cell lines from hepatic and breast carcinomas and EC [153]. The authors observed the formation of tube-like structures of EC in co-cultures with HepG2, but not with the breast cancer cells lines MCF-7 and MDA-MB-231. The mechanisms underlying this difference remain to be addressed. The tube-like structures deteriorated after three days; still, the authors were able to set up drug challenge assays using tyrosine kinase inhibitors for 2 days and observed reductions in tumour cell viability and EC tube-like structures [153]. Shoval et al., in 2017, used not only tumour cell lines but also patient-derived tumour cells, together with human umbilical vein endothelial cells (HUVEC) [154]. The authors assessed essentially morphological aspects and the formation of capillary-like structures within the heterotypic spheroids. EC network formation was dependent on the tumour cell line used. It would be interesting to explore the pathways involved in this cell line-dependent behaviour and challenge the model with antiangiogenic drugs to consolidate its potential.

Another combination of the 2D/3D approach was developed by Chaddad et al., in 2017, to co-culture spheroids from an osteosarcoma cell line with a monolayer of EC [155]. After 14 days of co-culture, the authors observed EC migration towards the tumour spheroid and formation of tubule-like structures, which was linked to higher levels of Vascular endothelial growth factor (VEGF) secreted by tumour cells at that time point in comparison to earlier culture days; there was also higher ECM deposition [155]. This system can provide clues to the factors important to perform successful co-cultures, namely VEGF concentration and ECM components, although, as observed by others, the tumour cell line can also impact EC tube-like formation efficiency.

\subsubsection{Matrix-Embedding Approaches}

A large proportion of models recapitulating steps of the tumour angiogenesis described in the literature explore cell or spheroid embedding in hydrogels. The use of hydrogels as ECM surrogates have been explored to define the spatial organization of the different cell types within the model and to mimic sprouting.

Ingthorsson et al., in 2010, co-cultured EC isolated from normal breast tissue with primary breast luminal and epithelial cells or normal and malignant breast cell lines, embedded in BME [156]. Two distinct cell compartments were seeded in different regions of the gel, without a physical separation. Increased proliferation and cloning efficiency of normal breast epithelial and tumour cells were observed in co-cultures. Control experiments in transwells suggested that these effects of EC over breast cells were at least partially associated with soluble factors derived from the EC, although their identification was not pursued. Tumour cell proliferation was higher in the vicinity of EC, which can be linked to higher concentrations of EC-derived soluble factors, due to diffusional gradients within the gel [156].

Chwalek et al., in 2014, proposed the use of glycosaminoglycan-based hydrogels (starPEG-heparin hydrogels) for co-culture of EC and tumour cells [77]. The authors explored the effect of biomaterial-associated parameters on the ability of EC to form capillary-like networks and tumour cells to proliferate, namely stiffness; content of RGD, a conserved tripeptide sequence recognized by integrins and other cell surface proteins; and 
growth factor content. Spheroids of the hepatic tumour cell line HepG2 were seeded into a hydrogel in which EC had previously formed tubular structures. The authors observed migration of tumour cells towards the EC and, reciprocally, infiltration of EC in the tumour spheroid [77]. Moreover, to increase EC culture duration, the authors combined EC with EC support cells, such as MSC, smooth muscle cells (SMC) and fibroblasts, and were able to maintain the tube-like network for 28 days. It would have been interesting to include tumour cells in these complex co-cultures.

Roudsari et al., in 2016, explored bilayer PEG-based hydrogels to generate a layer model to study the impact of soluble vs. direct cancer cell interactions; a lung tumour cell line (344SQ) was cultured in one of the layers and HUVEC and EC support cells (human vascular pericytes) in the other layer [157]. EC tube-like structures were observed to be in contact with the tip of tumour cell projections and larger tumour cell clusters were formed in the proximity of the EC layer, which the authors suggested as being related to TGF- $\beta$ secretion.

\subsubsection{Microfluidic Approaches}

In vitro systems of perfused human capillary networks have been extensively explored [158] and there have been attempts to integrate tumour cells into these systems to mimic tumour angiogenesis and provide models of vascularized tumours.

Aref et al. employed a two-chamber microfluidic system to combine 2D and 3D culture approaches. Spheroids of the A549 lung adenocarcinoma cell line were cultured within a collagen gel in one of the chambers and the adjacent compartment contained a monolayer of HUVEC [159]. The authors reported signs of EMT, such as loss of E-cadherin and spheroid dispersion only in the co-cultures [159]. Furthermore, a challenge with drugs blocking EMT-related factors, such as EGFR inhibitors, reverted the EMT indicators [159]. These results were reported for co-cultures with the A549 cell line and not further validated with other tumour cells.

Buchanan et al. employed a microfluidic approach with breast cancer cells (MDAMB-231) surrounding a cylindrical central channel, in which EC in collagen formed a confluent layer with increasing shear stress [160]. Upregulation of proangiogenic genes in flow conditions compared to static has been reported, making this a suitable model to study the influence of hydrodynamic forces on tumour angiogenesis.

In conclusion, co-culture of tumour cells with EC has been reported to depict features observed in vivo, particularly, signs of EMT or drug resistance (Table 2). Models employed usually portray specific events, such as tumour cell extravasation. Additionally, most models rely on HUVEC as an EC source and lack representation of the tortuous and leaky characteristics of the tumour vasculature [161].

Table 2. Examples of studies developing and employing 3D co-cultures of tumour and endothelial cells (EC).

\begin{tabular}{|c|c|c|c|c|c|}
\hline \multicolumn{2}{|c|}{ Tumour Cells } & \multirow{2}{*}{$\begin{array}{c}\text { EC } \\
\text { Source }\end{array}$} & \multirow{2}{*}{$\begin{array}{l}\text { Platform and } \\
\text { Matrix }\end{array}$} & \multirow{2}{*}{ Main Outcomes } & \multirow{2}{*}{ Ref. } \\
\hline Cancer Type & Source & & & & \\
\hline $\begin{array}{l}\text { Liver } \\
\text { Breast }\end{array}$ & $\begin{array}{l}\text { Human cell lines } \\
\text { (HepG2, MCF-7 } \\
\text { and MDA-MB-231) }\end{array}$ & HUVEC & Spheroids & $\begin{array}{l}\text { EC formed tube-like structures in } \\
\text { co-cultures with HepG2 but not with } \\
\text { breast cancer cell lines; structures } \\
\text { declined after } 3 \text { days of culture }\end{array}$ & [153] \\
\hline \multirow{2}{*}{ Breast } & $\begin{array}{l}\text { Human cell lines } \\
\text { (MCF7, T47-D and } \\
\text { MDA-MB-231) }\end{array}$ & $\begin{array}{c}\text { Primary (breast } \\
\text { tissue) }\end{array}$ & BME & $\begin{array}{l}\text { Increased breast cancer spheroid } \\
\text { growth (size and proliferation) in } \\
\text { co-culture with EC }\end{array}$ & [156] \\
\hline & $\begin{array}{l}\text { Murine cell line } \\
\qquad(4 \mathrm{~T} 1)\end{array}$ & $\begin{array}{l}\text { Murine } \\
\text { tumour-like EC } \\
\text { line }(2 \mathrm{H} 1)\end{array}$ & Spheroids & $\begin{array}{l}\text { EC infiltrated tumour spheroids; } \\
\text { increased sensitivity to chemotherapy } \\
\text { in co-culture but not to radiation }\end{array}$ & [152] \\
\hline
\end{tabular}


Table 2. Cont

\begin{tabular}{|c|c|c|c|c|c|}
\hline \multicolumn{2}{|c|}{ Tumour Cells } & \multirow{2}{*}{$\begin{array}{c}\text { EC } \\
\text { Source }\end{array}$} & \multirow{2}{*}{$\begin{array}{l}\text { Platform and } \\
\text { Matrix }\end{array}$} & \multirow{2}{*}{ Main Outcomes } & \multirow{2}{*}{ Ref. } \\
\hline Cancer Type & Source & & & & \\
\hline & $\begin{array}{l}\text { Human cell line } \\
\text { (MDA-MB-231) }\end{array}$ & $\begin{array}{l}\text { Human dermal } \\
\text { microvascular } \\
\text { cells }\end{array}$ & Microfluidics & $\begin{array}{l}\text { CXCR4 or CXCR7 on breast cancer } \\
\text { cells promoted adhesion to EC }\end{array}$ & [162] \\
\hline & $\begin{array}{l}\text { Human cell line } \\
\text { (MDA-MB-231) }\end{array}$ & HUVEC & $\begin{array}{l}\text { Collagen and } \\
\text { fibrin } \\
\text { Microfluidics }\end{array}$ & $\begin{array}{l}\text { Increased MDA-MB-231 invasion } \\
\text { in collagen, in co-culture }\end{array}$ & [163] \\
\hline & $\begin{array}{l}\text { Human cell line } \\
\text { (MDA-MB-231) }\end{array}$ & $\begin{array}{l}\text { Immortalized } \\
\text { microvascular } \\
\text { EC }\end{array}$ & $\begin{array}{l}\text { Collagen } \\
\text { Microfluidics }\end{array}$ & $\begin{array}{l}\text { EC formed a confluent layer aligned } \\
\text { with flow direction; } \\
\text { upregulation of proangiogenic genes } \\
\text { in flow vs. static conditions }\end{array}$ & [160] \\
\hline Lung & $\begin{array}{l}\text { Human cell line } \\
\text { (A549) }\end{array}$ & HUVEC & $\begin{array}{l}\text { Spheroids } \\
\text { Microfluidics }\end{array}$ & $\begin{array}{l}\text { Evidence of EMT in co-cultures, } \\
\text { reverted by EGFR inhibitor }\end{array}$ & [159] \\
\hline $\begin{array}{l}\text { Melanoma, } \\
\text { Breast, } \\
\text { Pancreatic }\end{array}$ & $\begin{array}{l}\text { Multiple cell lines } \\
\text { or patient-derived }\end{array}$ & HUVEC & Spheroids & Formation of capillary-like structures & [154] \\
\hline Liver & $\begin{array}{l}\text { Human cell line } \\
\qquad(\text { HepG2) }\end{array}$ & HUVEC & $\begin{array}{l}\text { Glycosaminoglycan- } \\
\text { based } \\
\text { hydrogel }\end{array}$ & $\begin{array}{l}\text { EC infiltration and tumour cell } \\
\text { migration in co-culture }\end{array}$ & [77] \\
\hline Colorectal & $\begin{array}{l}\text { Human cell line } \\
\qquad(\mathrm{HCT}-116)\end{array}$ & $\begin{array}{l}\text { Human } \\
\text { Colonic } \\
\text { microvascular } \\
\text { EC }\end{array}$ & $\begin{array}{l}\text { Matrigel } \\
\text { Microfluidics }\end{array}$ & $\begin{array}{l}\text { EC formed tube-like structures; } \\
\text { gemcitabine nanoparticles decreased } \\
\text { tumour cell proliferation }\end{array}$ & [164] \\
\hline $\begin{array}{l}\text { Colorectal } \\
\text { Glioma }\end{array}$ & $\begin{array}{l}\text { Cell lines (rat } \\
\text { glioma C6 and } \\
\text { human } \\
\text { colorectal LoVo } \\
\text { and HT29) }\end{array}$ & HUVEC & $\begin{array}{l}\text { Microfluidics } \\
\text { Matrigel }\end{array}$ & $\begin{array}{l}\text { Spheroid secreted higher levels of } \\
\text { VEGF than monolayers; } \\
\text { EC formed more tube-like structures } \\
\text { in 3D than in 2D co-cultures. }\end{array}$ & [165] \\
\hline \multirow[t]{2}{*}{$\begin{array}{l}\text { Glioma/ } \\
\text { Glioblastoma }\end{array}$} & $\begin{array}{l}\text { Patient-derived } \\
\text { glioma cell line } \\
\text { (GB3) }\end{array}$ & HUVEC & $\begin{array}{l}\text { Matrigel and } \\
\text { fibrin } \\
\text { Microfluidics }\end{array}$ & $\begin{array}{c}\text { Enhanced tumour cell migration in } \\
\text { co-culture and no effect on } \\
\text { proliferation; } \\
\text { CXCR4 inhibitor decreased } \\
\text { tumour cell } \\
\text { migration. }\end{array}$ & [166] \\
\hline & $\begin{array}{l}\text { Human } \\
\text { glioblastoma cell } \\
\text { line U87MG }\end{array}$ & HUVEC & $\begin{array}{l}\text { Spheroid } \\
\text { Microfluidics } \\
\text { Fibrin }\end{array}$ & $\begin{array}{c}\text { EC tube-like formation towards } \\
\text { tumour spheroid Antiangiogenics } \\
\text { (bevacizumab and sunitinib) reduced } \\
\text { EC migration }\end{array}$ & [167] \\
\hline
\end{tabular}

BME: Basement membrane extract; CXCR4: C-X-C chemokine receptor type 4; EC: Endothelial cells; EGFR: Epidermal growth factor receptor; EMT: Epithelial to mesenchymal transition; HUVEC: Human umbilical vein endothelial cells; VEGF: Vascular endothelial growth factor.

\subsection{Immune Cells}

The development of in vitro models of tumour-immune cell interactions has gained importance [168] (Table 3), particularly since the emergence of the next-generation immunotherapies, such as immune checkpoint inhibitors. Multiple immune cells can be recruited to the TME, and the dynamics of tumour-immune cell interactions are complex and constantly evolving during tumour progression [169]. Innate immunity cells, such as macrophages, neutrophils, natural killer (NK) cells or dendritic cells (DC), can be found within the TME, as well as adaptive immune cells, T and B lymphocytes [170]. Tumour cells can escape immune surveillance through different mechanisms, such as immune checkpoint expression, and harbour an immunosuppressive environment $[169,171]$. Tumours can be classified as cold or hot, depending on their lack or abundance of immune cell 
infiltration, respectively. Cold tumours are characterized by an immunosuppressive TME, rich in immunosuppressive cytokines, such as IL-10 and TGF- $\beta$ and presence of M2-like macrophages and T-regulatory cells (Treg); hot tumours are rich in T CD8+ lymphocytes, which have been linked to the ability to respond to immunomodulatory therapies $[172,173]$.

Table 3. Examples of studies developing and employing 3D co-cultures of tumour and immune cells.

\begin{tabular}{|c|c|c|c|c|c|c|}
\hline \multicolumn{2}{|c|}{ Immune Cells } & \multicolumn{2}{|c|}{ Tumour Cells } & \multirow{2}{*}{$\begin{array}{l}\text { Platform and } \\
\text { Matrix }\end{array}$} & \multirow{2}{*}{ Main Outcomes } & \multirow{2}{*}{ Ref. } \\
\hline Cell Type & Source & Cancer Type & Source & & & \\
\hline \multirow{4}{*}{$\begin{array}{l}\text { Monocytes/ } \\
\text { Macrophages }\end{array}$} & $\begin{array}{l}\text { Human } \\
\text { monocytic cell } \\
\text { line (THP-1) }\end{array}$ & Prostate & $\begin{array}{l}\text { Human cell line } \\
\quad(\text { BHP-1) }\end{array}$ & Transwell & $\begin{array}{l}\text { Polarization to M2-like } \\
\text { macrophages; } \\
\text { increased tumour cell } \\
\text { migration }\end{array}$ & [174] \\
\hline & $\begin{array}{c}\text { Murine } \\
\text { leukaemia cell } \\
\text { line } \\
\text { (RAW 264.7) }\end{array}$ & \multirow[t]{2}{*}{ Breast } & $\begin{array}{l}\text { Human cell line } \\
\text { (MDA-MB-231) }\end{array}$ & $\begin{array}{l}\text { Spheroids } \\
\text { embedded in } \\
\text { collagen }\end{array}$ & $\begin{array}{c}\text { Polarization to M2-like } \\
\text { macrophages; } \\
\text { increased resistance of tumour } \\
\text { cells to paclitaxel in co-cultures }\end{array}$ & [175] \\
\hline & $\begin{array}{c}\text { Murine } \\
\text { BM-derived } \\
\text { macrophages }\end{array}$ & & $\begin{array}{l}\text { Murine cell line } \\
\quad(\text { Py8119) }\end{array}$ & $\begin{array}{l}\text { Spheroids } \\
\text { embedded in } \\
\text { Matrigel }\end{array}$ & $\begin{array}{l}\text { Macrophage infiltration in 3D; } \\
\text { Increased tumour cell invasion } \\
\text { in co-culture }\end{array}$ & [176] \\
\hline & $\begin{array}{l}\text { Peripheral blood- } \\
\text { derived }\end{array}$ & Pancreatic & $\begin{array}{l}\text { Human cell line } \\
\quad \text { (Panc-1) }\end{array}$ & Microfluidics & $\begin{array}{l}\text { Increased macrophage migration } \\
\text { in co-culture or induced by flow } \\
\text { Partial blocking of macrophage } \\
\text { migration by anti-IL-8 and } \\
\text { anti-CCL2 }\end{array}$ & [177] \\
\hline \multirow{5}{*}{$\begin{array}{l}\text { Natural killer } \\
\text { cells (NK) }\end{array}$} & $\begin{array}{l}\text { Peripheral blood- } \\
\text { derived }\end{array}$ & Colorectal & $\begin{array}{l}\text { Human cell line } \\
\text { (HCT-116) }\end{array}$ & $\begin{array}{l}\text { Collagen; } \\
\text { Microfluidics }\end{array}$ & $\begin{array}{l}\text { Increased migration of NK } \\
\text { towards tumour cells }\end{array}$ & [178] \\
\hline & $\begin{array}{c}\text { Engineered NK } \\
\text { cells } \\
\text { (CAR-NK) }\end{array}$ & Colorectal & $\begin{array}{l}\text { Human } \\
\text { primary }\end{array}$ & $\begin{array}{l}\text { Organoids in } \\
\text { Matrigel }\end{array}$ & $\begin{array}{c}\text { CAR-NK recognizing different } \\
\text { antigens; } \\
\text { increased cytotoxicity of } \\
\text { CAR-NK towards tumour } \\
\text { organoids than normal } \\
\text { counterparts. }\end{array}$ & [179] \\
\hline & $\begin{array}{l}\text { Human cell line } \\
\text { (NK-92) }\end{array}$ & Lung & $\begin{array}{l}\text { Human cell line } \\
\text { (A549) }\end{array}$ & $\begin{array}{l}\text { Spheroids } \\
\text { Transwell }\end{array}$ & $\begin{array}{l}\text { Enhanced migration and } \\
\text { cytotoxicity of NK in the } \\
\text { presence of CXCL12 }\end{array}$ & [180] \\
\hline & $\begin{array}{l}\text { Peripheral blood- } \\
\text { derived }\end{array}$ & Cervical & $\begin{array}{l}\text { Human cell } \\
\text { lines (CaSki, } \\
\text { SiHa) }\end{array}$ & Spheroids & $\begin{array}{l}\text { NK infiltration in spheroids and } \\
\text { cytotoxicity towards } \\
\text { tumour cells }\end{array}$ & [181] \\
\hline & $\begin{array}{l}\text { Peripheral blood- } \\
\text { derived }\end{array}$ & Liver & $\begin{array}{l}\text { Human cell line } \\
\text { (HepG2) }\end{array}$ & Spheroids & $\begin{array}{l}\text { NK-mediated tumour lysis mainly } \\
\text { at the periphery of the spheroids }\end{array}$ & [182] \\
\hline \multirow[b]{2}{*}{$\begin{array}{l}\text { Dendritic cells } \\
\text { (DC) }\end{array}$} & $\begin{array}{l}\text { Monocytes from } \\
\text { peripheral blood }\end{array}$ & $\begin{array}{l}\text { Urothelial } \\
\text { Melanoma }\end{array}$ & $\begin{array}{l}\text { Several human } \\
\text { cell lines }\end{array}$ & Spheroids & $\begin{array}{c}\text { Distinct DC phenotypes } \\
\text { dependent on tumour cell line }\end{array}$ & [183] \\
\hline & $\begin{array}{l}\text { Monocytes from } \\
\text { peripheral blood }\end{array}$ & Colorectal & $\begin{array}{l}\text { Human cell line } \\
\text { (SW620) }\end{array}$ & Microfluidics & $\begin{array}{l}\text { DC migration towards tumour } \\
\text { cells; histone deacetylase } \\
\text { inhibitor and } \\
\text { IFN- } \alpha \text { led to increased DC } \\
\text { migration, through activation of } \\
\text { CXCR4/CCL12 axis }\end{array}$ & [184] \\
\hline \multirow{4}{*}{ T lymphocytes } & $\begin{array}{l}\text { Human CTL } \\
\text { clone }\end{array}$ & Lung & $\begin{array}{l}\text { Human cell line } \\
\text { (IGR-Heu) }\end{array}$ & Spheroids & $\begin{array}{l}\text { Less CTL activation in } \\
\text { 3D co-cultures than in } 2 \mathrm{D}\end{array}$ & [185] \\
\hline & $\begin{array}{l}\text { Human CTL } \\
\text { clone }\end{array}$ & $\begin{array}{l}\text { Metastatic } \\
\text { melanoma }\end{array}$ & $\begin{array}{l}\text { Human cell line } \\
\text { (HBL) }\end{array}$ & Spheroids & $\begin{array}{l}\text { Tumour associated antigen } \\
\text { recognition by CTL decreased } \\
\text { in 3D }\end{array}$ & [186] \\
\hline & $\begin{array}{l}\text { Human cell line } \\
\text { (Jurkat E6.1) }\end{array}$ & Lung & $\begin{array}{l}\text { Human cell line } \\
\text { (A549) }\end{array}$ & Transwell & $\begin{array}{l}\text { Co-culture secretome enriched in } \\
\text { proangiogenic and } \\
\text { proinflammatory } \\
\text { EMT-inducing factors. }\end{array}$ & [187] \\
\hline & $\begin{array}{l}\text { Engineered } \\
\text { T cells }\end{array}$ & Liver & $\begin{array}{l}\text { Human cell line } \\
\text { (HepG2) }\end{array}$ & Microfluidics & $\begin{array}{c}\mathrm{T} \text { cell infiltration and } \\
\text { induction of tumour cell death }\end{array}$ & [188] \\
\hline
\end{tabular}


Table 3. Cont

\begin{tabular}{|c|c|c|c|c|c|c|}
\hline \multicolumn{2}{|c|}{ Immune Cells } & \multicolumn{2}{|c|}{ Tumour Cells } & \multirow{2}{*}{$\begin{array}{c}\text { Platform and } \\
\text { Matrix }\end{array}$} & \multirow{2}{*}{ Main Outcomes } & \multirow{2}{*}{ Ref. } \\
\hline Cell Type & Source & Cancer Type & Source & & & \\
\hline & $\begin{array}{l}\text { Peripheral blood } \\
\text { lymphocytes }\end{array}$ & $\begin{array}{l}\text { Colorectal } \\
\text { and lung }\end{array}$ & $\begin{array}{l}\text { Human } \\
\text { organoids }\end{array}$ & $\begin{array}{c}\text { 96-well } \\
\text { U-bottom }\end{array}$ & $\begin{array}{l}\text { Autologous tumour T cells } \\
\text { recognized tumour organoids but } \\
\text { not healthy counterparts }\end{array}$ & [189] \\
\hline & $\begin{array}{c}\alpha \beta \text { T cells } \\
\text { carrying a } \\
\text { transgenic TCR } \\
\text { peptide-specific }\end{array}$ & Colorectal & $\begin{array}{l}\text { Human } \\
\text { organoids }\end{array}$ & $\mathrm{BME}$ & $\begin{array}{c}\text { Engineered T cells induced death } \\
\text { of antigen-specific } \\
\text { tumour cells }\end{array}$ & [190] \\
\hline & CAR-T & $\begin{array}{l}\text { Lung } \\
\text { Breast }\end{array}$ & $\begin{array}{l}\text { Human cell line } \\
\qquad(\text { A549; } \\
\text { MDA-MB-231) }\end{array}$ & $\begin{array}{l}\text { Microfluidics } \\
\text { Porcine } \\
\text { decellularized } \\
\text { matrix }\end{array}$ & $\begin{array}{l}\text { CAR-T decreased tumour cell } \\
\text { volume and increased tumour } \\
\text { apoptosis relative to untreated or } \\
\text { co-culture with non-engineered T } \\
\text { lymphocytes }\end{array}$ & [191] \\
\hline \multirow{6}{*}{ PBMC } & Human & Liver & $\begin{array}{l}\text { Human } \\
\text { primary } \\
\text { hepatocytes } \\
\text { (tumour and } \\
\text { healthy) }\end{array}$ & $2 \mathrm{D}$ & $\begin{array}{l}\text { T CD8+ showed increased } \\
\text { activation but less viability in } \\
\text { co-cultures }\end{array}$ & [192] \\
\hline & Human & Prostate & $\begin{array}{l}\text { Cell lines } \\
\text { (human LNCaP, } \\
\text { C4-2, C4-2B } \\
\text { and murine } \\
\text { TRAMP-C2) }\end{array}$ & $\begin{array}{l}\text { Spheroids in } \\
\text { chitosan- } \\
\text { alginate or } \\
\text { Matrigel }\end{array}$ & $\begin{array}{l}\text { Decreased proliferation of } \\
\text { tumour cells in comparison to } \\
\text { Matrigel; immune cells } \\
\text { infiltrated the tumour } \\
\text { spheroids }\end{array}$ & [193] \\
\hline & Human & HNSCC & $\begin{array}{l}\text { Human cell line } \\
\text { (EpCAM- } \\
\text { positive } \\
\text { FaDu) }\end{array}$ & $\begin{array}{l}\text { Spheroids } \\
\text { Spinner flask }\end{array}$ & $\begin{array}{c}\text { Immune cell infiltration into } \\
\text { spheroids; } \\
\text { bispecific antibody } \\
\text { (anti-EpCAM and anti-CD3) alone } \\
\text { or combined with } \\
\text { cisplatin decreased spheroid } \\
\text { viability }\end{array}$ & [194] \\
\hline & Human & HNSCC & $\begin{array}{c}\text { Human cell } \\
\text { lines (UD-SCC } \\
4, \\
5,6)\end{array}$ & Spheroids & $\begin{array}{l}\text { Anti-EGFR antibody induced } \\
\text { leukocyte infiltration into } \\
\text { tumour spheroids and the } \\
\text { effect was abrogated by } \\
\text { anti-CCL2 antibody }\end{array}$ & [195] \\
\hline & $\begin{array}{l}\mathrm{T} \text { and NK from } \\
\text { healthy donors or } \\
\text { patients }\end{array}$ & Colorectal & $\begin{array}{l}\text { Human cell line } \\
\text { (HT-29) or } \\
\text { primary }\end{array}$ & Spheroids & $\begin{array}{l}\text { T and NK infiltration into } \\
\text { spheroids and increased } \\
\text { tumour apoptosis in co-cultures; } \\
\text { both processes enhanced by IL-15 } \\
\text { supplementation }\end{array}$ & [196] \\
\hline & Treg and NK & Breast & $\begin{array}{c}\text { Human cell } \\
\text { lines (MCF-7 } \\
\text { and } \\
\text { MDA-MB-231) }\end{array}$ & Matrigel & $\begin{array}{l}\text { Model establishment and } \\
\text { implementation of analytical } \\
\text { methods (RNA extraction, } \\
\text { immunohistochemistry) }\end{array}$ & [197] \\
\hline
\end{tabular}

BM: Bone marrow; BME: Basement membrane extract; CAR: Chimeric antigen receptor; CCL2: C-C Motif Chemokine Ligand 2; CTL: Cytotoxic T lymphocyte; CXCR4: C-X-C chemokine receptor type 4; CXCL12: C-X-C Motif Chemokine Ligand 12; DC: Dendritic cells; EGFR: Epidermal growth factor receptor; EMT: Epithelial to mesenchymal transition; HNSCC: Head and neck squamous cell carcinoma; IFN- $\alpha$ : Interferon alpha; IL-15: Interleukin 15; EpCAM: Epithelial cell adhesion molecule; NK: Natural killer cells; TCR: T-cell receptor; Treg: Regulatory T cells.

\subsubsection{T Lymphocytes}

Since the beginning of the last decade, there have been reports on differences in immunogenicity of tumour cells cultured in 2D or 3D. Dangles-Marie et al. observed that when moving from 2D tumour cell monolayers to spheroids, autologous cytotoxic T lymphocytes (CTL) exhibited less activation, as measured by their cytokine secretion, specifically interferon (IFN) $\gamma$ and TNF- $\alpha$ [185]. This evident decrease was not linked to a diminished major histocompatibility complex (MHC) I or tumour antigen expression, but due to a downregulation of Hsp-70, a protein required for cytoplasmic transport of processed peptides for MHC I presentation. It was hypothesized that this downregulation was due to the slower growth rate of tumour cells observed in 3D [185]. Ghosh et al. also 
found a differential activation of $\mathrm{T}$ cells when a metastatic melanoma cell line was cultured as a monolayer or spheroids [186]. In this study, the authors reported a decreased activation of CTL by specific melanoma-associated antigens in $3 \mathrm{D}$, measured by IFN- $\gamma$ cytokine secretion, associated with a decrease in expression of MHC-I and specific antigens [186]. In another report from the same team [198], the authors confirmed the reduced activation of CTL by melanoma cells in spheroids and pointed out possible mechanisms in addition to MHC I and antigen expression downregulation in 3D: the architecture itself, with less exposed cell surface in 3D; increased production of lactic acid, which was previously linked to suppression of DC activation; and polarization towards M2-like macrophages, contributing to an immunosuppressive TME $[183,199,200]$. These studies emphasize the relevance of a 3D setting to scrutinize potential mechanisms of tumour immune escape, although multiple factors in the TME are reported to promote an immunosuppressive environment [199].

A T cell infiltration model was described by Alonso-Nocelo et al. [187]. The authors seeded a lung adenocarcinoma cell line (A549) and a T lymphocytic cell line (Jurkat E6.1) on a porous polystyrene scaffold to generate 3D co-cultures [187]. The authors found a distinctive secretome in co-cultures, revealing proteins involved in angiogenesis, EMT and inflammation processes [187]. Furthermore, the complement system pathway was only activated in 3D cultures [187]. This work provided a method to study tumour-T cell crosstalk, although using a leukaemia cell line as a model for T lymphocytes; the translational of the platform to peripheral $\mathrm{T}$ cells remains to be demonstrated.

Doumba et al. co-cultured autologous peripheral blood mononuclear cells (PBMC) with hepatic cancer cells or hepatocytes, in monolayers, and focused their analysis on $\mathrm{T}$ CD8+ cells, the major antitumour effector cells [192]. Both types of hepatic cells showed increased MHC-II expression when in co-culture with PBMC, and this correlated positively with the activation status of CD8+ T lymphocytes [192]. The mechanisms underlying this effect were not explored and the contribution of other PBMC subpopulations was not further investigated.

Recently, strategies to study immunotherapies such as adoptive cell therapies have been reported. Pavesi et al. tested engineered virus-specific T cells, previously shown to target hepatocarcinoma cell lines that express Hepatitis B Virus (HBV) antigens from naturally integrated viral DNA [201]. The authors developed a microfluidics approach, in which the central channel was populated with single cells or spheroids of a hepatic tumour cell line (HepG2) transduced to express HBV antigens, embedded in a collagen I gel. In parallel, the engineered $\mathrm{T}$ cells were added to one of the lateral channels. The authors observed T cell migration and induction of tumour cell death, whether using HepG2 as single cells or as spheroids. Furthermore, the authors tested T cell activity under hypoxia and observed reduced migration and a significant decreased antitumour effect in 3D, which were not observed in the $2 \mathrm{D}$ co-culture under hypoxia. This system can be applied to different cell types, as addressed in Section 4.1.1 [202]. Importantly, as in other studies, hypoxia and normoxia conditions need to be properly defined, namely the atmospheric oxygen vs. dissolved oxygen measurements [203].

Successful incorporation of intraepithelial lymphocytes in normal intestinal organoids of murine origin have been reported [204,205]. Briefly, the authors generated intestinal organoids in Matrigel and in parallel cultured intraepithelial lymphocytes isolated from the small intestine; after two days of monoculture, co-cultures were set up. The authors reported lymphocyte viability and motility for three or seven days, without or with cytokine (IL-2, IL-7, and IL-15) supplementation, respectively [204]. A similar work was performed in 2015 using murine enteroids and also intraepithelial lymphocytes [205]. Using patient-derived organoids, Dijkstra et al. used co-cultures of lung and colorectal cancer organoids with autologous T lymphocytes derived from peripheral blood [189]. Importantly, the authors found that $\mathrm{T}$ cells recognized tumour organoids but not organoids derived from healthy tissue. Thus far, studies with 3D co-cultures with Foxp3+ regulatory $\mathrm{T}$ lymphocytes (Tregs), which exhibit an immunosuppressor function, contributing to tumour 
growth, and are usually described as indicators of poor prognosis [206], have not been commonly reported.

\subsubsection{Macrophages}

Tumour-associated macrophages (TAM) have a spectrum of phenotypes that can range from M1-like, conventionally described as pro-inflammatory and anti-tumourigenic, to the pro-tumourigenic and immunosuppressive M2-like, that typically populate tumours in advanced stages [207-210]. Nonetheless, TAM can exhibit a mixture of macrophage phenotypes in between these two prototypical states [210,211]. Recently, efforts to dissect these subpopulations, as well as other immune cell populations, exploring single cell analysis have been made [211]. A TAM signature expressing SLC40A1, which encodes for the iron exporter ferroportin, and GPNMB, which encodes the glycoprotein nonmetastatic melanoma protein $\mathrm{B}(\mathrm{NMB})$, was correlated with poor prognosis in hepatocellular carcinoma [212]. The iron transporter has been previously associated with an attenuation of macrophage-mediated immunity [213] and the glycoprotein NMB was found to be upregulated by TAM and induce cancer stem cell markers and tumour progression via binding to the CD44 in tumour cells, eliciting the expression of IL-33 and its receptor in different murine cancer models [214].

The use of human peripheral blood-derived monocytes is well established as a source of macrophages for in vitro assays and considered more relevant than the use of monocytic cell lines, such as RAW 264.7 and THP-1, which express lower levels of monocyte marker CD14 but constitute a virtual unlimited cell source [215-217]. Both peripheral blood-derived monocytes or THP-1 can be polarized towards macrophages, for example, respectively, by M-CSF and Phorbol-12-myristate-13-acetate (PMA) stimulation. Both cell types can be further polarized towards a M2 phenotype, through different factors (such as IL-10) or induced by the presence of tumour cells [175,218]. However, M2 polarized from THP-1 do not exhibit the same spectrum of gene expression and protein markers as monocyte-derived M2 [215,218]. Conversely, both primary macrophages and THP-1 cells can be polarized toward a pro-inflammatory M1 phenotype after exposure to inflammatory stimuli, such as lipopolysaccharide (LPS) and IFN- $\gamma$ [215].

Regarding cell models depicting tumour-macrophage interactions, Maolake et al. employed a transwell approach to culture human prostate cancer cell lines and THP-1 [174]. They observed THP-1 polarization towards a M2-like phenotype and increased migration of tumour cells in the co-culture setting. The authors proposed the $\mathrm{C}-\mathrm{C}$ Motif Chemokine Receptor 4 (CCR4) as a potential drug target; the receptor has been previously implicated in Treg recruitment and resistance to immunotherapy [219]. Tevis et al. generated heterotypic spheroids of a breast tumour cell line and a murine monocytic cell line, embedded in collagen [175]. They have also reported polarization into M2-like macrophages by detection of secreted IL-10. Drug challenge experiments showed less sensitivity of heterotypic spheroids to paclitaxel compared to tumour homotypic spheroids.

Noel et al., in 2017, combined human intestinal organoids seeded in a monolayer with macrophages derived from peripheral monocytes and studied cell-cell interactions [220]. This study was not performed with tumour cells but opens new avenues to pivotal research on recapitulating TME applying organoid technology.

\subsubsection{Neutrophils}

As observed for other TME elements, neutrophils can also exhibit a dual phenotype, with anti- or pro-tumour action [221-223]. High numbers of tumour-associated neutrophils have been correlated with poor prognosis in patient samples [224]. However, the role of neutrophils is complex due to their plasticity and heterogeneity. In early stage lung cancer samples, a neutrophil phenotype compatible with antitumour functions due to induction of T cell proliferation and IFN- $\gamma$ release was reported [222,225]. In murine models, neutrophils' pro- or antitumour roles have also been described. Neutrophils favoured metastatic seeding of circulating tumour cells in a melanoma model, while decreased metastatic seeding in a 
breast cancer model $[226,227]$. Moreover, in murine models it was shown that neutrophil recruitment is dependent on granulocyte colony stimulating factor (G-CSF) and it can lead to a decreased tumour burden [221]. However, G-CSF-mediated neutrophil recruitment has also been linked to metastasis promotion [228]. Recently, it has been reported that the neutrophil effect was dependent on NK status [229]. This has been shown in murine models of breast tumour and in 2D triple cultures of breast cancer with neutrophils and NK cells, all from murine sources [229]. Particularly, neutrophils showed antitumour activity in the absence of NK cells. On the contrary, in the presence of NK cells, neutrophils played prometastatic roles by suppressing NK's tumoricidal role.

Few in vitro models of the TME comprising neutrophils have been reported so far. There are reports describing 2D co-cultures of tumour cells and neutrophils, in which the latter also showed a pro- or antitumour effect $[229,230]$. As for 3D approaches, a report described high viability of a neutrophil-like cell line in scaffold of BME and collagen I; a microfluidic device has also been proposed to study neutrophil migration [231,232]. Still, both studies comprised only monocultures. A 3D co-culture of a carcinoma cell line and neutrophils has been proposed as a model of bacterial infection; still, their applicability in cancer modelling still needs to be explored [233].

\subsubsection{Dendritic Cells}

DC are antigen-presenting cells involved in T-cell-mediated antitumour immunity [234,235]. Depending on the tumour type, immature or mature DC can be found in the TME. Immature phenotypes express low levels of co-stimulatory molecules (CD80, MHC II) and secretion of low levels of immunostimulatory cytokines (IL-12), and therefore are unable to activate T effector cells, contributing to an immunosuppressive TME $[183,236]$. DC can be isolated directly from PBMC or differentiated ex vivo from monocytes; DC are then pulsed with tumour-derived antigens ex vivo and reinfused in patients, aiming at eliciting a T-cell response against endogenous tumour antigens (DC antitumour vaccines). Various DC-based clinical trials are ongoing and Sipuleucel-T, for prostate cancer, is the first FDA-approved cancer vaccine [237]. Nonetheless, there are several bottlenecks on DC-based vaccines, namely the definition of the most suitable maturation stimuli or the need for uniformization of manufacturing processes [238-240].

Regarding in vitro recapitulation of tumour-DC interactions, Gottfried et al. used co-cultures of spheroids from different cancer cell lines with human monocytes from peripheral blood that were differentiated into DC along the co-culture time with specific cytokines, widely used to differentiate DC from blood monocytes, namely IL-4 and granulocyte-macrophage colony-stimulating factor (GM-CSF) [183]. The authors reported cancer cell line-dependent modulation of DC, with different cytokine secretion profiles differentially modulating the DC phenotype. Moreover, lactic acid secreted by tumour cells and previously implicated in immunosuppressive M2-macrophage polarization impairs DC antigen presentation ability [183]. Using a microfluidics approach, Parlato et al. showed DC migration towards tumour cells driven by the CXCR4/CCL12 axis [184] and antigen uptake. A 3D model has been reported to study the interaction between DC and T lymphocytes, measuring maturation and contact duration. The authors reported enhanced interaction time with more mature DC; it would be interesting to include tumour cells in this setting [241].

\subsubsection{NK Cells}

NK cells are considered a part of antitumour immunity and are involved in cancer immunosurveillance [242]. Like DC, NK cells have been proposed for immunotherapy [243-245]. NK infiltration levels in tumours are described as low [206], though in patient samples from different cancer types in which NK numbers were highly detected, it was associated with a better prognosis [246,247]. In contrast, in peripheral blood, high NK detection was linked with poor prognosis for gastric cancer [248] but with an increased overall survival in colorectal cancer patients [249]. Methods to study 3D NK infiltration 
into tumour spheroids have been proposed, through stimulation with different cytokines, such as IL-2 and IL-18 [250]. Ayuso et al. developed a microfluidic system using a colon adenocarcinoma cell line (HCT-116) within a collagen gel seeded in a central microchamber and flanked by two lateral microchannels [178]. In one of these lateral microchannels, the authors added activated NK cells, isolated from PBMC. The authors observed increased migration of NK towards the tumour ones, even though tumour cell cytotoxicity induced by NK was not determined.

\subsubsection{Other Immune Cells}

Regarding $\gamma \delta \mathrm{T}$ cells, a distinct subset of T lymphocytes with innate- and adaptive-like properties, pleiotropic roles of anticancer and pro-tumour have been described in mouse models, though elucidation on human $\gamma \delta$ T lymphocytes is still pending [251,252]. A co-culture between spheroids of a lymphoma cell line and a subset of primary $\gamma \delta \mathrm{T}$ cells (TCRV $\gamma 9$ ) derived from healthy donors was employed to study antibody-dependent cell cytotoxicity (ADCC) and response to Programmed cell death protein 1 (PD-1) blockade [253]. The authors found that $\gamma \delta$ T infiltration in tumour spheroids was facilitated by anti-CD20 and detected ADCC evidenced by spheroid volume decrease. Moreover, this cytotoxicity was potentiated by an anti-PD-1. Importantly, the authors found similar results in an in vivo lymphoma model and detected the presence of this subset of $\gamma \delta$ T lymphocytes in patient samples.

Myeloid-derived suppressor cells (MDSC) constitute a heterogeneous immature population of myeloid cells with immunosuppressive functions [254]. In vivo studies have shown that MDSC can strongly suppress T cells and inhibit cytotoxic activity from NK cells $[255,256]$. MDSC levels have been proposed as indicators of poor prognosis, with detection of increased circulating MDSC numbers associated with advanced breast cancer [257]. In a recent study, cancer patient-derived MDSC were shown to induce a more pronounced inhibition of T cell proliferation than MDSC derived from healthy donors, in a transwell co-culture set-up [257].

\subsection{Mesenchymal Stromal Cells}

MSC can be actively recruited by tumours and contribute to tumour promotion through diverse mechanisms [258]. Moreover, MSC are known for their plasticity and can differentiate into CAF, adipocytes or even EC and are associated with the build-up of an immunosuppressive TME [259]. Zhu et al. used stereolithography-based 3D bioprinting to fabricate a bone-like matrix with breast tumour cells (MDA-MB-231) co-cultured with bone marrow-MSC (BM-MSC) to mimic a bone metastasis environment $[260,261]$. In the presence of MSC (or osteoblasts), tumour cell growth was enhanced and VEGF secretion was increased in comparison to monocultures. Bersini et al. also used MSC differentiated into osteoblasts to study MDA-MB-231 extravasation to a bone-mimicking environment, in a microfluidic device [262]. Tumour cell extravasation through EC coated channels and migration were higher in the bone-like microenvironment than the collagen matrix [262].

Mosaad et al. used a co-culture of prostate cancer cell lines with BM-MSC, adipocytes or osteoblasts in a microwell platform. Tumour migration and proliferation were dependent on the specific tumour cell line aggressiveness, culture dimensionality and presence of stromal cells, with adipocytes leading to the highest tumour cell proliferation increase [263]. Moreover, drug assays in 3D co-cultures presented higher drug resistance to docetaxel but not to antiandrogen drugs [263]. The mechanism underlying these differences still needs to be clarified. Liu et al., in 2016, used a different source of MSC, from umbilical cord (UCMSC) instead of bone marrow-derived ones, and set up a co-culture with a hepatocellular carcinoma cell line (HCCLM3) in alginate [264]. The authors observed enhanced tumour cell invasion capacity and increased expression of MMP genes and EMT-related genes (vimentin), but no differences in tumour cell growth profile or drug response to cisplatin between co-cultures and monocultures. In a 2D study by Chao et al., in 2012, UC-MSC co-cultured with a breast tumour cell line exhibited an antitumour effect [265]. Further 
understanding on MSC effects and their different sources is still required, especially as MSC have been proposed as a therapeutic vehicle for antitumour treatments $[266,267]$.

Although the focus of this review is on solid tumours, TME recapitulation of non-solid tumours is also critical, as reviewed in [268]. Studies in 2D, with bone marrow accessory/stromal cells to mimic events of haematological malignancies, are common in the literature $[269,270]$. Purroy et al. aimed to mimic the chronic lymphocytic leukaemia (CLL) microenvironment in bone marrow [270]. The researchers used co-cultures of CLL cells isolated from patient's PBMC and bone marrow stromal cells (human cell line UE6E7T-2) [270]. In this co-culture system, tumour cells showed a proliferative phenotype comparable to the one found in vivo and found chemoresistance linked to upregulation of antiapoptotic proteins. Moreover, 3D co-cultures to depict the bone marrow microenvironment in different diseases have also been attempted [271-273]. A 3D approach using inert scaffold in which MSC derived from patient samples and differentiated into osteoblasts were co-cultured with myeloid leukaemia cell lines [274]. The authors found increased ECM deposition, though it was not identified its composition, and cell cycle arrest in the 3D vs. 2D culture setting. Upon chemotherapy challenge, fewer apoptotic cells were observed in 3D co-cultures than in monoculture and 2D. When combined with an integrin blocking agent, drug sensitivity was restored in 3D co-cultures, possibly due to disruption of cell adhesion and migration.

\subsection{Other Non-Malignant Cell Types of the TME}

Additional non-malignant cell types, such as cancer-associated adipocytes and SMC, can also be present in the tumour milieu [9]. Regarding adipocytes, there is evidence that cancer-associated adipocytes can secrete adipokines involved in tumour growth and immune evasion, dedifferentiate into fibroblasts and provide free fatty acids for tumour cell consumption [275]. A 2D co-culture of adipocytes and monocytes (THP-1 cell line) in transwell revealed that THP-1 were induced to differentiate towards a M2 phenotype in presence of adipocytes [276]. Yue et al. developed a co-culture of tumour cells and adipocytes. The authors embedded the 3T3 mouse fibroblast cell line in microwells loaded with a hydrogel mixture of PEG and methacrylated gelatine, and induced differentiation of $3 \mathrm{~T} 3$ to the adipocytic lineage [277]. After seven days, the authors introduced triple negative breast cancer cell lines, which formed spheroids inside the microwells, surrounded by adipocytes. The presence of tumour cell lines increased matrix stiffness relatively to coculture with non-malignant murine mammary spheroids. Furthermore, when using two hydrogels with different stiffnesses, adipogenesis was inhibited with higher stiffness when in the presence of tumour cells. As adipocytes are described to secrete cytokines involved in promoting angiogenesis [278], it would be interesting to incorporate EC in this system, as matrix stiffness also affects angiogenesis [279]. In fact, using a different 3D approach, Agarwal et al. incorporated EC with adipocytes and a breast tumour cell line (MCF-7) in a microfluidic device and observed increased stiffness as well [280]. Additionally, EC formed tube-like structures and drug resistance was increased in triple cultures than in double co-cultures without EC or in 2D monolayers. Herroon et al. used co-cultures of adipocytes (murine bone marrow derived) and prostate tumour cells (PC3) and found increased tumour spheroid volume in co-cultures [281]. In a parallel setting, using single cells in layered matrices, the authors observed increased invasion of tumour cells into the adipocyte layer. Unfortunately, the authors did not identify the paracrine factors involved in this crosstalk.

Devarasetty et al. used colon carcinoma cell lines and SMC isolated from rabbit colonic submucosa [282]. The authors embedded tumour spheroids and SMC in collagen I gels and observed that tumour cells exhibited decreased proliferation and less migratory potential (in terms of cell projections and EMT markers) in the SMC-containing matrix than in the collagen I alone. This phenotype was related to the differences in the matrix topography, with higher fibre alignment and organization due to ECM remodelling by SMC. In fact, there is evidence that aligned fibres can facilitate migration of tumour and other stromal 
cells [283]. Moreover, the authors challenged the cultures with 5-FU and observed that drug sus-ceptibility was dependent on the tumour cell line, but still lower susceptibility of the tumour cells within the SMC-matrix than in collagen only was observed. This could be linked with tumour cells diminished proliferation levels detected in the SMC-matrix. It is not clear if SMC are preserved along time or only their derived matrix is retained.

\section{Combination of Multiple Non-Malignant Cell Types}

The multiple cell types present in the TME can have several effects on tumour progression, metastasis and therapeutic outcome. Several reviews have focused on the role of these multiple cell types [84,284-286]. In addition to the crosstalk between tumour cells and other cell types, the interplay between different non-malignant cell types within the TME is also important. As examples, fibroblasts can either lead to $\mathrm{T}$ cell suppression by secreting different factors, e.g., TGF- $\beta$ and CXCL12, or increased effectiveness of T cells by enhancing their recruitment, highlighting CAF phenotypic and functional heterogeneity, although a T CD8+ immunosuppressive function seems to be more prevalent among CAF functions [287-289]; EC can also produce factors that hamper T cell function [290]; on the other hand, EC can decrease the expression levels of adhesion molecules, such as intercellular adhesion molecule 1 (ICAM-1), involved in leucocyte recruitment, contributing to a reduced immune tumour infiltration [291]; CAF-derived factors have been reported to promote angiogenesis $[16,292,293]$ and act synergistically with EC to induce chemoresistance [294]; macrophages are reported to secrete VEGF and FGF-2, two known proangiogenic factors [295]. Antiangiogenic therapy, namely anti-VEGF, has been correlated with increased lymphocyte infiltration and immunotherapy effectiveness [296,297]. However, anti-VEGF therapy has also been associated with reprogramming of CAF to a more proangiogenic phenotype, in a VEGF-independent manner, through the secretion of PDGF-C, and polarization of macrophages towards a M2-like immunosuppressive phenotype [298]. TAM can physically exclude CD8+ T lymphocytes and prevent their antitumour function [299]. Drugs targeting macrophages, such as colony stimulating factor 1 receptor (CSF1R) inhibitors, have shown limited antitumour effects in patients [300] and a role of CAF in this resistance has been identified, for example, by recruiting pro-tumorigenic MDSC [301]. Combination therapy of CSF1R inhibitors with chemotherapeutics or other immune-modulating therapies is under clinical trials [302]. It is therefore crucial to map and understand the complex and multifactorial set of cellular interactions within the TME that contribute to cancer progression and therapeutic resistance. Experimental humanrelevant models in which these multifactorial interactions can be interrogated, potential targets identified, and combinatorial therapies targeting multiple TME effectors tested. Development of cancer co-cultures with more than two cell types is a step closer to achieve those models (Figure 3) and in the next sections triple and tetracultures will be discussed. 


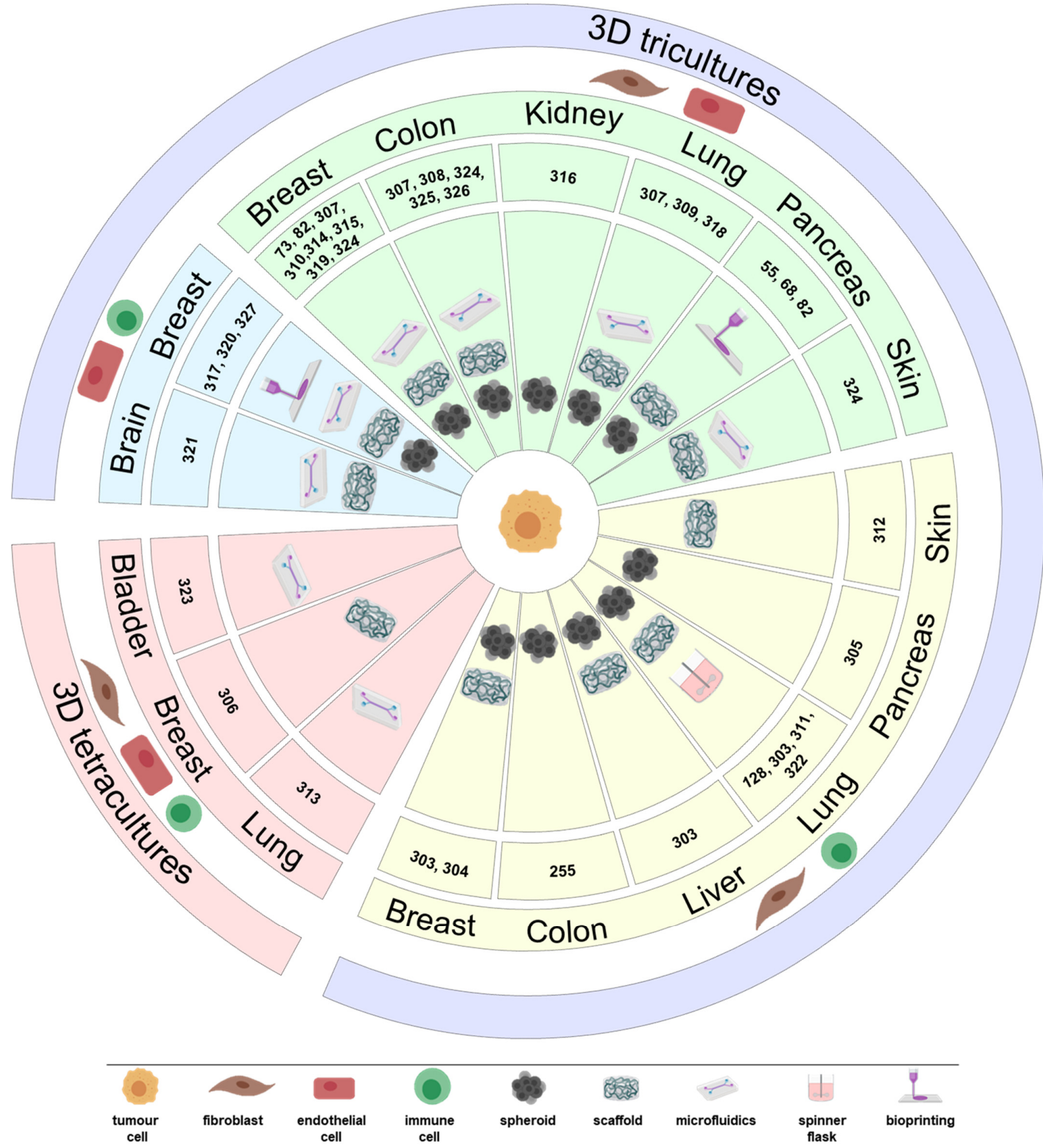

Figure 3. Schematic diagram showing examples of co-cultures of tumour cells with two or more tumour microenvironment cell components (fibroblasts, endothelial or immune cells) using different 3D approaches heterotypic spheroids and scaffoldbased methods (artificial or animal-derived), employing distinct culture systems, such as spinner-flasks and microfluidic devices, and innovative techniques for generation of the 3D cultures, such as bioprinting $[55,68,73,82,128,195,303-327]$. Created with Biorender icons.

\subsection{D Tricultures}

4.1.1. 3D Tricultures of Tumour and Stromal Cells

Various groups established culture models to recapitulate interactions between tumour, endothelial and stromal cells within the TME. Correa-Sampaio et al. developed a cell model to mimic the sprouting stages of tumour angiogenesis by generating heterotypic spheroids of a breast cancer cell line (MDA-MB-231), fibroblasts and EC (HUVEC), embedded in 
a collagen I gel [73]. The authors observed that EC formed networks intertwined with fibroblasts and that these sprouts (defined as HUVEC outgrowth from the spheroids) were in higher numbers in the presence of tumour cells than in double cultures of EC and fibroblasts. The authors challenged the model with antiangiogenics, such as anti-VEGF, and observed a reduction in the endothelial network, exhibiting less branching.

Ehsan et al. also combined tumour, fibroblasts and ECs but used a two-step approach [307]. First, lung, breast or colon tumour cell lines were combined with human EC (umbilical cord-derived) to generate heterotypic spheroids; then, spheroids were embedded on a fibrin gel with normal human lung fibroblasts [307]. The spheroids exhibited signs of sprouting angiogenesis and tumour cells migrated to the surrounding matrix, especially under hypoxic conditions [307].

The inclusion of fibroblasts has already been reported to promote the formation of capillaries [328]. Amann et al. developed a heterotypic spheroid-based triculture of EC (HUVEC and Human primary microvascular EC, HMVEC), a fibroblast cell line and two non-small cell lung cancer lines [329]. The authors used two approaches: direct co-culture of the three cell types or combining tumour cells and fibroblasts and adding the EC after 5 days. At day 10, no EC were detected in the direct triple cultures, but in the sequential approach, EC migrated towards the central area of the spheroid, where fibroblasts were located and hypoxic cores formed. Two antiangiogenic drugs were tested, with no statistically significant differences in EC migration. We have recently reported a strategy for long-term culture of triple heterotypic spheroids of EC (HUVEC), human dermal fibroblasts and a breast cancer cell line (HCC1954), under agitation; in accordance with other authors, we observed that EC were localized in close vicinity to fibroblasts, in the core of the spheroids [310]. In our system, EC maintenance for up a month of culture was dependent on the tumour cell line, the presence of fibroblasts, which secreted collagens I and IV, and agitation but occurred even without formation of hypoxic cores.

Tricultures with BM-MSC as source of stromal cells have also been proposed. Lamichhane et al. generated heterotypic spheroids of human BM-MSC combined with a lung adenocarcinoma cell line (A549) and human pulmonary microvascular EC (HPMEC) [330]. At day 15 of culture, only $0.1 \%$ of the initial seeded EC were present, though MSC were maintained [330]. The authors reported higher reactive oxygen species (ROS) levels in $3 \mathrm{D}$ than in 2D tricultures, which may have a pro- or antitumorigenic role [331]. In drug response assays with chemotherapeutics (gemcitabine and paclitaxel), no significant differences in cell death were observed between 3D triple cultures and 2D tricultures, despite the upregulation of ABC-B1, efflux transporter associated with drug resistance [330]. These findings require further clarification and suggest that although this might be a feasible platform for the three-cell type combination, improvements regarding EC viability and functionality in the presence of MSC are required. Bray et al. also performed triple cultures of tumour, MSC and EC, using acute myeloid leukaemia cells (cell lines or primary), all embedded in starPEG-heparin hydrogels; EC survival and formation of EC-tube-like structures was favoured in this system [332]. Upon chemotherapy challenge, increased drug resistance was detected in the triple cultures vs. 3D and 2D monocultures. A CXCR4 antagonist led to decreased tumour-EC contacts in 2 out of 3 primary samples but did not affect viability in the three samples. Work from the same group used the same hydrogel for setting up triple cultures with breast and prostate cancer cell lines. They described similar results in terms of EC behaviour and chemotherapy resistance [333]. Moreover, the same authors showed the versatility of this system by applying it to triple cultures with primary fibroblasts (instead of MSC), EC-HUVEC or HMVEC, and the non-malignant MCF10A cell line. Still, the triple cultures of EC, MSC and breast tumour epithelial cells were not performed.

Applying a microfluidic approach, Rogers et al. used co-cultures of MDA-MB-231, fibroblasts (human or murine) and EC (HMVEC) [334]. The researchers seeded fibroblasts within a collagen I and Matrigel scaffold in the central chamber of the device and one tumour spheroid was added on top. EC were seeded in one of the lateral channels. Fi- 
broblasts formed fibril-like structures and tumour cells preferentially migrated along these fibrils. Lee et al. also used a microfluidic device for the generation of tricultures of lung tumour cells (A549), murine fibroblasts (3T3) and EC (HUVEC) [309]. Cells were seeded sequentially: the tumour cells embedded in collagen I were placed in a microwell, fibroblasts in collagen I were seeded on top of the tumour cells, and EC were then seeded in a channel placed on top of the microwell. Tumour cells and fibroblasts spontaneously aggregated into a heterotypic spheroid and HUVECs formed vessel-like structures along the channel, and some reached and interacted with cancer cell spheroids. In the absence of fibroblasts, these tube-like structures were not observed, reinforcing the concept that fibroblasts sustain EC. When exposed to chemotherapeutic agents (paclitaxel and gemcitabine), tumour cells from cultures containing fibroblasts presented higher drug resistance [309]. In double co-cultures of fibroblasts and tumour cells, increased expression of genes involved in pathways related to metastasis and angiogenesis were observed over time. Although Rogers et al. and Lee et al. performed triple cultures, their analyses focused on tumour-fibroblast interactions; it would be relevant to characterize the EC population.

Pape et al. used scaffolds of collagen and laminin to set up triple cultures of colorectal cancer cell lines, HUVEC and normal fibroblasts or CAF (patient-derived) [308]. The authors found that in the presence of CAF, there was an induction of a tumour invasive phenotype with increased expression of HGF and Tissue inhibitor of metalloproteinases 1 (TIMP-1) and disruption of the EC network, not observed with normal fibroblasts. Herrera-Perez et al. developed a co-culture model with glioblastoma-derived cell lines and astrocytes and/or endothelial precursors, embedded in a matrix of collagen and hyaluronan [335]. The researchers observed that, in the presence of astrocytes, all glioblastoma cell lines tested exhibited higher migration, while in double or triple cultures with endothelial precursors, different migration effects were observed, depending on the cell line [335]. Endothelial precursors impaired migration in a stem-like population of glioblastoma cells. This finding might seem controversial as vascular networks can constitute migration routes but, in this study, endothelial precursors did not form tube-like structures.

Altogether, these data point out the relevance of stromal-endothelial interactions to support EC in heterotypic cultures along with tumour cells but also that these processes are largely influenced by the tumour cell line and origin of the stromal cells. Further research will be required to pinpoint the critical molecular components required to sustain EC in these complex models. The EC-tube-like phenotype seems to be favoured in 3D triple cultures of with tumour cells and fibroblast relatively to double co-cultures with tumour cells. This constitutes a step closer to recapitulating in vivo processes, still improvements are needed regarding culture duration.

\subsubsection{Triple Cultures with Immune Cells}

Concerning studies including immune cell populations, several models have been proposed incorporating monocytic cells. Linde et al. set up co-cultures of skin squamous cell carcinoma cell lines, human dermal fibroblasts and macrophages differentiated from PBMC-derived monocytes. Fibroblasts and monocytes were embedded in collagen gel and tumour cells were placed on top [312]. The study was performed with human cells and murine equivalents in parallel [312]. The authors showed M2 macrophage polarization after three weeks of co-culture, both when using human or murine tumour cells. Moreover, they observed increased tumour cell protrusions within the hydrogel in the presence of both fibroblasts and macrophages or only macrophages, but not with fibroblasts only. This was linked to increased detection of MMP in the presence of macrophages [312]. Similar results were reported by Liu et al. on co-cultures of tumour cell lines (lung adenocarcinoma) with fibroblast and monocytic cell lines, all embedded in a collagen gel [311]. In triple cultures, the authors found the highest expressions of MMP-1 and VEGF, two factors known to be involved in tumour progression, invasion and angiogenesis [336,337].

Our group explored a strategy based on an inert biomaterial, alginate, to generate triple co-cultures of tumour cells, fibroblasts and monocytes and evaluate cellular crosstalk 
without the interference of active exogenous ECM and soluble factors [128]. For this, spheroids of non-small cell lung cancer cells (NCI-H157 cell line), human fibroblasts and human monocytes (PBMC-derived or THP-1) were co-encapsulated in alginate [128]. This triple culture (3D-3 culture) exhibited characteristics of an immunosuppressive TME, such as secretion of immunosuppressive cytokines (IL-4), and matrix remodelling enzymes (MMP-1) and accumulation of ECM components. Moreover, monocytes infiltrated the tumour spheroids, polarizing towards a M2-like phenotype without supplementation of growth factors and cytokines. Drug challenge with cisplatin and a CSF1R inhibitor (BLZ945) induced modulation of genes associated with macrophage transition from M2 to M1, as previously reported [338,339]. This culture system has been recently expanded to breast cancer cell lines [340].

Aiming at recapitulating the complexity of the immune infiltrate, several authors developed co-cultures with whole PBMC. Hoffmann et al. used two models, heterotypic spheroids of tumour cell lines, CAF and PBMC and explants derived from tumour samples [195]. Both models showed that were amenable to drug challenges with different chemotherapeutic compounds (e.g., 5-FU and SN38, the active metabolite of irinotecan) and targeted agents, such as cetuximab (anti-EGFR) and trastuzumab (anti-Her2) [195]. Due to easier availability, the spheroid model with cell lines is proposed for drug screening, while explants are proposed for precision medicine approaches, although it is not clear if the stromal compartment in patient-derived explants was preserved, since the authors only mentioned the lack of EC. Co-cultures of spheroids of a breast cancer cell line (MDA-MB-231) and PBMC derived from breast cancer patients have also been proposed as an approach to test immunotherapies [341]. Further elucidation of the immune cells infiltrating and their preservation in this culture setting is needed, as well as the relevance of employing just one tumour cell line. Koeck et al. generated heterotypic spheroids of lung cancer cell lines (Calu-2 and A549) and a fibroblast cell line (SV80), to which PBMC were added after 10 days [342]. The authors observed that, in the presence of fibroblasts and with the Calu-2 cell line, PBMC did not migrate, remaining in the spheroid periphery. Using A549, in double culture with PBMC, and in triple cultures, PBMC were visible in the central area of the spheroid. Moreover, the authors characterized immune cell types present and observed more activated CD8+ T lymphocytes in triple cultures than in double cultures. Phenotypic status and PBMC infiltration were dependent on the tumour cell line. For example, T lymphocyte infiltration was decreased in triple vs. double cultures when using Calu-2 cell line, but no differences were found with A549, while activated NK were increased in triple vs. double cultures when using the A549 cell line and no differences were found when using Calu-2. Nonetheless, triple cultures showed increased levels of cytokine secretion, including chemokines, independently of the tumour cell line used. Further dissection on these interactions would clarify the mechanisms underlying these observations, but it seems that the increased activation of $\mathrm{T}$ cells in the triple cultures is counterbalanced by possible physical limitation to infiltration due to the fibroblast presence; therefore, it would be interesting to analyse ECM components. Herter et al. also followed a similar approach but for colorectal cancer and tested immunotherapeutics: heterotypic spheroids of tumour and fibroblast cell lines were co-cultured with PBMC [343]. The authors challenged the system with a variant of IL-2, a bispecific antibody that binds to carcinoembryonic antigen (CEA, an antigen overexpressed on different tumour cells) and to CD3 (T lymphocytes), and the combination of these. The latter was more effective than monotherapy on T, NK and NKT cell activation and tumour cell death [343]. It would be interesting to test the system with patient-derived tumour cells and address infiltrated lymphocytes, which usually are suppressed and exhibit suboptimal activity [343].

A microfluidic approach was used to explore the effects of monocytes in T cell-based immunotherapies [202]. The authors have previously developed a microdevice with engineered T cells and tumour cells [188]; and here the authors generated tumour cell spheroids from a hepatic tumour cell line (HepG2) transduced to express HBV antigens and embedded the tumour aggregates with monocytes isolated from PBMC in a collagen I 
gel. The gel was injected in the central chamber of the microdevice, and $\mathrm{T}$ cells were added to only one of the lateral channels. A significant decrease in T cell antitumour activity was observed in the presence of monocytes, which was reversed once checkpoint inhibitors were used, namely anti-PD-1 or anti-programmed death-ligand-1 (PD-L1) antibodies. Importantly, this inhibitory action on T cells exerted by monocytes was not observed in a 2D setting. This study highlights the importance of a 3D context to study such interactions and highlight the clinical relevance of increased PD-L1+ monocytes identified in HBV-associated hepatocarcinoma patient samples [344]. Importantly, the suppression of $\mathrm{T}$ cell activity by monocytes was also dependent on the method of $\mathrm{T}$ cell engineering, making this a pertinent model to study different CAR-T cell manufacturing approaches and their interaction with the TME [202]. These 3D co-cultures incorporating different immune cells lack full characterization and profiling of the immune compartment. Still, they can constitute a useful tool to explore immunotherapeutics once better characterized. Triple cultures of immune cells and fibroblasts have a lot of room for improvement as CAF can exert an immunosuppressive effect and most 3D cultures fail to recapitulate this phenomenon or do not address it.

Regarding triple cultures of tumour, immune and EC, only few studies are reported $[317,320,321,327]$ and include mainly monocytes as the immune cell type; therefore, advances on these tricultures are needed as EC-immune interactions are involved in defining an immunosuppressive TME and influence therapeutic response $[345,346]$.

\subsection{Tetracultures}

Co-culture strategies have been expanded to include an increased number of cell types and better recapitulate the network of cellular interactions within the TME. Xu et al. used a microfluidic chip to recapitulate lung cancer microenvironment using a lung cancer cell line (A549), a human bronchial epithelial cell line (16HBE), HUVEC, a human lung fibroblast cell line (WI38) and a mononuclear cell line (THP-1), all in different compartments [313]. They observed changes in fibroblast and monocytes towards pro-tumourigenic phenotypes. This was most probably due to the interaction with cancer cells. In a reciprocal manner, they found markers of EMT and invasion in tumour cells co-cultured in presence of the other cell types [313]. Tang et al. aimed to mimic glioblastoma TME by employing bioprinted scaffolds of gelatine methacrylate with hyaluronic acid, the main component of brain ECM, and co-cultured monocytes (differentiated from THP-1 or induced pluripotent stem cells, iPSC) with neural populations (astrocytes and neural stem cells) and glioblastoma cells derived from xenografts [347]. The authors found an enrichment in hypoxia response genes, stemness markers and genes associated with an invasiveness signature. Drug challenge with EGFR inhibitors and temozolomide showed enhanced resistance in tetracultures compared to tumour homotypic spheroids. Neufeld et al. also developed a bioprinted platform to mimic the glioblastoma microenvironment, but used a different bioink based on fibrin and gelatine [348]. The authors combined tumour cells from cell lines or patient-derived with primary astrocytes, microglia in a perfusion chip with channels covered with EC (HUVEC) and pericytes. This pentaculture system showed similar results with mouse models than the $2 \mathrm{D}$ in terms of tumour growth and transcriptional profiles, and drug response to a P-selectin inhibitor. Langer et al. used a bioprinting approach to design a versatile tetraculture system [82]. The authors used tumour cell lines or patient/xenograft-derived breast or pancreatic tumour cells, fibroblasts and EC, and adipocytes or MSC according to their relevance in the TME of specific cancer types. They observed ECM deposition and formation of EC-tube-like structures. Drug response to different drug modalities was assessed: more increased doxorubicin resistance was seen in 3D as opposed to 2D tetracultures and sunitinib (a receptor tyrosine kinase inhibitor) inhibited the EC network.

Focusing on recapitulating specific features of the metastatic process, multiple studies have been developed to mimic cell types and ECM characteristic of the metastatic site [349]. Jeon et al. aimed to assess cancer cell extravasation by using a microfluidic device to harbour 
a bone-mimicking environment through co-culture of BM-MSC, osteoblast (differentiated from MSC) and EC (HUVEC) in a fibrin gel [350]. In this setting, EC formed branched structures and MSC colocalized and adhered to EC, suggesting a supportive role, like mural cells or pericytes in vivo. Afterwards, a bone-seeking clone of a breast metastatic cancer cell line was added. Tumour cell adhesion and extravasation towards the bone-like ECM was higher than towards the matrix without stromal cells. Interestingly, a control experiment was performed using a myoblast cell line instead of osteoblasts and the events described above were significantly decreased. Furthermore, the authors identified the A3 adenosine receptor as potentially responsible for the lower extravasation of cancer cells into the muscle-mimicking environment [350]. The same group, applying a similar experimental microfluidic approach, found that MDA-MB-231 extravasation was mediated by C-X-C Motif Chemokine Receptor 2 (CXCR2) in tumour cells and the chemokine CXCL5 secreted by the bone mimicking environment, as CXCR2 blocking decreased extravasation [262].

These multiple co-culture systems depict specific events according to the study goal. The inclusion of multiple cell types poses greater challenges as it increases modelling complexity, as addressed in the Section 5.

\section{Concluding Remarks and Future Perspectives}

In summary, the studies performed with 3D heterotypic models were important to determine the molecular mechanisms governing the TME and recapitulate in vitro those molecular interactions. Despite the intensive TME model development in recent years and their enormous potential, the field faces various drawbacks and challenges. Several variables underlying 3D modelling, namely, the methodology to obtain the 3D architecture (spheroid, scaffold, bioprinting), the culture platform (agitation or static systems, microfluidics), model setting (direct or indirect cell contact and cell distance), cell source (cell lines or primary cells; human or animal-derived), scaffold source (human, animal or synthetic) and properties (bioactivity, stiffness), among other specifications. All of these features can impact the study outcome, cause confounding factors and therefore need to be carefully addressed. This variability hinders a direct comparison of the outcomes. Even with similar approaches, difficulties in interpreting results can emerge from the use of different readouts and timepoints of analysis. In fact, the plethora of in vitro 3D models of the TME have in common the need for increased comparability and reproducibility.

\subsection{Choice of Scaffold}

Scaffold-based approaches are numerous and scaffold selection can interfere with the contributions of the different cellular types. The choice of biomaterial to mimic ECM has been an extensively investigated subject [35,351-353]. Different matrices can impact the outcome of the experimental study [354]. The same tumour cell lines in Matrigelembedded spheroids exhibited enhanced growth in comparison to spheroids embedded in collagen [42] or in chitosan-alginate [193]. Collagen gels are conventionally used as the tumour ECM is abundant on collagens and collagen I is typically associated with migration of tumour cells [355]. However, tumour-derived ECM are much more complex and ECM specificity has been reported, suggesting that matched tumour-derived matrices may improve the recapitulative power of 3D co-cultures. Along with collagen, Matrigel has also been broadly used in 3D models, but it has a murine origin and presents high batch-tobatch variability, which pose the evident problem of experimental reproducibility [356]. Therefore, other matrices with defined compositions have been proposed, such as other natural hydrogels such as alginate or artificial-based scaffolds [353,357]. Not only does biomaterial composition need to be taken into account, but its stiffness does as well, as this can impact cellular phenotype and tumours are described to present a higher stiffness than normal tissues [75,358-360]. Paszek et al. observed that mammary epithelial cells seeded in stiffer gels led to loss of organization and disrupted adherens junctions, while in softer gels they maintained mammary acini architecture [359]. In 2016, a study using a breast cancer cell line (MCF-7) and different percentages of alginate showed not only differences 
in cell morphology in the $2 \mathrm{D}$ vs. 3D approach, but also that the highest proliferation rate occurred in the softest hydrogel, resembling the initial stages of tumour formation [358].

Overall, biomaterial selection should consider adequate environmental cues for cellular processes and ECM interactions and has defined composition and is reproducible [45]. Artificial scaffolds, namely PEG-based hydrogels, allow for customized control of scaffold properties [74,75] but require a high level of knowledge of the interactions defining the TME, which is a challenge per se [77]. For organoids, engineered synthetic matrices functionalized with different motifs, such as collagen peptide GFOGER and laminin motif IKVAV, have been reported but did not show the same performance as Matrigel in terms of organoid formation efficiency [361].

The experimental setting based on physical contact between cells or distance, only allowing paracrine signalling, should be selected according to the study's purpose. In this light, microfluidic approaches are becoming widely employed and allow this type of control. Still, they can restrict downstream analysis due to the small cell number and amount of mRNA available in the microdevice chambers [164]. Improvements on cell retrieval and single cell analysis have been remarkable [362,363]; still, they are very expensive and technical demanding.

\subsection{Choice of Cell Source}

Concerning cell source, in several studies, murine tumour or TME cells are used. Moreover, the tumour type and the origin of the stromal components seldom do not match, which may introduce confounding factors to the model. Although the representativity of tumour cell lines has been debated, and a lot of cell line-dependent effects have been reported [364-366], they represent a virtually unlimited source in comparison to the scarce tumour patient material. Cell lines should be carefully selected, and a panel of cell lines should be employed for correct interpretation of the results and formulation of conclusions.

In addition to these considerations on cancer cell lines, there is also the open question on the use of normal fibroblasts instead of CAF, as phenotypic and functional differences have been reported, though this should be dependent on the study's purpose. Some studies aim to portray fibroblast activation by tumour cells; therefore, normal fibroblasts should be employed; when aiming to assess the reciprocal CAF effects on tumour cells, there is a need to carefully address the phenotype of the CAF-representing component, as the activation state may vary depending on source and culture conditions. The culture time is also an important parameter, as the amount of time required to induce CAF activation and/or observe CAF effects on tumour cells will vary, depending on the fibroblast origin (normal or CAF). In fact, the timeframe for inclusion of different cell types can also affect the outcome of the co-cultures. Sequential addition may favour previous build-up of favourable/detrimental microenvironments influencing certain cell types, as observed with sequential seeding of fibroblasts in tumour spheroids, resulting in more homogeneous distribution of fibroblasts and reduced formation of necrotic cores [108]. Sequential inclusion can also help define the spatial distribution [108,329], which can be enhanced using microfluidics and bioprinting techniques.

Patient-derived cells are being increasingly employed to develop precision medicine approaches [367]. Patient-derived tumour organoids are reported to be representative of tumour cell heterogeneity $[65,66]$ and have been proposed as a preclinical tool for drug development [368]. However, organoids are strictly epithelial, and the addition of TME components has been hampered by difficulties in fine-tuning the culture conditions to allow carcinoma cell expansion and survival of TME non-malignant cells [369]. Recently, a few studies reported important breakthroughs in the co-culture of organoids with immune cells and inclusion of vascularization $[69,370]$, which will be for sure further explored and refined in the near future. A few studies tried to tackle the limitations of propagation and viability of primary human cells by performing expansion in murine models, and then proceed to in vitro 3D cultures $[87,371]$; the evidence cumulated so far point to retention of 
patient heterogeneity along expansion; however, the limitation in terms of non-malignant cells from the patient tumour remain.

Ex vivo approaches, such as explants and tissue slices, represent the tumour heterogeneity, TME heterogeneity and architecture, and are amenable to drug challenges, including immunotherapeutics [372,373]. However, ex vivo approaches are limited by the amount of patient material and need technical improvements regarding culture viability and long-term preservation of TME elements ex vivo [374].

\subsection{Physicochemical Parameters}

Hypoxia is prevalent in the TME and can influence the phenotype and behaviour of different cell types and even drug diffusion, as described in [375-378]. Therefore, the systems should be well characterized in terms of oxygen availability, by measuring dissolved oxygen and evaluate oxygen diffusion within the 3D structures to precisely define cellular normoxia or hypoxia. Culture medium requirements can also vary between cell types, which is also a current limitation for complex co-cultures. An example is the effect of lactate, typically accumulated in immunosuppressive TME, on immune cells activity and motility. In particular, DC and T lymphocytes are negatively impacted by lactate, which also induces macrophage polarization towards pro-tumoral M2-like phenotypes $[183,255,379,380]$.

\subsection{Current Challenges and Applications}

In conclusion, there are still significant challenges in generating recapitulative TME in vitro models, though they represent multiple advantages, not only in terms of time and cost but also in allowing one to define and control microenvironmental parameters and isolate the effects of each component.

In order to simulate systemic interactions, multiple organ-on-a-chip devices based on microfluidics have been recently under intense development, with advances being made in bioprinting, as reviewed by Radhakrishnan et al. [381]. Despite their great potential, the recapitulation of each individual organ faces the bottlenecks mentioned for the 3D TME model; in particular, recapitulating immune system complexity is a major challenge [382].

Regarding drug challenge experiments, critical parameters are the duration of drug exposure, the drug concentrations and the readouts for assessment of drug effect, all profoundly influenced by the cell model characteristics [383,384]. Furthermore, the controls should be carefully interpreted, as several studies compare 3D co-cultures to the $2 \mathrm{D}$ setting and in distinct timepoints, but differences between 3D and 2D are largely acknowledged and the comparison with the real tumour/clinical setting is most often lacking. The challenges regarding the application of 3D cancer models to drug assays has been discussed in detail by Langhans et al., 2018, and Nii et al., 2020 [35,385].

We envisage that the 3D cancer modelling field, especially strategies based on coculture to depict the TME, will be critical to dissect the full network of molecular interactions underlying cancer progression. Despite the advances, there is a plethora of open scientific questions that could be effectively investigated employing 3D TME models.

CAF have been described to have a pro-tumorigenic role within the TME, but most of the studies were based on the analysis of the differential impact of normal fibroblast vs. CAF-like cells on the tumorigenicity of cancer cells. Still, the molecular mechanisms that drive normal fibroblast activation, from a healthy tissue context to a pro-tumorigenic CAF phenotype in tumorous tissues, are not well defined. This knowledge will open the possibility to counteract the CAF activation process within the TME. It is plausible to hypothesize that this is a long process, similarly to the majority of tumorigenic developmental processes. Two-dimensional approaches for co-culture of tumour cells and fibroblasts are normally short-term due to an intrinsic property of the 2D system - cell proliferation is limited by the available surface area, which may not be sufficient to induce the transition from normal fibroblasts to the CAF phenotype. Three-dimensional co-culture strategies enable substantially longer culture times compared to 2D ones and can therefore be helpful to shed light on this topic. Specifically, we envisage the use of long-term 3D co-cultures 
of normal fibroblasts present in the tissue of origin, matched with tumour-specific cell spheroids. Studies will take advantage of powerful analytical techniques such as mass cytometry and single-cell RNA sequencing analysis of the isolated fibroblasts to evaluate the potential molecular signals associated with CAF differentiation; the recently developed spatially resolved variations of both analytical techniques can reach a new level of knowledge on the influence of tissue architecture on intercellular communication.

Immunotherapy approaches have been proposed for "cold" tumours, such as highgrade gliomas [386] and other solid tumours, but immunosuppression represents one of the hurdles against the effectiveness of these therapeutic modalities, as, for example, antitumour CAR-T technology have been successfully applied against leukaemia's such as B cell acute lymphoblastic leukaemia, but CAR-T therapies are still not considered very effective against "cold" solid tumours [387]. This occurs mostly because of the immunosuppressive TME in solid tumours (e.g., secretion of immunosuppressive cytokines, presence of inhibitory immune-checkpoint ligands and immunosuppressive cells, namely Treg and M2 macrophages) and the lack of accessibility towards tumour cells due to the dense ECM and chaotic vascular network. There is robust evidence that TME reconstruction approaches based on 3D co-culture can depict the immunosuppressive milieu that is typical of those "cold" tumours; therefore, these strategies can play a critical role in studying and counteract the immunosuppressive signals.

The 3D co-culture approaches may enable us to study CAR-T chemotaxis toward the tumour and especially CAR-T infiltration. ECM deposition reduces T-cell tumour penetration into lung tumour slices [388] and reduced T cell cytotoxicity against tumour cells has been reported after T-cell culture in the high-density collagen matrix [389]. In this regard, 3D cell culture models enabling native ECM deposition within 3D multicellular structures [128] provide suitable platforms to analyse and challenge such phenomena in a reconstructed 3D TME, with pre-clinical and clinical translation potential. Under this perspective, we foresee the application of representative advanced 3D tumour cell models, which enable the co-culture of tumour cells, stromal, immune and EC to assess the synergistic therapeutical potential of novel immunotherapies and antiangiogenics [346].

\subsection{Towards Increased Comparability and Reproducibility of 3D TME Models}

Finally, quoting the famous sentence by the statistician George Box, "Essentially, all models are wrong, but some are useful", it is important to point out that an ideal, universal 3D TME model is not envisioned. Still, they are collectively very useful in basic and applied cancer research and are expected to continue to occupy an important position, as enabling tools in tumour cell biology, oncoimmunology and anticancer drug discovery. As it was made clear in this review, many methodologies exist to set up 3D cell models in parallel with a plethora of readouts to interrogate these models, employed in a multitude of applications. It is important to stress that this abundance claims for a collaborative longterm effort of the transdisciplinary research community focused on 3D model development, characterization and validation. The collaborative effort should also be focused on assay readout development and standardization, with the objective to develop a toolbox of less time-consuming, user-friendly analytical tools, with spatial resolution for widespread application to distinct 3D model set-ups [390]. Moreover, establishment of 3D cell model validated guidelines and common methodologies is also critical for the definite acceptance of 3D TME models as human in vitro alternatives to understand how to challenge tumours cells and the TME, aiming at providing better therapeutic solutions for cancer patients.

Author Contributions: Conceptualization, T.F.-M. and C.B.; figure preparation, T.F.-M., R.E. and C.B.; writing—original draft preparation, T.F.-M., G.D. and C.B.; writing—review and editing, T.F.-M., R.E., G.D. and C.B. All authors have read and agreed to the published version of the manuscript.

Funding: We acknowledge funding sources: Fundação para a Ciência e Tecnologia (FCT) for the individual PhD fellowship of T.F.-M. (SFRH/PD/BD/128377/2017); iNOVA4Health (UIDB/04462/2020), a program financially supported by FCT/Ministry of Education and Science, Portugal, through 
national funds and co-funded by FEDER under the PT2020 Partnership Agreement; "The Discoveries Centre for Regenerative and Precision Medicine" (European Commission Horizon 2020 Research and Innovation programme, under the Grant Agreement number 739572).

Conflicts of Interest: The authors declare no conflict of interest.

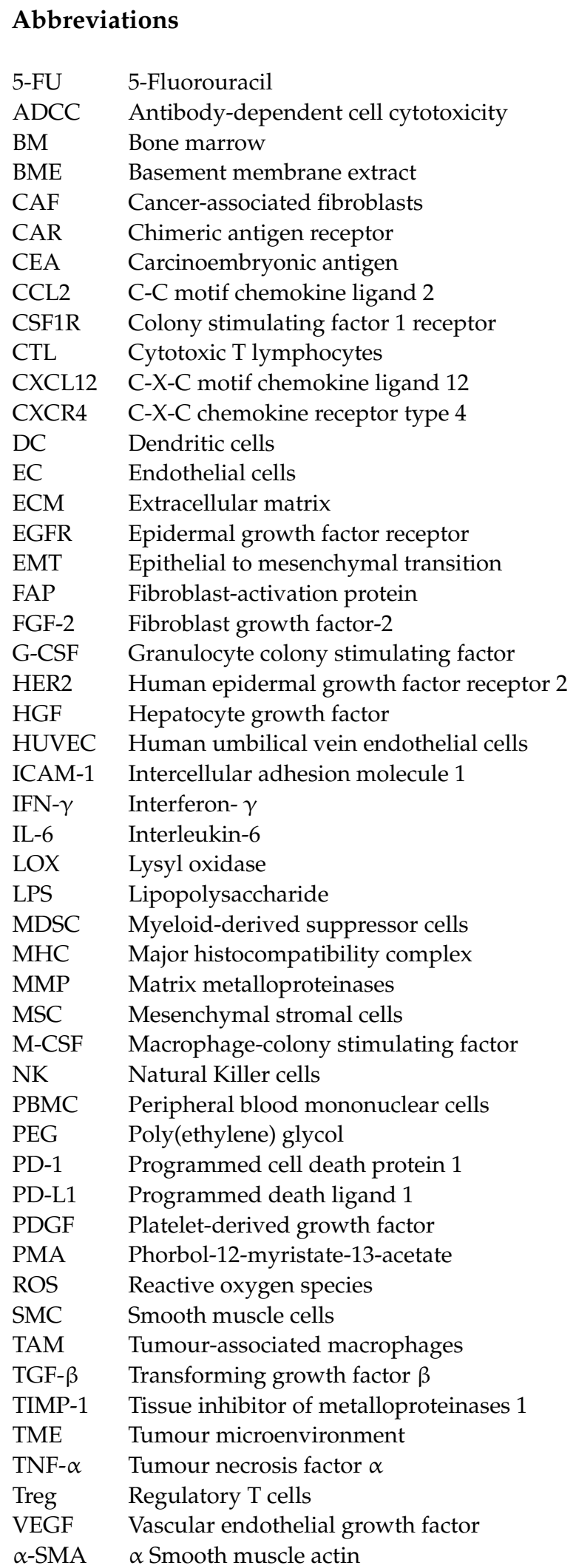




\section{References}

1. Liu, Z.; Delavan, B.; Roberts, R.; Tong, W. Lessons Learned from Two Decades of Anticancer Drugs. Trends Pharmacol. Sci. 2017, 38, 852-872. [CrossRef]

2. Moreno, L.; Pearson, A.D.J. How Can Attrition Rates Be Reduced in Cancer Drug Discovery? Expert Opin. Drug Discov. 2013, 8 , 363-368. [CrossRef] [PubMed]

3. Quail, D.F.; Joyce, J.A. Microenvironmental Regulation of Tumor Progression and Metastasis. Nat. Med. 2013, 19 , $1423-1437$. [CrossRef]

4. Bissell, M.J.; Radisky, D. Putting Tumours in Context. Nat. Rev. Cancer 2001, 1, 46-54. [CrossRef]

5. Bizzarri, M.; Cucina, A. Tumor and the Microenvironment: A Chance to Reframe the Paradigm of Carcinogenesis? BioMed Res. Int. 2014, 2014, 934038. [CrossRef]

6. Vermeulen, L.; De Sousa, E.; Melo, F.; van der Heijden, M.; Cameron, K.; de Jong, J.H.; Borovski, T.; Tuynman, J.B.; Todaro, M.; Merz, C.; et al. Wnt Activity Defines Colon Cancer Stem Cells and Is Regulated by the Microenvironment. Nat. Cell Biol. 2010, 12, 468-476. [CrossRef] [PubMed]

7. Critelli, R.; Milosa, F.; Faillaci, F.; Condello, R.; Turola, E.; Marzi, L.; Lei, B.; Dituri, F.; Andreani, S.; Sighinolfi, P.; et al. Microenvironment Inflammatory Infiltrate Drives Growth Speed and Outcome of Hepatocellular Carcinoma: A Prospective Clinical Study. Cell Death Dis. 2017, 8, e3017. [CrossRef] [PubMed]

8. Klemm, F.; Joyce, J.A. Microenvironmental Regulation of Therapeutic Response in Cancer. Trends Cell Biol. 2015, 25, 198-213. [CrossRef]

9. Junttila, M.R.; de Sauvage, F.J. Influence of Tumour Micro-Environment Heterogeneity on Therapeutic Response. Nature 2013, 501, 346-354. [CrossRef] [PubMed]

10. Mink, S.R.; Vashistha, S.; Zhang, W.; Hodge, A.; Agus, D.B.; Jain, A. Cancer-Associated Fibroblasts Derived from EGFR-TKIResistant Tumors Reverse EGFR Pathway Inhibition by EGFR-TKIs. Mol. Cancer Res. 2010, 8, 809-820. [CrossRef]

11. Amornsupak, K.; Insawang, T.; Thuwajit, P.; O-Charoenrat, P.; Eccles, S.A.; Thuwajit, C. Cancer-Associated Fibroblasts Induce High Mobility Group Box 1 and Contribute to Resistance to Doxorubicin in Breast Cancer Cells. BMC Cancer 2014, 14, 955. [CrossRef] [PubMed]

12. Nakasone, E.S.; Askautrud, H.A.; Kees, T.; Park, J.H.; Plaks, V.; Ewald, A.J.; Fein, M.; Rasch, M.G.; Tan, Y.X.; Qiu, J.; et al. Imaging Tumor-Stroma Interactions during Chemotherapy Reveals Contributions of the Microenvironment to Resistance. Cancer Cell 2012, 21, 488-503. [CrossRef] [PubMed]

13. Jain, R.K.; Duda, D.G.; Clark, J.W.; Loeffler, J.S. Lessons from Phase III Clinical Trials on Anti-VEGF Therapy for Cancer. Nat. Clin. Pract. Oncol. 2006, 3, 24-40. [CrossRef]

14. Pardoll, D.M. The Blockade of Immune Checkpoints in Cancer Immunotherapy. Nat. Rev. Cancer 2012, 12, 252-264. [CrossRef]

15. Hill, B.S.; Sarnella, A.; D'Avino, G.; Zannetti, A. Recruitment of Stromal Cells into Tumour Microenvironment Promote the Metastatic Spread of Breast Cancer. Semin. Cancer Biol. 2020, 60, 202-213. [CrossRef]

16. De Palma, M.; Biziato, D.; Petrova, T.V. Microenvironmental Regulation of Tumour Angiogenesis. Nat. Rev. Cancer 2017, 17, 457-474. [CrossRef]

17. Winkler, J.; Abisoye-Ogunniyan, A.; Metcalf, K.J.; Werb, Z. Concepts of Extracellular Matrix Remodelling in Tumour Progression and Metastasis. Nat. Commun. 2020, 11, 5120. [CrossRef]

18. Walker, C.; Mojares, E.; Hernández, A.D.R. Role of Extracellular Matrix in Development and Cancer Progression. Int. J. Mol. Sci. 2018, 19, 3028. [CrossRef]

19. Liu, T.; Zhou, L.; Li, D.; Andl, T.; Zhang, Y. Cancer-Associated Fibroblasts Build and Secure the Tumor Microenvironment. Front. Cell Dev. Biol. 2019, 7, 60. [CrossRef] [PubMed]

20. Friedl, P.; Alexander, S. Cancer Invasion and the Microenvironment: Plasticity and Reciprocity. Cell 2011, 147, 992-1009. [CrossRef] [PubMed]

21. Kai, F.B.; Drain, A.P.; Weaver, V.M. The Extracellular Matrix Modulates the Metastatic Journey. Dev. Cell 2019, 49, 332-346. [CrossRef] [PubMed]

22. Provenzano, P.P.; Inman, D.R.; Eliceiri, K.W.; Knittel, J.G.; Yan, L.; Rueden, C.T.; White, J.G.; Keely, P.J. Collagen Density Promotes Mammary Tumor Initiation and Progression. BMC Med. 2008, 6, 11. [CrossRef] [PubMed]

23. Neve, A.; Cantatore, F.P.; Maruotti, N.; Corrado, A.; Ribatti, D. Extracellular Matrix Modulates Angiogenesis in Physiological and Pathological Conditions. BioMed Res. Int. 2014, 2014, 756078. [CrossRef]

24. Yamauchi, M.; Gibbons, D.L.; Zong, C.; Fradette, J.J.; Bota-Rabassedas, N.; Kurie, J.M. Fibroblast Heterogeneity and Its Impact on Extracellular Matrix and Immune Landscape Remodeling in Cancer. Matrix Biol. 2020, 91-92, 8-18. [CrossRef]

25. Provenzano, P.P.; Eliceiri, K.W.; Campbell, J.M.; Inman, D.R.; White, J.G.; Keely, P.J. Collagen Reorganization at the Tumor-Stromal Interface Facilitates Local Invasion. BMC Med. 2006, 4, 38. [CrossRef] [PubMed]

26. Lu, P.; Weaver, V.M.; Werb, Z. The Extracellular Matrix: A Dynamic Niche in Cancer Progression. J. Cell Biol. 2012, 196, 395-406. [CrossRef] [PubMed]

27. Kessenbrock, K.; Plaks, V.; Werb, Z. Matrix Metalloproteinases: Regulators of the Tumor Microenvironment. Cell 2010, $141,52-67$. [CrossRef] [PubMed] 
28. Perentes, J.Y.; Kirkpatrick, N.D.; Nagano, S.; Smith, E.Y.; Shaver, C.M.; Sgroi, D.; Garkavtsev, I.; Munn, L.L.; Jain, R.K.; Boucher, Y. Cancer Cell-Associated MT1-MMP Promotes Blood Vessel Invasion and Distant Metastasis in Triple-Negative Mammary Tumors. Cancer Res. 2011, 71, 4527-4538. [CrossRef]

29. Mehner, C.; Hockla, A.; Miller, E.; Ran, S.; Radisky, D.C.; Radisky, E.S. Tumor Cell-Produced Matrix Metalloproteinase 9 (MMP-9) Drives Malignant Progression and Metastasis of Basal-like Triple Negative Breast Cancer. Oncotarget 2014, 5, $2736-2749$. [CrossRef]

30. Baker, A.M.; Bird, D.; Lang, G.; Cox, T.R.; Erler, J.T. Lysyl Oxidase Enzymatic Function Increases Stiffness to Drive Colorectal Cancer Progression through FAK. Oncogene 2013, 32, 1863-1868. [CrossRef]

31. Levental, K.; Yu, H.; Kass, L.; Lakins, J.N.; Egeblad, M.; Erler, J.; Fong, S.F.; Csiszar, K.; Giaccia, A.; Weninger, W.; et al. Matrix Crosslinking Forces Tumor Progression by Enhancing Integrin Signaling. Cell 2009, 139, 891-906. [CrossRef]

32. Blanco-Fernandez, B.; Gaspar, V.M.; Engel, E.; Mano, J.F. Proteinaceous Hydrogels for Bioengineering Advanced 3D Tumor Models. Adv. Sci. 2021, 8, 2003129. [CrossRef]

33. Lee, H.J.; Mun, S.; Pham, D.M.; Kim, P. Extracellular Matrix-Based Hydrogels to Tailoring Tumor Organoids. ACS Biomater. Sci. Eng. 2021, 7, 4128-4135. [CrossRef]

34. Micek, H.M.; Visetsouk, M.R.; Masters, K.S.; Kreeger, P.K. Engineering the Extracellular Matrix to Model the Evolving Tumor Microenvironment. iScience 2020, 23, 101742. [CrossRef]

35. Nii, T.; Makino, K.; Tabata, Y. Three-Dimensional Culture System of Cancer Cells Combined with Biomaterials for Drug Screening. Cancers 2020, 12, 2754. [CrossRef]

36. Wilding, J.L.; Bodmer, W. Cancer Cell Lines for Drug Discovery and Development. Cancer Res. 2014, 74, 2377-2384. [CrossRef] [PubMed]

37. Bhimani, J.; Ball, K.; Stebbing, J. Patient-derived xenograft models-The future of personalised cancer treatment. Br. J. Cancer 2020, 122, 601-602. [CrossRef] [PubMed]

38. Laplagne, C.; Domagala, M.; Le Naour, A.; Quemerais, C.; Hamel, D.; Fournié, J.-J.; Couderc, B.; Bousquet, C.; Ferrand, A.; Poupot, M. Latest Advances in Targeting the Tumor Microenvironment for Tumor Suppression. Int. J. Mol. Sci. 2019, $20,4719$. [CrossRef] [PubMed]

39. Miki, Y.; Ono, K.; Hata, S.; Suzuki, T.; Kumamoto, H.; Sasano, H. The advantages of co-culture over mono cell culture in simulating in vivo environment. J. Steroid Biochem. Mol. Biol. 2012, 131, 68-75. [CrossRef]

40. Fong, E.L.; Harrington, D.A.; Farach-Carson, M.C.; Yu, H. Heralding a new paradigm in 3D tumor modeling. Biomaterials 2016, 108, 197-213. [CrossRef]

41. Choi, S.Y.C.; Lin, D.; Gout, P.W.; Collins, C.C.; Xu, Y.; Wang, Y. Lessons from patient-derived xenografts for better in vitro modeling of human cancer. Adv. Drug Deliv. Rev. 2014, 79-80, 222-237. [CrossRef]

42. Stock, K.; Estrada, M.; Vidic, S.; Gjerde, K.; Rudisch, A.; Santo, V.E.; Barbier, M.; Blom, S.; Arundkar, S.C.; Selvam, I.; et al. Capturing tumor complexity in vitro: Comparative analysis of 2D and 3D tumor models for drug discovery. Sci. Rep. 2016, 6, 28951. [CrossRef]

43. Kapałczyńska, M.; Kolenda, T.; Przybyła, W.; Zajączkowska, M.; Teresiak, A.; Filas, V.; Ibbs, M.; Bliźniak, R.; Łuczewski, L.; Lamperska, K. 2D and 3D cell cultures-A comparison of different types of cancer cell cultures. Arch. Med. Sci. 2016, 12, 910-919. [CrossRef]

44. Breslin, S.; O'Driscoll, L. Three-dimensional cell culture: The missing link in drug discovery. Drug Discov. Today 2013, 18, 240-249. [CrossRef] [PubMed]

45. Rodrigues, J.; Heinrich, M.A.; Teixeira, L.M.; Prakash, J. 3D In Vitro Model (R)evolution: Unveiling Tumor-Stroma Interactions. Trends Cancer 2021, 7, 249-264. [CrossRef]

46. Lee, J.M.; Mhawech-Fauceglia, P.; Lee, N.; Parsanian, L.C.; Lin, Y.G.; Gayther, S.A.; Lawrenson, K. A three-dimensional microenvironment alters protein expression and chemosensitivity of epithelial ovarian cancer cells in vitro. Lab. Investig. 2013, 93, 528-542. [CrossRef]

47. Luca, A.C.; Mersch, S.; Deenen, R.; Schmidt, S.; Messner, I.; Schäfer, K.-L.; Baldus, S.E.; Huckenbeck, W.; Piekorz, R.P.; Knoefel, W.T.; et al. Impact of the 3D Microenvironment on Phenotype, Gene Expression, and EGFR Inhibition of Colorectal Cancer Cell Lines. PLoS ONE 2013, 8, e59689. [CrossRef]

48. Imamura, Y.; Mukohara, T.; Shimono, Y.; Funakoshi, Y.; Chayahara, N.; Toyoda, M.; Kiyota, N.; Takao, S.; Kono, S.; Nakatsura, T.; et al. Comparison of 2D- and 3D-culture models as drug-testing platforms in breast cancer. Oncol. Rep. 2015, 33, 1837-1843. [CrossRef]

49. Riedl, A.; Schlederer, M.; Pudelko, K.; Stadler, M.; Walter, S.; Unterleuthner, D.; Unger, C.; Kramer, N.; Hengstschläger, M.; Kenner, L.; et al. Comparison of cancer cells in 2D vs 3D culture reveals differences in AKT-mTOR-S6K signaling and drug responses. J. Cell Sci. 2017, 130, 203-218. [CrossRef]

50. Costa, E.C.; Moreira, A.F.; Diogo, D.M.D.M.; Gaspar, V.; Carvalho, M.P.; Correia, I.J. 3D tumor spheroids: An overview on the tools and techniques used for their analysis. Biotechnol. Adv. 2016, 34, 1427-1441. [CrossRef]

51. Weiswald, L.-B.; Bellet, D.; Dangles-Marie, V. Spherical Cancer Models in Tumor Biology. Neoplasia 2015, 17, 1-15. [CrossRef]

52. Fitzgerald, A.A.; Li, E.; Weiner, L.M. 3D Culture Systems for Exploring Cancer Immunology. Cancers 2020, 13, 56. [CrossRef]

53. Reidy, E.; Leonard, N.A.; Treacy, O.; Ryan, A.E. A 3D View of Colorectal Cancer Models in Predicting Therapeutic Responses and Resistance. Cancers 2021, 13, 227. [CrossRef] [PubMed] 
54. Hickman, J.A.; Graeser, R.; De Hoogt, R.; Vidic, S.; Brito, C.; Gutekunst, M.; Van Der Kuip, H. IMI PREDECT consortium Three-dimensional models of cancer for pharmacology and cancer cell biology: Capturing tumor complexity in vitro/ex vivo. Biotechnol. J. 2014, 9, 1115-1128. [CrossRef]

55. Lazzari, G.; Nicolas, V.; Matsusaki, M.; Akashi, M.; Couvreur, P.; Mura, S. Multicellular spheroid based on a triple co-culture: A novel 3D model to mimic pancreatic tumor complexity. Acta Biomater. 2018, 78, 296-307. [CrossRef] [PubMed]

56. Santo, V.E.; Estrada, M.; Rebelo, S.P.; Abreu, S.; Silva, I.; Pinto, C.; Veloso, S.C.; Serra, A.T.; Boghaert, E.; Alves, P.; et al. Adaptable stirred-tank culture strategies for large scale production of multicellular spheroid-based tumor cell models. J. Biotechnol. 2016, 221, 118-129. [CrossRef]

57. Fey, S.J.; Wrzesinski, K. Determination of Drug Toxicity Using 3D Spheroids Constructed From an Immortal Human Hepatocyte Cell Line. Toxicol. Sci. 2012, 127, 403-411. [CrossRef]

58. Däster, S.; Amatruda, N.; Calabrese, D.; Ivanek, R.; Turrini, E.; Droeser, R.A.; Zajac, P.; Fimognari, C.; Spagnoli, G.C.; Iezzi, G.; et al. Induction of hypoxia and necrosis in multicellular tumor spheroids is associated with resistance to chemotherapy treatment. Oncotarget 2017, 8, 1725-1736. [CrossRef]

59. Fang, Y.; Eglen, R.M. Three-Dimensional Cell Cultures in Drug Discovery and Development. SLAS Discov. 2017, 22, 456-472. [CrossRef] [PubMed]

60. Santo, V.E.; Rebelo, S.P.; Estrada, M.; Alves, P.; Boghaert, E.; Brito, C. Drug screening in 3D in vitro tumor models: Overcoming current pitfalls of efficacy read-outs. Biotechnol. J. 2017, 12, 1600505. [CrossRef]

61. Schutgens, F.; Clevers, H. Human Organoids: Tools for Understanding Biology and Treating Diseases. Annu. Rev. Pathol. Mech. Dis. 2020, 15, 211-234. [CrossRef] [PubMed]

62. Weeber, F.; van de Wetering, M.; Hoogstraat, M.; Dijkstra, K.K.; Krijgsman, O.; Kuilman, T.; Gadellaa-van Hooijdonk, C.G.; van der Velden, D.L.; Peeper, D.S.; Cuppen, E.P.; et al. Preserved genetic diversity in organoids cultured from biopsies of human colorectal cancer metastases. Proc. Natl. Acad. Sci. USA 2015, 112, 13308-13311. [CrossRef]

63. Rosenbluth, J.M.; Schackmann, R.C.J.; Gray, G.K.; Selfors, L.M.; Li, C.M.-C.; Boedicker, M.; Kuiken, H.J.; Richardson, A.; Brock, J.; Garber, J.; et al. Organoid cultures from normal and cancer-prone human breast tissues preserve complex epithelial lineages. Nat. Commun. 2020, 11, 1711. [CrossRef]

64. Baker, L.; Tiriac, H.; Clevers, H.; Tuveson, D.A. Modeling Pancreatic Cancer with Organoids. Trends Cancer 2016, 2, 176-190. [CrossRef] [PubMed]

65. Van De Wetering, M.; Francies, H.E.; Francis, J.M.; Bounova, G.; Iorio, F.; Pronk, A.; Van Houdt, W.; Van Gorp, J.; Taylor-Weiner, A.; Kester, L.; et al. Prospective derivation of a living organoid biobank of colorectal cancer patients. Cell 2015, 161, 933-945. [CrossRef]

66. Sachs, N.; De Ligt, J.; Kopper, O.; Gogola, E.; Bounova, G.; Weeber, F.; Balgobind, A.V.; Wind, K.; Gracanin, A.; Begthel, H.; et al. A Living Biobank of Breast Cancer Organoids Captures Disease Heterogeneity. Cell 2018, 172, 373-386.e10. [CrossRef]

67. Vlachogiannis, G.; Hedayat, S.; Vatsiou, A.; Jamin, Y.; Fernández-Mateos, J.; Khan, K.; Lampis, A.; Eason, K.; Huntingford, I.; Burke, R.; et al. Patient-derived organoids model treatment response of metastatic gastrointestinal cancers. Science 2018, 359, 920-926. [CrossRef]

68. Tsai, S.; McOlash, L.; Palen, K.; Johnson, B.; Duris, C.; Yang, Q.; Dwinell, M.B.; Hunt, B.; Evans, D.B.; Gershan, J.; et al. Development of primary human pancreatic cancer organoids, matched stromal and immune cells and 3D tumor microenvironment models. BMC Cancer 2018, 18, 335. [CrossRef] [PubMed]

69. Bar-Ephraim, Y.E.; Kretzschmar, K.; Clevers, H. Organoids in immunological research. Nat. Rev. Immunol. 2020, 20, $279-293$. [CrossRef]

70. Hughes, C.S.; Postovit, L.M.; Lajoie, G.A. Matrigel: A complex protein mixture required for optimal growth of cell culture. Proteomics 2010, 10, 1886-1890. [CrossRef]

71. Benton, G.; Arnaoutova, I.; George, J.; Kleinman, H.K.; Koblinski, J. Matrigel: From discovery and ECM mimicry to assays and models for cancer research. Adv. Drug Deliv. Rev. 2014, 79-80, 3-18. [CrossRef]

72. Asghar, W.; El Assal, R.; Shafiee, H.; Pitteri, S.; Paulmurugan, R.; Demirci, U. Engineering cancer microenvironments for in vitro 3-D tumor models. Mater. Today 2015, 18, 539-553. [CrossRef]

73. de Sampaio, P.C.; Auslaender, D.; Krubasik, D.; Failla, A.V.; Skepper, J.N.; Murphy, G.; English, W.R. A Heterogeneous In Vitro Three Dimensional Model of Tumour-Stroma Interactions Regulating Sprouting Angiogenesis. PLoS ONE 2012, 7, e30753. [CrossRef]

74. Mollica, P.A.; Booth-Creech, E.N.; Reid, J.A.; Zamponi, M.; Sullivan, S.M.; Palmer, X.-L.; Sachs, P.C.; Bruno, R.D. 3D bioprinted mammary organoids and tumoroids in human mammary derived ECM hydrogels. Acta Biomater. 2019, 95, 201-213. [CrossRef] [PubMed]

75. Gjorevski, N.; Sachs, N.; Manfrin, A.; Giger, S.; Bragina, M.E.; Ordóñez-Morán, P.; Clevers, N.S.H.; Lutolf, N.G.A.M.S.G.M.E.B.M.P. Designer matrices for intestinal stem cell and organoid culture. Nat. Cell Biol. 2016, 539, 560-564. [CrossRef]

76. Aisenbrey, E.A.; Murphy, W.L. Synthetic alternatives to Matrigel. Nat. Rev. Mater. 2020, 5, 539-551. [CrossRef] [PubMed]

77. Chwalek, K.; Tsurkan, M.; Freudenberg, U.; Werner, C. Glycosaminoglycan-based hydrogels to modulate heterocellular communication in in vitro angiogenesis models. Sci. Rep. 2015, 4, 4414. [CrossRef]

78. Ma, Y.-H.V.; Middleton, K.; You, L.; Sun, Y. A review of microfluidic approaches for investigating cancer extravasation during metastasis. Microsyst. Nanoeng. 2018, 4, 17104. [CrossRef] 
79. Sontheimer-Phelps, A.; Hassell, B.A.; Ingber, D.E. Modelling cancer in microfluidic human organs-on-chips. Nat. Rev. Cancer 2019, 19, 65-81. [CrossRef]

80. Shemesh, J.; Jalilian, I.; Shi, A.; Yeoh, G.H.; Tate, M.L.K.; Warkiani, M.E. Flow-induced stress on adherent cells in microfluidic devices. Lab Chip 2015, 15, 4114-4127. [CrossRef]

81. Vanderburgh, J.; Sterling, J.A.; Guelcher, S.A. 3D Printing of Tissue Engineered Constructs for In Vitro Modeling of Disease Progression and Drug Screening. Ann. Biomed. Eng. 2017, 45, 164-179. [CrossRef] [PubMed]

82. Langer, E.M.; Allen-Petersen, B.; King, S.M.; Kendsersky, N.D.; Turnidge, M.A.; Kuziel, G.M.; Riggers, R.; Samatham, R.; Amery, T.S.; Jacques, S.L.; et al. Modeling Tumor Phenotypes In Vitro with Three-Dimensional Bioprinting. Cell Rep. 2019, 26, 608-623.e6. [CrossRef]

83. Sahai, E.; Astsaturov, I.; Cukierman, E.; DeNardo, D.G.; Egeblad, M.; Evans, R.M.; Fearon, D.; Greten, F.R.; Hingorani, S.R.; Hunter, T.; et al. A framework for advancing our understanding of cancer-associated fibroblasts. Nat. Rev. Cancer 2020, 20, 174-186. [CrossRef]

84. Gascard, P.; Tlsty, T.D. Carcinoma-associated fibroblasts: Orchestrating the composition of malignancy. Genes Dev. 2016, 30, 1002-1019. [CrossRef]

85. Jeong, S.-Y.; Lee, J.-H.; Shin, Y.; Chung, S.; Kuh, H.-J. Co-Culture of Tumor Spheroids and Fibroblasts in a Collagen MatrixIncorporated Microfluidic Chip Mimics Reciprocal Activation in Solid Tumor Microenvironment. PLoS ONE 2016, 11, e0159013. [CrossRef]

86. Öhlund, D.; Handly-Santana, A.; Biffi, G.; Elyada, E.; Almeida, A.S.; Ponz-Sarvise, M.; Corbo, V.; Oni, T.E.; Hearn, S.A.; Lee, E.J.; et al. Distinct populations of inflammatory fibroblasts and myofibroblasts in pancreatic cancer. J. Exp. Med. 2017, 214, 579-596. [CrossRef]

87. Onion, D.; Argent, R.H.; Reece-Smith, A.M.; Craze, M.L.; Pineda, R.G.; Clarke, P.; Ratan, H.L.; Parsons, S.L.; Lobo, D.; Duffy, J.P.; et al. 3-Dimensional Patient-Derived Lung Cancer Assays Reveal Resistance to Standards-of-Care Promoted by Stromal Cells but Sensitivity to Histone Deacetylase Inhibitors. Mol. Cancer Ther. 2016, 15, 753-763. [CrossRef]

88. Attieh, Y.; Vignjevic, D.M. The hallmarks of CAFs in cancer invasion. Eur. J. Cell Biol. 2016, 95, 493-502. [CrossRef]

89. Li, M.; Li, M.; Yin, T.; Shi, H.; Wen, Y.; Zhang, B.; Chen, M.; Xu, G.; Ren, K.; Wei, Y. Targeting of cancer-associated fibroblasts enhances the efficacy of cancer chemotherapy by regulating the tumor microenvironment. Mol. Med. Rep. 2016, 13, 2476-2484. [CrossRef]

90. Wang, L.-C.S.; Lo, A.; Scholler, J.; Sun, J.; Majumdar, R.S.; Kapoor, V.; Antzis, M.; Cotner, C.; Johnson, L.A.; Durham, A.C.; et al. Targeting Fibroblast Activation Protein in Tumor Stroma with Chimeric Antigen Receptor T Cells Can Inhibit Tumor Growth and Augment Host Immunity without Severe Toxicity. Cancer Immunol. Res. 2014, 2, 154-166. [CrossRef]

91. Lo, A.; Wang, L.-C.S.; Scholler, J.; Monslow, J.; Avery, D.; Newick, K.; O’Brien, S.; Evans, R.A.; Bajor, D.J.; Clendenin, C.; et al. Tumor-Promoting Desmoplasia Is Disrupted by Depleting FAP-Expressing Stromal Cells. Cancer Res. 2015, 75, 2800-2810. [CrossRef] [PubMed]

92. Fabre, M.; Ferrer, C.; Domínguez-Hormaetxe, S.; Bockorny, B.; Murias, L.; Seifert, O.; Eisler, S.A.; Kontermann, R.E.; Pfizenmaier, K.; Lee, S.Y.; et al. OMTX705, a Novel FAP-Targeting ADC Demonstrates Activity in Chemotherapy and Pembrolizumab-Resistant Solid Tumor Models. Clin. Cancer Res. 2020, 26, 3420-3430. [CrossRef] [PubMed]

93. Su, S.; Chen, J.; Yao, H.; Liu, J.; Yu, S.; Lao, L.; Wang, M.; Luo, M.; Xing, Y.; Chen, F.; et al. CD10(+)GPR77(+) Cancer-Associated Fibroblasts Promote Cancer Formation and Chemoresistance by Sustaining Cancer Stemness. Cell 2018, 172, 841-856.e16. [CrossRef] [PubMed]

94. Kim, S.-A.; Lee, E.K.; Kuh, H.-J. Co-culture of 3D tumor spheroids with fibroblasts as a model for epithelial-mesenchymal transition in vitro. Exp. Cell Res. 2015, 335, 187-196. [CrossRef]

95. Dolznig, H.; Rupp, C.; Puri, C.; Haslinger, C.; Schweifer, N.; Wieser, E.; Kerjaschki, D.; Garin-Chesa, P. Modeling colon adenocarcinomas in vitro a 3D co-culture system induces cancer-relevant pathways upon tumor cell and stromal fibroblast interaction. Am. J. Pathol. 2011, 179, 487-501. [CrossRef]

96. Attieh, Y.; Clark, A.G.; Grass, C.; Richon, S.; Pocard, M.; Mariani, P.; Elkhatib, N.; Betz, T.; Gurchenkov, B.; Vignjevic, D.M. Cancer-associated fibroblasts lead tumor invasion through integrin- $\beta 3$-dependent fibronectin assembly. J. Cell Biol. 2017, 216, 3509-3520. [CrossRef]

97. Horie, M.; Saito, A.; Mikami, Y.; Ohshima, M.; Morishita, Y.; Nakajima, J.; Kohyama, T.; Nagase, T. Characterization of human lung cancer-associated fibroblasts in three-dimensional in vitro co-culture model. Biochem. Biophys. Res. Commun. 2012, 423, 158-163. [CrossRef]

98. Jacobi, N.; Seeboeck, R.; Hofmann, E.; Schweiger, H.; Smolinska, V.; Mohr, T.; Boyer, A.; Sommergruber, W.; Lechner, P.; PichlerHuebschmann, C.; et al. Organotypic three-dimensional cancer cell cultures mirror drug responses in vivo: Lessons learned from the inhibition of EGFR signaling. Oncotarget 2017, 8, 107423-107440. [CrossRef]

99. Wang, W.; Li, Q.; Yamada, T.; Matsumoto, K.; Matsumoto, I.; Oda, M.; Watanabe, G.; Kayano, Y.; Nishioka, Y.; Sone, S.; et al. Crosstalk to Stromal Fibroblasts Induces Resistance of Lung Cancer to Epidermal Growth Factor Receptor Tyrosine Kinase Inhibitors. Clin. Cancer Res. 2009, 15, 6630-6638. [CrossRef]

100. Nii, T.; Makino, K.; Tabata, Y. A Cancer Invasion Model Combined with Cancer-Associated Fibroblasts Aggregates Incorporating Gelatin Hydrogel Microspheres Containing a p53 Inhibitor. Tissue Eng. Part C Methods 2019, 25, 711-720. [CrossRef] 
101. Estrada, M.; Rebelo, S.P.; Davies, E.J.; Pinto, M.; Pereira, H.A.; Santo, V.E.; Smalley, M.; Barry, S.T.; Gualda, E.J.; Alves, P.; et al. Modelling the tumour microenvironment in long-term microencapsulated 3D co-cultures recapitulates phenotypic features of disease progression. Biomaterials 2016, 78, 50-61. [CrossRef]

102. Dondajewska, E.; Juzwa, W.; Mackiewicz, A.; Dams-Kozlowska, H. Heterotypic breast cancer model based on a silk fibroin scaffold to study the tumor microenvironment. Oncotarget 2017, 9, 4935-4950. [CrossRef]

103. Kunz-Schughart, L.; Heyder, P.; Schroeder, J.; Knuechel, R. A Heterologous 3-D Coculture Model of Breast Tumor Cells and Fibroblasts to Study Tumor-Associated Fibroblast Differentiation. Exp. Cell Res. 2001, 266, 74-86. [CrossRef]

104. Seidl, P.; Huettinger, R.; Knuechel, R.; Kunz-Schughart, L. Three-dimensional fibroblast-tumor cell interaction causes downregulation ofRACK1 mRNA expression in breast cancer cellsin vitro. Int. J. Cancer 2002, 102, 129-136. [CrossRef]

105. Kaur, P.; Ward, B.; Saha, B.; Young, L.; Groshen, S.; Techy, G.; Lu, Y.; Atkinson, R.; Taylor, C.R.; Ingram, M.; et al. Human Breast Cancer Histoid. J. Histochem. Cytochem. 2011, 59, 1087-1100. [CrossRef]

106. Angelucci, C.; Maulucci, G.; Lama, G.; Proietti, G.; Colabianchi, A.; Papi, M.; Maiorana, A.; De Spirito, M.; Micera, A.; Balzamino, O.B.; et al. Epithelial-Stromal Interactions in Human Breast Cancer: Effects on Adhesion, Plasma Membrane Fluidity and Migration Speed and Directness. PLoS ONE 2012, 7, e50804. [CrossRef] [PubMed]

107. Anastasov, N.; Höfig, I.; Radulovic, V.; Ströbel, S.; Salomon, M.; Lichtenberg, J.; Rothenaigner, I.; Hadian, K.; Kelm, J.M.; Thirion, C.; et al. A 3D-microtissue-based phenotypic screening of radiation resistant tumor cells with synchronized chemotherapeutic treatment. BMC Cancer 2015, 15, 466. [CrossRef] [PubMed]

108. Yakavets, I.; Francois, A.; Benoit, A.; Merlin, J.-L.; Bezdetnaya, L.; Vogin, G. Advanced co-culture 3D breast cancer model for investigation of fibrosis induced by external stimuli: Optimization study. Sci. Rep. 2020, 10, 21273. [CrossRef] [PubMed]

109. Xin, X.; Yang, S.-T. A Dual Fluorescent 3-D Multicellular Coculture of Breast Cancer MCF-7 and Fibroblast NIH-3T3 Cells for High Throughput Cancer Drug Screening. Biochem. Eng. J. 2019, 148, 152-161. [CrossRef]

110. Saini, H.; Eliato, K.R.; Veldhuizen, J.; Zare, A.; Allam, M.; Silva, C.; Kratz, A.; Truong, D.; Mouneimne, G.; LaBaer, J.; et al. The role of tumor-stroma interactions on desmoplasia and tumorigenicity within a microengineered 3D platform. Biomaterials 2020, 247, 119975. [CrossRef] [PubMed]

111. Hanley, C.J.; Henriet, E.; Sirka, O.K.; Thomas, G.J.; Ewald, A.J. Tumor-Resident Stromal Cells Promote Breast Cancer Invasion through Regulation of the Basal Phenotype. Mol. Cancer Res. 2020, 18, 1615-1622. [CrossRef]

112. Liu, C.; Lewin Mejia, D.; Chiang, B.; Luker, K.E.; Luker, G.D. Hybrid collagen alginate hydrogel as a platform for 3D tumor spheroid invasion. Acta Biomater. 2018, 75, 213-225. [CrossRef]

113. Froeling, F.E.; Mirza, T.A.; Feakins, R.M.; Seedhar, A.; Elia, G.; Hart, I.R.; Kocher, H. Organotypic Culture Model of Pancreatic Cancer Demonstrates that Stromal Cells Modulate E-Cadherin, $\beta$-Catenin, and Ezrin Expression in Tumor Cells. Am. J. Pathol. 2009, 175, 636-648. [CrossRef]

114. Noel, P.; Muñoz, R.; Rogers, G.W.; Neilson, A.; Von Hoff, D.D.; Han, H. Preparation and Metabolic Assay of 3-dimensional Spheroid Co-cultures of Pancreatic Cancer Cells and Fibroblasts. J. Vis. Exp. 2017, e56081. [CrossRef] [PubMed]

115. Brancato, V.; Comunanza, V.; Imparato, G.; Corà, D.; Urciuolo, F.; Noghero, A.; Bussolino, F.; Netti, P.A. Bioengineered tumoral microtissues recapitulate desmoplastic reaction of pancreatic cancer. Acta Biomater. 2017, 49, 152-166. [CrossRef] [PubMed]

116. Ware, M.; Keshishian, V.; Law, J.J.; Ho, J.C.; Favela, C.A.; Rees, P.; Smith, B.; Mohammad, S.; Hwang, R.F.; Rajapakshe, K.; et al. Generation of an in vitro 3D PDAC stroma rich spheroid model. Biomaterials 2016, 108, 129-142. [CrossRef] [PubMed]

117. Majety, M.; Pradel, L.P.; Gies, M.; Ries, C.H. Fibroblasts Influence Survival and Therapeutic Response in a 3D Co-Culture Model. PLoS ONE 2015, 10, e0127948. [CrossRef] [PubMed]

118. Yip, D.; Cho, C.H. A multicellular 3D heterospheroid model of liver tumor and stromal cells in collagen gel for anti-cancer drug testing. Biochem. Biophys. Res. Commun. 2013, 433, 327-332. [CrossRef]

119. Liu, J.; Li, P.; Wang, L.; Li, M.; Ge, Z.; Noordam, L.; Lieshout, R.; Verstegen, M.M.; Ma, B.; Su, J.; et al. Cancer-Associated Fibroblasts Provide a Stromal Niche for Liver Cancer Organoids That Confers Trophic Effects and Therapy Resistance. Cell. Mol. Gastroenterol. Hepatol. 2021, 11, 407-431. [CrossRef] [PubMed]

120. Clark, A.K.; Taubenberger, A.; Taylor, R.; Niranjan, B.; Chea, Z.Y.; Zotenko, E.; Sieh, S.; Pedersen, J.S.; Norden, S.; Frydenberg, M.; et al. A bioengineered microenvironment to quantitatively measure the tumorigenic properties of cancerassociated fibroblasts in human prostate cancer. Biomaterials 2013, 34, 4777-4785. [CrossRef] [PubMed]

121. Liu, T.; Lin, B.; Qin, J. Carcinoma-associated fibroblasts promoted tumor spheroid invasion on a microfluidic 3D co-culture device. Lab Chip 2010, 10, 1671-1677. [CrossRef] [PubMed]

122. Xu, F.; Celli, J.; Rizvi, I.; Moon, S.; Hasan, T.; Demirci, U. A three-dimensional in vitro ovarian cancer coculture model using a high-throughput cell patterning platform. Biotechnol. J. 2011, 6, 204-212. [CrossRef] [PubMed]

123. Priwitaningrum, D.L.; Blondé, J.-B.G.; Sridhar, A.; van Baarlen, J.; Hennink, W.E.; Storm, G.; Le Gac, S.; Prakash, J. Tumor stroma-containing 3D spheroid arrays: A tool to study nanoparticle penetration. J. Control. Release 2016, 244, 257-268. [CrossRef] [PubMed]

124. Wenzel, C.; Otto, S.; Prechtl, S.; Parczyk, K.; Steigemann, P. A novel 3D high-content assay identifies compounds that prevent fibroblast invasion into tissue surrogates. Exp. Cell Res. 2015, 339, 35-43. [CrossRef]

125. Zhao, L.; Liu, Y.; Liu, Y.; Zhang, M.; Zhang, X. Microfluidic Control of Tumor and Stromal Cell Spheroids Pairing and Merging for Three-Dimensional Metastasis Study. Anal. Chem. 2020, 92, 7638-7645. [CrossRef] [PubMed] 
126. Fang, X.; Sittadjody, S.; Gyabaah, K.; Opara, E.C.; Balaji, K.C. Novel 3D Co-Culture Model for Epithelial-Stromal Cells Interaction in Prostate Cancer. PLoS ONE 2013, 8, e75187. [CrossRef]

127. Nissen, N.I.; Karsdal, M.; Willumsen, N. Collagens and Cancer associated fibroblasts in the reactive stroma and its relation to Cancer biology. J. Exp. Clin. Cancer Res. 2019, 38, 1-12. [CrossRef]

128. Rebelo, S.P.; Pinto, C.; Martins, T.R.; Harrer, N.; Estrada, M.; Loza-Alvarez, P.; Cabeçadas, J.; Alves, P.M.; Gualda, E.J.; Sommergruber, W.; et al. 3D-3-culture: A tool to unveil macrophage plasticity in the tumour microenvironment. Biomaterials 2018, 163, 185-197. [CrossRef]

129. Holliday, D.L.; Brouilette, K.T.; Markert, A.; Gordon, L.A.; Jones, J.L. Novel multicellular organotypic models of normal and malignant breast: Tools for dissecting the role of the microenvironment in breast cancer progression. Breast Cancer Res. 2009, 11, 3-11. [CrossRef]

130. Cho, J.; Lee, H.-J.; Hwang, S.J.; Min, H.-Y.; Na Kang, H.; Park, A.-Y.; Hyun, S.Y.; Sim, J.Y.; Lee, H.J.; Jang, H.-J.; et al. The interplay between slow-cycling, chemoresistant cancer cells and fibroblasts creates a proinflammatory niche for tumor progression. Cancer Res. 2020, 80, 2257-2272. [CrossRef]

131. Hwang, R.F.; Moore, T.; Arumugam, T.; Ramachandran, V.; Amos, K.D.; Rivera, A.; Ji, B.; Evans, D.B.; Logsdon, C.D. CancerAssociated Stromal Fibroblasts Promote Pancreatic Tumor Progression. Cancer Res. 2008, 68, 918-926. [CrossRef] [PubMed]

132. Shekhar, M.P.; Werdell, J.; Santner, S.J.; Pauley, R.J.; Tait, L. Breast Stroma Plays a Dominant Regulatory Role in Breast Epi-thelial Growth and Differentiation: Implications for Tumor Development and Progression. Cancer Res. 2001, 61, $1320-1326$.

133. Weigelt, B.; Lo, A.T.; Park, C.C.; Gray, J.W.; Bissell, M.J. HER2 signaling pathway activation and response of breast cancer cells to HER2-targeting agents is dependent strongly on the 3D microenvironment. Breast Cancer Res. Treat. 2009, 122, 35-43. [CrossRef] [PubMed]

134. Pickl, M.; Ries, C.H. Comparison of 3D and 2D tumor models reveals enhanced HER2 activation in 3D associated with an increased response to trastuzumab. Oncogene 2008, 28, 461-468. [CrossRef] [PubMed]

135. Ekert, J.E.; Johnson, K.; Strake, B.; Pardinas, J.; Jarantow, S.; Perkinson, R.; Colter, D.C. Three-Dimensional Lung Tumor Microenvironment Modulates Therapeutic Compound Responsiveness In Vitro-Implication for Drug Development. PLoS ONE 2014, 9, e92248. [CrossRef]

136. Choe, C.; Shin, Y.-S.; Choi, S.-J.; Lee, J.; Kim, S.Y.; Cho, Y.B.; Kim, J.; Kim, C. Crosstalk with cancer-associated fibroblasts induces resistance of non-small cell lung cancer cells to epidermal growth factor receptor tyrosine kinase inhibition. OncoTargets Ther. 2015, 8, 3665-3678. [CrossRef] [PubMed]

137. Noriega-Guerra, H.; Freitas, V.M. Extracellular Matrix Influencing HGF/c-MET Signaling Pathway: Impact on Cancer Progression. Int. J. Mol. Sci. 2018, 19, 3300. [CrossRef]

138. Rupp, C.; Dolznig, H.; Puri, C.; Schweifer, N.; Sommergruber, W.; Kraut, N.; Rettig, W.J.; Kerjaschki, D.; Garin-Chesa, P. Laser Capture Microdissection of Epithelial Cancers Guided by Antibodies Against Fibroblast Activation Protein and Endosialin. Diagn. Mol. Pathol. 2006, 15, 35-42. [CrossRef]

139. Helms, E.; Onate, M.K.; Sherman, M.H. Fibroblast Heterogeneity in the Pancreatic Tumor Microenvironment. Cancer Discov. 2020, 10, 648-656. [CrossRef]

140. Herrera, M.; Islam, A.B.; Herrera, A.; Martín, P.; García, V.; Silva, J.; Garcia, J.M.; Salas, C.; Casal, I.; De Herreros, A.G.; et al. Functional Heterogeneity of Cancer-Associated Fibroblasts from Human Colon Tumors Shows Specific Prognostic Gene Expression Signature. Clin. Cancer Res. 2013, 19, 5914-5926. [CrossRef]

141. Sebastian, A.; Hum, N.R.; Martin, K.A.; Gilmore, S.F.; Peran, I.; Byers, S.W.; Wheeler, E.K.; Coleman, M.A.; Loots, G.G. Single-Cell Transcriptomic Analysis of Tumor-Derived Fibroblasts and Normal Tissue-Resident Fibroblasts Reveals Fibroblast Heterogeneity in Breast Cancer. Cancers 2020, 12, 1307. [CrossRef]

142. Kidd, S.; Spaeth, E.; Watson, K.; Burks, J.; Lu, H.; Klopp, A.; Andreeff, M.; Marini, F.C. Origins of the Tumor Microenvironment: Quantitative Assessment of Adipose-Derived and Bone Marrow-Derived Stroma. PLoS ONE 2012, 7, e30563. [CrossRef]

143. Räsänen, K.; Vaheri, A. Activation of fibroblasts in cancer stroma. Exp. Cell Res. 2010, 316, 2713-2722. [CrossRef]

144. Bartoschek, M.; Oskolkov, N.; Bocci, M.; Lövrot, J.; Larsson, C.; Sommarin, M.; Madsen, C.D.; Lindgren, D.; Pekar, G.; Karlsson, G.; et al. Spatially and functionally distinct subclasses of breast cancer-associated fibroblasts revealed by single cell RNA sequencing. Nat. Commun. 2018, 9, 5150. [CrossRef]

145. Torres, S.; Bartolome, R.A.; Mendes, M.; Barderas, R.; Fernández-Aceñerp, M.J.; Peláez-García, A.; Peña, C.; Lopez-Lucendo, M.; Villar-Vázquez, R.; De Herreros, A.G.; et al. Proteome Profiling of Cancer-Associated Fibroblasts Identifies Novel Proinflammatory Signatures and Prognostic Markers for Colorectal Cancer. Clin. Cancer Res. 2013, 19, 6006-6019. [CrossRef]

146. González-Silva, L.; Quevedo, L.; Varela, I. Tumor Functional Heterogeneity Unraveled by scRNA-seq Technologies. Trends Cancer 2020, 6, 13-19. [CrossRef]

147. Hanahan, D.; Weinberg, R.A. Hallmarks of Cancer: The Next Generation. Cell 2011, 144, 646-674. [CrossRef]

148. Lu, J.; Ye, X.; Fan, F.; Xia, L.; Bhattacharya, R.; Bellister, S.; Tozzi, F.; Sceusi, E.; Zhou, Y.; Tachibana, I.; et al. Endothelial Cells Promote the Colorectal Cancer Stem Cell Phenotype through a Soluble Form of Jagged-1. Cancer Cell 2013, 23, 171-185. [CrossRef]

149. Hida, K.; Maishi, N.; Sakurai, Y.; Hida, Y.; Harashima, H. Heterogeneity of Tumor Endothelial Cells and Drug Delivery. Adv. Drug Deliv. Reviews. 2016, 99, 140-147. [CrossRef]

150. Aird, W.C. Endothelial Cell Heterogeneity. Cold Spring Harb. Perspect. Med. 2011, 2, a006429. [CrossRef] 
151. Gunti, S.; Hoke, A.; Vu, K.; London, N. Organoid and Spheroid Tumor Models: Techniques and Applications. Cancers 2021, 13, 874. [CrossRef]

152. Upreti, M.; Jamshidi-Parsian, A.; Koonce, N.A.; Webber, J.S.; Sharma, S.K.; Asea, A.; Mader, M.J.; Griffin, R. Tumor-Endothelial Cell Three-dimensional Spheroids: New Aspects to Enhance Radiation and Drug Therapeutics. Transl. Oncol. 2011, 4, 365-376. [CrossRef]

153. Chiew, G.G.Y.; Wei, N.; Sultania, S.; Lim, S.; Luo, K.Q. Bioengineered three-dimensional co-culture of cancer cells and endothelial cells: A model system for dual analysis of tumor growth and angiogenesis. Biotechnol. Bioeng. 2017, 114, 1865-1877. [CrossRef]

154. Shoval, H.; Karsch-Bluman, A.; Brill-Karniely, Y.; Stern, T.; Zamir, G.; Hubert, A.; Benny, O. Tumor cells and their crosstalk with endothelial cells in 3D spheroids. Sci. Rep. 2017, 7, 10428. [CrossRef]

155. Chaddad, H.; Kuchler-Bopp, S.; Fuhrmann, G.; Gegout, H.; Ubeaud-Sequier, G.; Schwinté, P.; Bornert, F.; Benkirane-Jessel, N.; Idoux-Gillet, Y. Combining 2D angiogenesis and 3D osteosarcoma microtissues to improve vascularization. Exp. Cell Res. 2017, 360, 138-145. [CrossRef] [PubMed]

156. Ingthorsson, S.; Sigurdsson, V.; Fridriksdottir, A.J.; Jonasson, J.G.; Kjartansson, J.; Magnusson, M.K.; Gudjonsson, T. Endothelial cells stimulate growth of normal and cancerous breast epithelial cells in 3D culture. BMC Res. Notes 2010, 3, 184. [CrossRef]

157. Roudsari, L.C.; Jeffs, S.E.; Witt, A.S.; Gill, B.J.; West, J.L. A 3D Poly(ethylene glycol)-based Tumor Angiogenesis Model to Study the Influence of Vascular Cells on Lung Tumor Cell Behavior. Sci. Rep. 2016, 6, 32726. [CrossRef] [PubMed]

158. Moya, M.L.; Hsu, Y.-H.; Lee, A.; Hughes, C.C.; George, S.C. In Vitro Perfused Human Capillary Networks. Tissue Eng. Part C Methods 2013, 19, 730-737. [CrossRef]

159. Aref, A.R.; Huang, Y.; Thiery, J.P.; Kamm, R.D.; Huang, R.Y.J.; Yu, W.; Chua, K.N.; Sun, W.; Tu, T.Y.; Bai, J.; et al. Screening Therapeutic EMT Blocking Agents in a Threedimensional Microenvi-ronment. Integr. Biol. 2013, 5, 381-389. [CrossRef]

160. Buchanan, C.F.; Voigt, E.E.; Szot, C.S.; Freeman, J.W.; Vlachos, P.P.; Rylander, M.N. Three-Dimensional Microfluidic Collagen Hydrogels for Investigating Flow-Mediated Tumor-Endothelial Signaling and Vascular Organization. Tissue Eng. Part C Methods 2014, 20, 64-75. [CrossRef]

161. Roudsari, L.C.; West, J.L. Studying the influence of angiogenesis in in vitro cancer model systems. Adv. Drug Deliv. Rev. 2016, 97, 250-259. [CrossRef]

162. Song, J.; Cavnar, S.P.; Walker, A.C.; Luker, K.; Gupta, M.; Tung, Y.-C.; Luker, G.D.; Takayama, S. Microfluidic Endothelium for Studying the Intravascular Adhesion of Metastatic Breast Cancer Cells. PLoS ONE 2009, 4, e5756. [CrossRef]

163. Nagaraju, S.; Truong, D.; Mouneimne, G.; Nikkhah, M. Microfluidic Tumor-Vascular Model to Study Breast Cancer Cell Invasion and Intravasation. Adv. Healthc. Mater. 2018, 7, e1701257. [CrossRef]

164. Carvalho, M.R.; Barata, D.; Teixeira, L.M.; Giselbrecht, S.; Reis, R.L.; Oliveira, J.M.; Truckenmüller, R.; Habibovic, P. Colorectal tumor-on-a-chip system: A 3D tool for precision onco-nanomedicine. Sci. Adv. 2019, 5, eaaw1317. [CrossRef]

165. Du, X.; Li, W.; Du, G.-S.; Cho, H.; Yu, M.; Fang, Q.; Lee, L.P.; Fang, J. Droplet Array-Based 3D Coculture System for HighThroughput Tumor Angiogenesis Assay. Anal. Chem. 2018, 90, 3253-3261. [CrossRef]

166. Truong, D.; Fiorelli, R.; Barrientos, E.S.; Melendez, E.L.; Sanai, N.; Mehta, S.; Nikkhah, M. A three-dimensional (3D) organotypic microfluidic model for glioma stem cells-Vascular interactions. Biomaterials 2019, 198, 63-77. [CrossRef]

167. Ko, J.; Ahn, J.; Kim, S.; Lee, Y.; Lee, J.; Park, D.; Jeon, N.L. Tumor spheroid-on-a-chip: A standardized microfluidic culture platform for investigating tumor angiogenesis. Lab Chip 2019, 19, 2822-2833. [CrossRef] [PubMed]

168. Nyga, A.; Neves, J.B.; Stamati, K.; Loizidou, M.; Emberton, M.; Cheema, U. The next level of 3D tumour models: Immunocompetence. Drug Discov. Today 2016, 21, 1421-1428. [CrossRef]

169. Gil Del Alcazar, C.R.; Huh, S.J.; Ekram, M.B.; Trinh, A.; Liu, L.L.; Beca, F.; Zi, X.; Kwak, M.; Bergholtz, H.; Su, Y.; et al. Immune Escape in Breast Cancer During In Situ to Invasive Carcinoma Transition. Cancer Discov. 2017, 7, 1098-1115. [CrossRef] [PubMed]

170. Varn, F.S.; Mullins, D.W.; Arias-Pulido, H.; Fiering, S.; Cheng, C. Adaptive immunity programmes in breast cancer. Immunology 2016, 150, 25-34. [CrossRef]

171. Jiang, X.; Wang, J.; Deng, X.; Xiong, F.; Ge, J.; Xiang, B.; Wu, X.; Ma, J.; Zhou, M.; Li, X.; et al. Role of the tumor microenvironment in PD-L1/PD-1-mediated tumor immune escape. Mol. Cancer 2019, 18, 1-17. [CrossRef]

172. Haanen, J.B. Converting Cold into Hot Tumors by Combining Immunotherapies. Cell 2017, 170, 1055-1056. [CrossRef]

173. Ribas, A.; Dummer, R.; Puzanov, I.; VanderWalde, A.; Andtbacka, R.H.I.; Michielin, O.; Olszanski, A.J.; Malvehy, J.; Cebon, J.; Fernandez, E.; et al. Oncolytic Virotherapy Promotes Intratumoral T Cell Infiltration and Improves Anti-PD-1 Immunotherapy. Cell 2017, 170, 1109-1119.e10. [CrossRef]

174. Maolake, A.; Izumi, K.; Shigehara, K.; Natsagdorj, A.; Iwamoto, H.; Kadomoto, S.; Takezawa, Y.; Machioka, K.; Narimoto, K.; Namiki, M.; et al. Tumor-associated macrophages promote prostate cancer migration through activation of the CCL22-CCR4 axis. Oncotarget 2016, 8, 9739-9751. [CrossRef]

175. Tevis, K.M.; Cecchi, R.J.; Colson, Y.L.; Grinstaff, M.W. Mimicking the tumor microenvironment to regulate macrophage phenotype and assessing chemotherapeutic efficacy in embedded cancer cell/macrophage spheroid models. Acta Biomater. 2017, 50, 271-279. [CrossRef] [PubMed]

176. Dwyer, A.; Ellies, L.G.; Holme, A.L.; Pixley, F.J. A three-dimensional co-culture system to investigate macrophage-dependent tumor cell invasion. J. Biol. Methods 2016, 3, e49. [CrossRef] [PubMed] 
177. Lee, S.W.L.; Seager, R.J.; Litvak, F.; Spill, F.; Sieow, J.L.; Leong, P.H.; Kumar, D.; Tan, A.S.M.; Wong, S.C.; Adriani, G.; et al. Integrated in silico and 3D in vitro model of macrophage migration in response to physical and chemical factors in the tumor microenvironment. Integr. Biol. 2020, 12, 90-108. [CrossRef]

178. Ayuso, J.M.; Virumbrales-Muñoz, M.; Lacueva, A.; Lanuza, P.M.; Checa-Chavarria, E.; Botella, P.; Fernandez, E.P.-A.; Doblare, M.; Allison, S.; Phillips, R.M.; et al. Development and characterization of a microfluidic model of the tumour microenvironment. Sci. Rep. 2016, 6, 36086. [CrossRef]

179. Schnalzger, T.E.; De Groot, M.H.; Zhang, C.; Mosa, M.H.; Michels, B.E.; Röder, J.; Darvishi, T.; Wels, W.S.; Farin, H.F. 3D model for CAR -mediated cytotoxicity using patient-derived colorectal cancer organoids. EMBO J. 2019, 38, e100928. [CrossRef]

180. Sherman, H.; Gitschier, H.J.; Rossi, A.E. A Novel Three-Dimensional Immune Oncology Model for High-Throughput Testing of Tumoricidal Activity. Front. Immunol. 2018, 9, 857. [CrossRef] [PubMed]

181. Giannattasio, A.; Weil, S.; Kloess, S.; Ansari, N.; Stelzer, E.H.K.; Cerwenka, A.; Steinle, A.; Koehl, U.; Koch, J. Cytotoxicity and infiltration of human NK cells in in vivo-like tumor spheroids. BMC Cancer 2015, 15, 351. [CrossRef] [PubMed]

182. Christakou, A.E.; Ohlin, M.; Önfelt, B.; Wiklund, M. Ultrasonic three-dimensional on-chip cell culture for dynamic studies of tumor immune surveillance by natural killer cells. Lab Chip 2015, 15, 3222-3231. [CrossRef]

183. Gottfried, E.; Kunz-Schughart, L.; Ebner, S.; Mueller-Klieser, W.; Hoves, S.; Andreesen, R.; Mackensen, A.; Kreutz, M. Tumorderived lactic acid modulates dendritic cell activation and antigen expression. Blood 2006, 107, 2013-2021. [CrossRef] [PubMed]

184. Parlato, S.; de Ninno, A.; Molfetta, R.; Toschi, E.; Salerno, D.; Mencattini, A.; Romagnoli, G.; Fragale, A.; Roccazzello, L.; Buoncervello, M.; et al. 3D Microfluidic model for evaluating immunotherapy efficacy by tracking dendritic cell behaviour toward tumor cells. Sci. Rep. 2017, 7, 1093. [CrossRef]

185. Dangles-Marie, V.; Richon, S.; El Behi, M.; Echchakir, H.; Dorothée, G.; Thiery, J.; Validire, P.; Vergnon, I.; Menez, J.; Ladjimi, M.; et al. A Three-Dimensional Tumor Cell Defect in Activating Autologous CTLs Is As-sociated with Inefficient Antigen Presentation Correlated with Heat Shock Protein-70 down-Regulation. Cancer Res. 2003, 63, 3682-3687. [PubMed]

186. Ghosh, S.; Rosenthal, R.; Zajac, P.; Weber, W.P.; Oertli, D.; Heberer, M.; Martin, I.; Spagnoli, G.C.; Reschner, A. Culture of Melanoma Cells in 3-Dimensional Architectures Results in Impaired Immunorecognition by Cytotoxic T Lymphocytes Specific for Melan-A/MART-1 Tumor-Associated Antigen. Ann. Surg. 2005, 242, 851-858. [CrossRef] [PubMed]

187. Alonso-Nocelo, M.; Abuín, C.; López-López, R.; De La Fuente, M.; Freire, M.D.L.F. Development and characterization of a three-dimensional co-culture model of tumor T cell infiltration. Biofabrication 2016, 8, 025002. [CrossRef] [PubMed]

188. Pavesi, A.; Tan, A.T.; Koh, S.; Chia, A.; Colombo, M.; Antonecchia, E.; Miccolis, C.; Ceccarello, E.; Adriani, G.; Raimondi, M.T.; et al. A 3D microfluidic model for preclinical evaluation of TCR-engineered T cells against solid tumors. JCI Insight 2017, 2, e89762. [CrossRef]

189. Dijkstra, K.K.; Cattaneo, C.M.; Weeber, F.; Chalabi, M.; Van De Haar, J.; Fanchi, L.F.; Slagter, M.; Van Der Velden, D.L.; Kaing, S.; Kelderman, S.; et al. Generation of Tumor-Reactive T Cells by Co-culture of Peripheral Blood Lymphocytes and Tumor Organoids. Cell 2018, 174, 1586-1598.e12. [CrossRef]

190. Bar-Ephraim, Y.; Kretzschmar, K.; Asra, P.; de Jongh, E.; Boonekamp, K.; Drost, J.; van Gorp, J.; Pronk, A.; Smakman, N.; Gan, I.; et al. Modelling Cancer Immunomodulation Using Epithelial Organoid Cultures. bioRxiv. 2018. [CrossRef]

191. Wallstabe, L.; Göttlich, C.; Nelke, L.C.; Kühnemundt, J.; Schwarz, T.; Nerreter, T.; Einsele, H.; Walles, H.; Dandekar, G.; Nietzer, S.L.; et al. ROR1-CAR T cells are effective against lung and breast cancer in advanced microphysiologic 3D tumor models. JCI Insight 2019, 4, e126345. [CrossRef] [PubMed]

192. Doumba, P.P.; Nikolopoulou, M.; Gomatos, I.P.; Konstadoulakis, M.M.; Koskinas, J. Co-culture of primary human tumor hepatocytes from patients with hepatocellular carcinoma with autologous peripheral blood mononuclear cells: Study of their in vitro immunological interactions. BMC Gastroenterol. 2013, 13, 17. [CrossRef]

193. Florczyk, S.; Liu, G.; Kievit, F.; Lewis, A.M.; Wu, J.D.; Zhang, M. 3D Porous Chitosan-Alginate Scaffolds: A New Matrix for Studying Prostate Cancer Cell-Lymphocyte Interactions In Vitro. Adv. Healthc. Mater. 2012, 1, 590-599. [CrossRef]

194. Hirschhaeuser, F.; Walenta, S.; Mueller-Klieser, W. Efficacy of catumaxomab in tumor spheroid killing is mediated by its trifunctional mode of action. Cancer Immunol. Immunother. 2010, 59, 1675-1684. [CrossRef]

195. Hoffmann, O.I.; Ilmberger, C.; Magosch, S.; Joka, M.; Jauch, K.-W.; Mayer, B. Impact of the spheroid model complexity on drug response. J. Biotechnol. 2015, 205, 14-23. [CrossRef] [PubMed]

196. Courau, T.; Bonnereau, J.; Chicoteau, J.; Bottois, H.; Remark, R.; Assante Miranda, L.; Toubert, A.; Blery, M.; Aparicio, T.; Allez, M.; et al. Cocultures of human colorectal tumor spheroids with immune cells reveal the therapeutic potential of MICA/B and NKG2A targeting for cancer treatment. J. Immunother. Cancer 2019, 7, 74. [CrossRef]

197. Augustine, T.N.; Dix-Peek, T.; Duarte, R.; Candy, G.P. Establishment of a heterotypic 3D culture system to evaluate the interaction of TREG lymphocytes and NK cells with breast cancer. J. Immunol. Methods 2015, 426, 1-13. [CrossRef] [PubMed]

198. Feder-Mengus, C.; Ghosh, S.; Weber, W.P.; Wyler, S.; Zajac, P.; Terracciano, L.; Oertli, D.; Heberer, M.; Martin, I.; Spagnoli, G.C.; et al. Multiple mechanisms underlie defective recognition of melanoma cells cultured in three-dimensional architectures by antigen-specific cytotoxic T lymphocytes. Br. J. Cancer 2007, 96, 1072-1082. [CrossRef]

199. Cohen, I.J.; Blasberg, R. Impact of the Tumor Microenvironment on Tumor-Infiltrating Lymphocytes: Focus on Breast Cancer. Breast Cancer Basic Clin. Res. 2017, 11, 1178223417731565. [CrossRef]

200. Ohashi, T.; Aoki, M.; Tomita, H.; Akazawa, T.; Sato, K.; Kuze, B.; Mizuta, K.; Hara, A.; Nagaoka, H.; Inoue, N.; et al. M2-like macrophage polarization in high lactic acid-producing head and neck cancer. Cancer Sci. 2017, 108, 1128-1134. [CrossRef] 
201. Gehring, A.; Xue, S.-A.; Ho, Z.Z.; Teoh, D.; Ruedl, C.; Chia, A.; Koh, S.; Lim, S.G.; Maini, M.; Stauss, H.; et al. Engineering virus-specific T cells that target HBV infected hepatocytes and hepatocellular carcinoma cell lines. J. Hepatol. 2011, 55, 103-110. [CrossRef]

202. Lee, S.W.L.; Adriani, G.; Ceccarello, E.; Pavesi, A.; Tan, A.T.; Bertoletti, A.; Kamm, R.D.; Wong, S.C. Characterizing the Role of Monocytes in T Cell Cancer Immunotherapy Using a 3D Microfluidic Model. Front. Immunol. 2018, 9, 416. [CrossRef]

203. Place, T.L.; Domann, F.E.; Case, A.J. Limitations of oxygen delivery to cells in culture: An underappreciated problem in basic and translational research. Free. Radic. Biol. Med. 2017, 113, 311-322. [CrossRef]

204. Nozaki, K.; Mochizuki, W.; Matsumoto, Y.; Matsumoto, T.; Fukuda, M.; Mizutani, T.; Watanabe, M.; Nakamura, T. Co-culture with intestinal epithelial organoids allows efficient expansion and motility analysis of intraepithelial lymphocytes. J. Gastroenterol. 2016, 51, 206-213. [CrossRef]

205. Rogoz, A.; Reis, B.S.; Karssemeijer, R.A.; Mucida, D. A 3-D enteroid-based model to study T-cell and epithelial cell interaction. J. Immunol. Methods 2015, 421, 89-95. [CrossRef]

206. Hirt, C.; Papadimitropoulos, A.; Mele, V.; Muraro, M.G.; Mengus, C.; Iezzi, G.; Terracciano, L.; Martin, I.; Spagnoli, G.C. “In vitro” 3D models of tumor-immune system interaction. Adv. Drug Deliv. Rev. 2014, 79-80, 145-154. [CrossRef]

207. Kang, J.-C.; Chen, J.-S.; Lee, C.-H.; Chang, J.-J.; Shieh, Y.-S. Intratumoral macrophage counts correlate with tumor progression in colorectal cancer. J. Surg. Oncol. 2010, 102, 242-248. [CrossRef] [PubMed]

208. Erreni, M.; Mantovani, A.; Allavena, P. Tumor-associated Macrophages (TAM) and Inflammation in Colorectal Cancer. Cancer Microenviron. 2011, 4, 141-154. [CrossRef] [PubMed]

209. Pinto, M.L.; Rios, E.; Durães, C.; Ribeiro, R.; Machado, J.C.; Mantovani, A.; Barbosa, M.A.; Carneiro, F.; Oliveira, M.J. The Two Faces of Tumor-Associated Macrophages and Their Clinical Significance in Colorectal Cancer. Front. Immunol. 2019, $10,1875$. [CrossRef] [PubMed]

210. Cortese, N.; Carriero, R.; Laghi, L.; Mantovani, A.; Marchesi, F. Prognostic significance of tumor-associated macrophages: Past, present and future. Semin. Immunol. 2020, 48, 101408. [CrossRef] [PubMed]

211. Azizi, E.; Carr, A.J.; Plitas, G.; Cornish, A.E.; Konopacki, C.; Prabhakaran, S.; Nainys, J.; Wu, K.; Kiseliovas, V.; Setty, M.; et al. Single-Cell Map of Diverse Immune Phenotypes in the Breast Tumor Microenvironment. Cell 2018, 174, 1293-1308.e36. [CrossRef]

212. Zhang, Q.; He, Y.; Luo, N.; Patel, S.J.; Han, Y.; Gao, R.; Modak, M.; Carotta, S.; Haslinger, C.; Kind, D.; et al. Landscape and Dynamics of Single Immune Cells in Hepatocellular Carcinoma. Cell 2019, 179, 829-845.e20. [CrossRef]

213. Johnson, E.E.; Sandgren, A.; Cherayil, B.J.; Murray, M.; Wessling-Resnick, M. Role of Ferroportin in Macrophage-Mediated Immunity. Infect. Immun. 2010, 78, 5099-5106. [CrossRef]

214. Liguori, M.; Digifico, E.; Vacchini, A.; Avigni, R.; Colombo, F.S.; Borroni, E.M.; Farina, F.M.; Milanesi, S.; Castagna, A.; Mannarino, L.; et al. The soluble glycoprotein NMB (GPNMB) produced by macrophages induces cancer stemness and metastasis via CD44 and IL-33. Cell. Mol. Immunol. 2021, 18, 711-722. [CrossRef] [PubMed]

215. Tedesco, S.; De Majo, F.; Kim, J.; Trenti, A.; Trevisi, L.; Fadini, G.P.; Bolego, C.; Zandstra, P.W.; Cignarella, A.; Vitiello, L. Convenience versus Biological Significance: Are PMA-Differentiated THP-1 Cells a Reliable Substitute for Blood-Derived Macrophages When Studying in Vitro Polarization? Front. Pharmacol. 2018, 9, 71. [CrossRef] [PubMed]

216. Bosshart, H.; Heinzelmann, M. THP-1 cells as a model for human monocytes. Ann. Transl. Med. 2016, 4, 438. [CrossRef] [PubMed]

217. Taciak, B.; Białasek, M.; Braniewska, A.; Sas, Z.; Sawicka, P.; Kiraga, Ł.; Rygiel, T.; Król, M. Evaluation of phenotypic and functional stability of RAW 264.7 cell line through serial passages. PLoS ONE 2018, 13, e0198943. [CrossRef]

218. Shiratori, H.; Feinweber, C.; Luckhardt, S.; Linke, B.; Resch, E.; Geisslinger, G.; Weigert, A.; Parnham, M.J. THP-1 and human peripheral blood mononuclear cell-derived macrophages differ in their capacity to polarize in vitro. Mol. Immunol. 2017, 88, 58-68. [CrossRef]

219. Marshall, L.A.; Marubayashi, S.; Jorapur, A.; Jacobson, S.; Zibinsky, M.; Robles, O.; Hu, D.X.; Jackson, J.J.; Pookot, D.; Sanchez, J.; et al. Tumors establish resistance to immunotherapy by regulating Treg recruitment via CCR4. J. Immunother. Cancer 2020, 8, e000764. [CrossRef]

220. Noel, G.; Baetz, N.W.; Staab, J.F.; Donowitz, M.; Kovbasnjuk, O.; Pasetti, M.F.; Zachos, N.C. A primary human macrophageenteroid co-culture model to investigate mucosal gut physiology and host-pathogen interactions. Sci. Rep. 2017, 7, 45270. [CrossRef]

221. Gregory, A.D.; Houghton, A.M. Tumor-Associated Neutrophils: New Targets for Cancer Therapy. Cancer Res. 2011, 71, 2411-2416. [CrossRef]

222. Giese, M.A.; Hind, L.E.; Huttenlocher, A. Neutrophil plasticity in the tumor microenvironment. Blood 2019, $133,2159-2167$. [CrossRef]

223. Shaul, M.E.; Fridlender, Z.G. Tumour-associated neutrophils in patients with cancer. Nat. Rev. Clin. Oncol. 2019, 16, 601-620. [CrossRef]

224. Jensen, H.K.; Donskov, F.; Marcussen, N.; Nordsmark, M.; Lundbeck, F.; von der Maase, H. Presence of Intratumoral Neutrophils Is an Independent Prognostic Factor in Localized Renal Cell Carcinoma. J. Clin. Oncol. 2009, 27, 4709-4717. [CrossRef] [PubMed]

225. Eruslanov, E.B.; Bhojnagarwala, P.S.; Quatromoni, J.G.; Stephen, T.L.; Ranganathan, A.; Deshpande, C.; Akimova, T.; Vachani, A.; Litzky, L.; Hancock, W.W.; et al. Tumor-associated neutrophils stimulate T cell responses in early-stage human lung cancer. J. Clin. Investig. 2014, 124, 5466-5480. [CrossRef] 
226. Huh, S.J.; Liang, S.; Sharma, A.; Dong, C.; Robertson, G.P. Transiently Entrapped Circulating Tumor Cells Interact with Neutrophils to Facilitate Lung Metastasis Development. Cancer Res. 2010, 70, 6071-6082. [CrossRef]

227. Granot, Z.; Henke, E.; Comen, E.A.; King, T.A.; Norton, L.; Benezra, R. Tumor entrained neutrophils inhibit seeding in the premetastatic lung. Cancer Cell 2011, 20, 300-314. [CrossRef] [PubMed]

228. Mouchemore, K.; Anderson, R.; Hamilton, J.A. Neutrophils, G-CSF and their contribution to breast cancer metastasis. FEBS J. 2018, 285, 665-679. [CrossRef]

229. Li, P.; Lu, M.; Shi, J.; Hua, L.; Gong, Z.; Li, Q.; Shultz, L.D.; Ren, G. Dual roles of neutrophils in metastatic colonization are governed by the host NK cell status. Nat. Commun. 2020, 11, 4387. [CrossRef] [PubMed]

230. Sun, B.; Qin, W.; Song, M.; Liu, L.; Yu, Y.; Qi, X.; Sun, H. Neutrophil Suppresses Tumor Cell Proliferation via Fas /Fas Ligand Pathway Mediated Cell Cycle Arrested. Int. J. Biol. Sci. 2018, 14, 2103-2113. [CrossRef] [PubMed]

231. Gonzalez, M.G.; Cichon, I.; Scislowska-Czarnecka, A.; Kolaczkowska, E. Challenges in 3D culturing of neutrophils: Assessment of cell viability. J. Immunol. Methods 2018, 457, 73-77. [CrossRef]

232. McMINN, P.H.; Hind, L.E.; Huttenlocher, A.; Beebe, D.J. Neutrophil trafficking on-a-chip: An in vitro, organotypic model for investigating neutrophil priming, extravasation, and migration with spatiotemporal control. Lab Chip 2019, 19, 3697-3705. [CrossRef] [PubMed]

233. Heydarian, M.; Schweinlin, M.; Schwarz, T.; Rawal, R.; Walles, H.; Metzger, M.; Rudel, T.; Kozjak-Pavlovic, V. Triple co-culture and perfusion bioreactor for studying the interaction between Neisseria gonorrhoeae and neutrophils: A novel 3D tissue model for bacterial infection and immunity. J. Tissue Eng. 2021, 12, 2041731420988802. [CrossRef] [PubMed]

234. Gardner, A.; Ruffell, B. Dendritic Cells and Cancer Immunity. Trends Immunol. 2016, 37, 855-865. [CrossRef] [PubMed]

235. Fong, L.; Engleman, E.G. Dendritic Cells in Cancer Immunotherapy. Annu. Rev. Immunol. 2000, 18, 245-273. [CrossRef]

236. Curiel, T.J.; Cheng, P.; Mottram, P.; Alvarez, X.; Moons, L.; Evdemon-Hogan, M.; Wei, S.; Zou, L.; Kryczek, I.; Hoyle, G.; et al. Dendritic Cell Subsets Differentially Regulate Angiogenesis in Human Ovarian Cancer. Cancer Res. 2004, 64, 5535-5538. [CrossRef]

237. Cheever, M.A.; Higano, C.S. PROVENGE (Sipuleucel-T) in Prostate Cancer: The First FDA-Approved Therapeutic Cancer Vaccine. Clin. Cancer Res. 2011, 17, 3520-3526. [CrossRef] [PubMed]

238. Bol, K.F.; Schreibelt, G.; Gerritsen, W.R.; de Vries, J.; Figdor, C.G. Dendritic Cell-Based Immunotherapy: State of the Art and Beyond. Clin. Cancer Res. 2016, 22, 1897-1906. [CrossRef]

239. Constantino, J.; Gomes, C.; Falcão, A.; Cruz, M.T.; Neves, B.M. Antitumor dendritic cell-based vaccines: Lessons from 20 years of clinical trials and future perspectives. Transl. Res. 2016, 168, 74-95. [CrossRef]

240. Sabado, R.L.; Balan, S.; Bhardwaj, N. Dendritic cell-based immunotherapy. Cell Res. 2017, 27, 74-95. [CrossRef]

241. Steponavicius-Cruz, K.; Freitas, V.M.; Barbuto, J.A.M. Dendritic Cells and T Lymphocytes Interactions in a Novel 3D System. Procedia Eng. 2013, 59, 166-173. [CrossRef]

242. Shimasaki, N.; Jain, A.; Campana, D. NK cells for cancer immunotherapy. Nat. Rev. Drug Discov. 2020, 19, 200-218. [CrossRef]

243. Guillerey, C.; Huntington, N.D.; Smyth, M. Targeting natural killer cells in cancer immunotherapy. Nat. Immunol. 2016, 17, 1025-1036. [CrossRef]

244. Ljunggren, H.-G.; Malmberg, K.-J. Prospects for the use of NK cells in immunotherapy of human cancer. Nat. Rev. Immunol. 2007, 7, 329-339. [CrossRef]

245. Waldhauer, I.; Steinle, A. NK cells and cancer immunosurveillance. Oncogene 2008, 27, 5932-5943. [CrossRef]

246. Zhang, S.; Liu, W.; Hu, B.; Wang, P.; Lv, X.; Chen, S.; Shao, Z. Prognostic Significance of Tumor-Infiltrating Natural Killer Cells in Solid Tumors: A Systematic Review and Meta-Analysis. Front. Immunol. 2020, 11, 1242. [CrossRef]

247. Takanami, I.; Takeuchi, K.; Giga, M. The prognostic value of natural killer cell infiltration in resected pulmonary adenocarcinoma. J. Thorac. Cardiovasc. Surg. 2001, 121, 1058-1063. [CrossRef] [PubMed]

248. Chen, Y.; Feng, Y.; Mao, Q.; Ma, P.; Liu, J.; Lu, W.; Liu, Y.; Chen, X.; Hu, Y.; Xue, W. Diagnostic and prognostic value of the peripheral natural killer cell levels in gastric cancer. Exp. Ther. Med. 2020, 20, 3816-3822. [CrossRef]

249. Tang, Y.-P.; Xie, M.-Z.; Li, K.-Z.; Li, J.-L.; Cai, Z.-M.; Hu, B.-L. Prognostic value of peripheral blood natural killer cells in colorectal cancer. BMC Gastroenterol. 2020, 20, 31. [CrossRef] [PubMed]

250. Osswald, A.; Hedrich, V.; Sommergruber, W. 3D-3 Tumor Models in Drug Discovery for Analysis of Immune Cell Infiltration. In Methods in Molecular Biology; Springer Science and Business Media LLC: Berlin, Germany, 2019.

251. Silva-Santos, B.; Serre, K.; Norell, H. $\gamma \delta$ T cells in cancer. Nat. Rev. Immunol. 2015, 15, 683-691. [CrossRef] [PubMed]

252. Yazdanifar, M.; Barbarito, G.; Bertaina, A.; Airoldi, I. $\gamma \delta$ T Cells: The Ideal Tool for Cancer Immunotherapy. Cells 2020, 9 , 1305. [CrossRef] [PubMed]

253. Rossi, C.; Gravelle, P.; Decaup, E.; Bordenave, J.; Poupot, M.; Tosolini, M.; Franchini, D.M.; Laurent, C.; Morin, R.; Lagarde, J.-M.; et al. Boosting $\gamma \delta \mathrm{T}$ cell-mediated antibody-dependent cellular cytotoxicity by PD-1 blockade in follicular lymphoma. OncoImmunology 2019, 8, 1554175. [CrossRef] [PubMed]

254. Bronte, V.; Brandau, S.; Chen, S.-H.; Colombo, M.P.; Frey, A.B.; Greten, T.F.; Mandruzzato, S.; Murray, P.J.; Ochoa, A.; OstrandRosenberg, S.; et al. Recommendations for myeloid-derived suppressor cell nomenclature and characterization standards. Nat. Commun. 2016, 7, 12150. [CrossRef]

255. Husain, Z.; Huang, Y.; Seth, P.; Sukhatme, V.P. Tumor-Derived Lactate Modifies Antitumor Immune Response: Effect on Myeloid-Derived Suppressor Cells and NK Cells. J. Immunol. 2013, 191, 1486-1495. [CrossRef] [PubMed] 
256. Solito, S.; Falisi, E.; Diaz-Montero, C.M.; Doni, A.; Pinton, L.; Rosato, A.; Francescato, S.; Basso, G.; Zanovello, P.; Onicescu, G.; et al. A human promyelocytic-like population is responsible for the immune suppression mediated by myeloid-derived suppressor cells. Blood 2011, 118, 2254-2265. [CrossRef] [PubMed]

257. Safarzadeh, E.; Hashemzadeh, S.; Duijf, P.H.; Mansoori, B.; Khaze, V.; Mohammadi, A.; Kazemi, T.; Yousefi, M.; Asadi, M.; Mohammadi, H.; et al. Circulating myeloid-derived suppressor cells: An independent prognostic factor in patients with breast cancer. J. Cell. Physiol. 2019, 234, 3515-3525. [CrossRef]

258. Jung, Y.; Kim, J.K.; Shiozawa, Y.; Wang, J.; Mishra, A.; Joseph, J.; Berry, J.E.; Mcgee, S.; Lee, E.; Sun, H.; et al. Recruitment of Mesenchymal Stem Cells Into Prostate Tu-mors Promotes Metastasis. Nat. Commun. 2013, 4, 1795. [CrossRef]

259. Poggi, A.; Varesano, S.; Zocchi, M.R. How to Hit Mesenchymal Stromal Cells and Make the Tumor Microenvironment Immunostimulant Rather Than Immunosuppressive. Front. Immunol. 2018, 9, 262. [CrossRef]

260. Zhu, W.; Holmes, B.; Glazer, R.I.; Zhang, L.G. 3D printed nanocomposite matrix for the study of breast cancer bone metastasis. Nanomed. Nanotechnol. Biol. Med. 2016, 12, 69-79. [CrossRef]

261. Zhou, X.; Zhu, W.; Nowicki, M.; Miao, S.; Cui, H.; Holmes, B.; Glazer, R.I.; Zhang, L.G. 3D Bioprinting a Cell-Laden Bone Matrix for Breast Cancer Metastasis Study. ACS Appl. Mater. Interfaces 2016, 8, 30017-30026. [CrossRef]

262. Bersini, S.; Jeon, J.; Dubini, G.; Arrigoni, C.; Chung, S.; Charest, J.L.; Moretti, M.; Kamm, R.D. A microfluidic 3D in vitro model for specificity of breast cancer metastasis to bone. Biomaterials 2014, 35, 2454-2461. [CrossRef]

263. Mosaad, E.; Chambers, K.; Futrega, K.; Clements, J.; Doran, M.R. Using high throughput microtissue culture to study the difference in prostate cancer cell behavior and drug response in 2D and 3D co-cultures. BMC Cancer 2018, 18, 592. [CrossRef]

264. Liu, C.; Liu, Y.; Xu, X.-X.; Guo, X.; Sun, G.-W.; Ma, X.-J. Mesenchymal stem cells enhance the metastasis of 3D-cultured hepatocellular carcinoma cells. BMC Cancer 2016, 16, 566. [CrossRef] [PubMed]

265. Chao, K.-C.; Yang, H.-T.; Chen, M.-W. Human umbilical cord mesenchymal stem cells suppress breast cancer tumourigenesis through direct cell-cell contact and internalization. J. Cell. Mol. Med. 2012, 16, 1803-1815. [CrossRef] [PubMed]

266. Rossignoli, F.; Spano, C.; Grisendi, G.; Foppiani, E.M.; Golinelli, G.; Mastrolia, I.; Bestagno, M.; Candini, O.; Petrachi, T.; Recchia, A.; et al. MSC-Delivered Soluble TRAIL and Paclitaxel as Novel Combinatory Treatment for Pancreatic Adenocarcinoma. Theranostics 2019, 9, 436-448. [CrossRef]

267. Silva, M.; Monteiro, G.A.; Fialho, A.; Bernardes, N.; Da Silva, C.L. Conditioned Medium From Azurin-Expressing Human Mesenchymal Stromal Cells Demonstrates Antitumor Activity Against Breast and Lung Cancer Cell Lines. Front. Cell Dev. Biol. 2020, 8, 471. [CrossRef] [PubMed]

268. Ham, J.; Lever, L.; Fox, M.; Reagan, M.R. In Vitro 3D Cultures to Reproduce the Bone Marrow Niche. JBMR Plus 2019,3 , e10228. [CrossRef]

269. Görgün, G.; Calabrese, E.; Soydan, E.; Hideshima, T.; Perrone, G.; Bandi, M.; Cirstea, D.; Santo, L.; Hu, Y.; Tai, Y.-T.; et al. Immunomodulatory effects of lenalidomide and pomalidomide on interaction of tumor and bone marrow accessory cells in multiple myeloma. Blood 2010, 116, 3227-3237. [CrossRef] [PubMed]

270. Purroy, N.; Abrisqueta, P.; Carabia, J.; Carpio, C.; Palacio, C.; Bosch, F.; Crespo, M. Co-culture of primary CLL cells with bone marrow mesenchymal cells, CD40 ligand and CpG ODN promotes proliferation of chemoresistant CLL cells phenotypically comparable to those proliferating in vivo. Oncotarget 2014, 6, 7632-7643. [CrossRef]

271. Raic, A.; Naolou, T.; Mohra, A.; Chatterjee, C.; Lee-Thedieck, C. 3D models of the bone marrow in health and disease: Yesterday, today, and tomorrow. MRS Commun. 2019, 9, 37-52. [CrossRef]

272. de la Puente, P.; Muz, B.; Gilson, R.; Azab, F.; Luderer, M.; King, J.; Achilefu, S.; Vij, R.; Azab, A.K. 3D tissue-engineered bone marrow as a novel model to study pathophysiology and drug resistance in multiple myeloma. Biomaterials 2015, 73, 70-84. [CrossRef]

273. Aljitawi, O.S.; Li, D.; Xiao, Y.; Zhang, D.; Ramachandran, K.; Stehno-Bittel, L.; Van Veldhuizen, P.; Lin, T.; Kambhampati, S.; Garimella, R. A novel three-dimensional stromal-based model forin vitrochemotherapy sensitivity testing of leukemia cells. Leuk. Lymphoma 2014, 55, 378-391. [CrossRef] [PubMed]

274. Shen, Z.-H.; Zeng, D.-F.; Wang, X.-Y.; Ma, Y.-Y.; Zhang, X.; Kong, P.-Y. Targeting of the leukemia microenvironment by c(RGDfV) overcomes the resistance to chemotherapy in acute myeloid leukemia in biomimetic polystyrene scaffolds. Oncol. Lett. 2016, 12, 3278-3284. [CrossRef]

275. Corrêa, L.H.; Corrêa, R.; Farinasso, C.M.; Dourado, L.P.D.S.; Magalhães, K.G. Adipocytes and Macrophages Interplay in the Orchestration of Tumor Microenvironment: New Implications in Cancer Progression. Front. Immunol. 2017, 8, 1129. [CrossRef] [PubMed]

276. Spencer, M.; Yao-Borengasser, A.; Unal, R.; Rasouli, N.; Gurley, C.M.; Zhu, B.; Peterson, C.A.; Kern, P.A. Adipose tissue macrophages in insulin-resistant subjects are associated with collagen VI and fibrosis and demonstrate alternative activation. Am. J. Physiol. Metab. 2010, 299, E1016-E1027. [CrossRef]

277. Yue, X.; Nguyen, T.D.; Zellmer, V.; Zhang, S.; Zorlutuna, P. Stromal cell-laden 3D hydrogel microwell arrays as tumor microenvironment model for studying stiffness dependent stromal cell-cancer interactions. Biomaterials 2018, 170, 37-48. [CrossRef] [PubMed]

278. Cao, Y. Angiogenesis and Vascular Functions in Modulation of Obesity, Adipose Metabolism, and Insulin Sensitivity. Cell Metab. 2013, 18, 478-489. [CrossRef] [PubMed] 
279. Mason, B.N.; Starchenko, A.; Williams, R.; Bonassar, L.J.; Reinhart-King, C.A. Tuning three-dimensional collagen matrix stiffness independently of collagen concentration modulates endothelial cell behavior. Acta Biomater. 2013, 9, 4635-4644. [CrossRef] [PubMed]

280. Agarwal, P.; Wang, H.; Sun, M.; Xu, J.; Zhao, S.; Liu, Z.; Gooch, K.J.; Zhao, Y.; Lu, X.; He, X. Microfluidics Enabled Bottom-Up Engineering of 3D Vascularized Tumor for Drug Discovery. ACS Nano 2017, 11, 6691-6702. [CrossRef] [PubMed]

281. Herroon, M.K.; Diedrich, J.D.; Podgorski, I. New 3D-Culture Approaches to Study Interactions of Bone Marrow Adipocytes with Metastatic Prostate Cancer Cells. Front. Endocrinol. 2016, 7, 84. [CrossRef]

282. Devarasetty, M.; Skardal, A.; Cowdrick, K.; Marini, F.; Soker, S. Bioengineered Submucosal Organoids for In Vitro Modeling of Colorectal Cancer. Tissue Eng. Part A 2017, 23, 1026-1041. [CrossRef]

283. Drifka, C.R.; Loeffler, A.G.; Mathewson, K.; Keikhosravi, A.; Eickhoff, J.C.; Liu, Y.; Weber, S.M.; Kao, W.J.; Eliceiri, K.W. Highly aligned stromal collagen is a negative prognostic factor following pancreatic ductal adenocarcinoma resection. Oncotarget 2016, 7, 76197-76213. [CrossRef] [PubMed]

284. Pietras, K.; Östman, A. Hallmarks of cancer: Interactions with the tumor stroma. Exp. Cell Res. 2010, 316, 1324-1331. [CrossRef] [PubMed]

285. McMillin, D.W.; Negri, J.M.; Mitsiades, C.S. The role of tumour-stromal interactions in modifying drug response: Challenges and opportunities. Nat. Rev. Drug Discov. 2013, 12, 217-228. [CrossRef]

286. Mao, Y.; Keller, E.T.; Garfield, D.H.; Shen, K.; Wang, J. Stromal cells in tumor microenvironment and breast cancer. Cancer Metastasis Rev. 2013, 32, 303-315. [CrossRef] [PubMed]

287. Barnas, J.L.; Simpson-Abelson, M.R.; Yokota, S.J.; Kelleher, R.J.; Bankert, R.B. T Cells and Stromal Fibroblasts in Human Tumor Microenvironments Represent Potential Therapeutic Targets. Cancer Microenviron. 2010, 3, 29-47. [CrossRef]

288. Tang, D.; Yuan, Z.; Xue, X.; Lu, Z.; Zhang, Y.; Wang, H.; Chen, M.; An, Y.; Wei, J.; Zhu, Y.; et al. High expression of Galectin-1 in pancreatic stellate cells plays a role in the development and maintenance of an immunosuppressive microenvironment in pancreatic cancer. Int. J. Cancer 2011, 130, 2337-2348. [CrossRef]

289. Barnas, J.L.; Simpson-Abelson, M.R.; Brooks, S.P.; Kelleher, R.J.; Bankert, R.B.; Kelleher, R.J., Jr. Reciprocal Functional Modulation of the Activation of T Lymphocytes and Fibroblasts Derived from Human Solid Tumors. J. Immunol. 2010, 185, 2681-2692. [CrossRef] [PubMed]

290. Buckanovich, R.J.; Facciabene, A.; Kim, S.; Benencia, F.; Sasaroli, D.; Balint, K.; Katsaros, D.; O’Brien-Jenkins, A.; Gimotty, P.A.; Coukos, G. Endothelin B receptor mediates the endothelial barrier to T cell homing to tumors and disables immune therapy. Nat. Med. 2008, 14, 28-36. [CrossRef]

291. Griffioen, A.W.; Damen, C.A.; Martinotti, S.; Blijham, G.H.; Groenewegen, G. Endothelial intercellular adhesion molecule-1 expression is suppressed in human malignancies: The role of angiogenic factors. Cancer Res. 1996, 56, $1111-1117$.

292. Tang, N.; Gao, J.; Wang, S.; Ye, N.; Chong, Y.; Huang, Y.; Wang, J.; Li, B.; Yin, W.; Wang, D. Cancer-associated fibroblasts promote angiogenesis in gastric cancer through galectin-1 expression. Tumor Biol. 2016, 37, 1889-1899. [CrossRef]

293. De Francesco, E.M.; Lappano, R.; Santolla, M.F.; Marsico, S.; Caruso, A.; Maggiolini, M. HIF-1 $\alpha /$ GPER signaling mediates the expression of VEGF induced by hypoxia in breast cancer associated fibroblasts (CAFs). Breast Cancer Res. 2013, 15, R64. [CrossRef]

294. Leung, C.S.; Yeung, T.-L.; Yip, K.-P.; Wong, K.-K.; Ho, S.Y.; Mangala, L.S.; Sood, A.K.; Lopez-Berestein, G.; Sheng, J.; Wong, S.T.; et al. Cancer-associated fibroblasts regulate endothelial adhesion protein LPP to promote ovarian cancer chemoresistance. J. Clin. Investig. 2017, 128, 589-606. [CrossRef] [PubMed]

295. Esposito, I.; Menicagli, M.; Funel, N.; Bergmann, F.; Boggi, U.; Mosca, F.; Bevilacqua, G.; Campani, D. Inflammatory cells contribute to the generation of an angiogenic phenotype in pancreatic ductal adenocarcinoma. J. Clin. Pathol. 2004, 57, 630-636. [CrossRef]

296. Shrimali, R.K.; Yu, Z.; Theoret, M.R.; Chinnasamy, D.; Restifo, N.P.; Rosenberg, S.A. Antiangiogenic Agents Can Increase Lymphocyte Infiltration into Tumor and Enhance the Effectiveness of Adoptive Immunotherapy of Cancer. Cancer Res. 2010, 70, 6171-6180. [CrossRef] [PubMed]

297. Huang, Y.; Kim, B.Y.S.; Chan, C.K.; Hahn, S.M.; Weissman, I.L.; Jiang, W. Improving immune-vascular crosstalk for cancer immunotherapy. Nat. Rev. Immunol. 2018, 18, 195-203. [CrossRef]

298. Gabrusiewicz, K.; Liu, D.; Cortes-Santiago, N.; Hossain, M.B.; Conrad, C.A.; Aldape, K.D.; Fuller, G.; Marini, F.C.; Alonso, M.; Idoate-Gastearena, M.-A.; et al. Anti-vascular endothelial growth factor therapy-induced glioma invasion is associated with accumulation of Tie2-expressing monocytes. Oncotarget 2014, 5, 2208-2220. [CrossRef] [PubMed]

299. Peranzoni, E.; Lemoine, J.; Vimeux, L.; Feuillet, V.; Barrin, S.; Kantari-Mimoun, C.; Bercovici, N.; Guérin, M.; Biton, J.; Ouakrim, H.; et al. Macrophages impede CD8 T cells from reaching tumor cells and limit the efficacy of anti-PD-1 treatment. Proc. Natl. Acad. Sci. USA 2018, 115, E4041-E4050. [CrossRef]

300. Butowski, N.; Colman, H.; De Groot, J.F.; Omuro, A.M.; Nayak, L.; Wen, P.Y.; Cloughesy, T.F.; Marimuthu, A.; Haidar, S.; Perry, A.; et al. Orally administered colony stimulating factor 1 receptor inhibitor PLX3397 in recurrent glioblastoma: An Ivy Foundation Early Phase Clinical Trials Consortium phase II study. Neuro-Oncology 2015, 18, 557-564. [CrossRef]

301. Kumar, V.; Donthireddy, L.; Marvel, D.; Condamine, T.; Wang, F.; Lavilla-Alonso, S.; Hashimoto, A.; Vonteddu, P.; Behera, R.; Goins, M.A.; et al. Cancer-Associated Fibroblasts Neutralize the Anti-tumor Effect of CSF1 Receptor Blockade by Inducing PMN-MDSC Infiltration of Tumors. Cancer Cell 2017, 32, 654-668.e5. [CrossRef] 
302. Cannarile, M.A.; Weisser, M.; Jacob, W.; Jegg, A.-M.; Ries, C.H.; Rüttinger, D. Colony-stimulating factor 1 receptor (CSF1R) inhibitors in cancer therapy. J. Immunother. Cancer 2017, 5, 53. [CrossRef]

303. Ehsan, S.M.; Welch-Reardon, K.M.; Waterman, M.L.; Hughes, C.C.W.; George, S.C. A three-dimensional in vitro model of tumor cell intravasation. Integr. Biol. 2014, 6, 603-610. [CrossRef]

304. Pape, J.; Magdeldin, T.; Stamati, K.; Nyga, A.; Loizidou, M.; Emberton, M.; Cheema, U. Cancer-associated fibroblasts mediate cancer progression and remodel the tumouroid stroma. Br. J. Cancer 2020, 123, 1178-1190. [CrossRef] [PubMed]

305. Lee, S.W.; Kwak, H.S.; Kang, M.-H.; Park, Y.-Y.; Jeong, G.S. Fibroblast-associated tumour microenvironment induces vascular structure-networked tumouroid. Sci. Rep. 2018, 8, 2365. [CrossRef] [PubMed]

306. Franchi-Mendes, T.; Lopes, N.; Brito, C. Heterotypic Tumor Spheroids in Agitation-Based Cultures: A Scaffold-Free Cell Model That Sustains Long-Term Survival of Endothelial Cells. Front. Bioeng. Biotechnol. 2021, 9, 447. [CrossRef] [PubMed]

307. Liu, X.-Q.; Kiefl, R.; Roskopf, C.; Tian, F.; Huber, R.M. Interactions among Lung Cancer Cells, Fibroblasts, and Macrophages in 3D Co-Cultures and the Impact on MMP-1 and VEGF Expression. PLoS ONE 2016, 11, e0156268. [CrossRef]

308. Linde, N.; Gutschalk, C.M.; Hoffmann, C.; Yilmaz, D.; Mueller, M.M. Integrating Macrophages into Organotypic Co-Cultures: A 3D In Vitro Model to Study Tumor-Associated Macrophages. PLoS ONE 2012, 7, e40058. [CrossRef]

309. Xu, Z.; Li, E.; Guo, Z.; Yu, R.; Hao, H.; Xu, Y.; Sun, Z.; Li, X.; Lyu, J.; Wang, Q. Design and Construction of a Multi-Organ Microfluidic Chip Mimicking the in vivo Microenvironment of Lung Cancer Metastasis. ACS Appl. Mater. Interfaces 2016, 8 , 25840-25847. [CrossRef]

310. Teixeira, F.C.; Chaves, S.; Torres, A.L.; Barrias, C.C.; Bidarra, S.J. Engineering a Vascularized 3D Hybrid System to Model Tumor-Stroma Interactions in Breast Cancer. Front. Bioeng. Biotechnol. 2021, 9, 166. [CrossRef]

311. Kwak, T.J.; Lee, E. In vitro modeling of solid tumor interactions with perfused blood vessels. Sci. Rep. 2020, 10, 20142. [CrossRef]

312. Rausch, M.; Blanc, L.; Silva, O.D.S.; Dormond, O.; Griffioen, A.; Nowak-Sliwinska, P. Characterization of Renal Cell Carcinoma Heterotypic 3D Co-Cultures with Immune Cell Subsets. Cancers 2021, 13, 2551. [CrossRef]

313. Qiao, S.; Zhao, Y.; Tian, H.; Manike, I.; Ma, L.; Yan, H.; Tian, W. 3D Co-cultured Endothelial Cells and Monocytes Promoted Cancer Stem Cells' Stemness and Malignancy. ACS Appl. Bio Mater. 2021, 4, 441-450. [CrossRef]

314. Campisi, M.; Sundararaman, S.K.; Shelton, S.E.; Knelson, E.H.; Mahadevan, N.R.; Yoshida, R.; Tani, T.; Ivanova, E.; Cañadas, I.; Osaki, T.; et al. Tumor-Derived cGAMP Regulates Activation of the Vasculature. Front. Immunol. 2020, 11, 2090. [CrossRef]

315. Nashimoto, Y.; Okada, R.; Hanada, S.; Arima, Y.; Nishiyama, K.; Miura, T.; Yokokawa, R. Vascularized cancer on a chip: The effect of perfusion on growth and drug delivery of tumor spheroid. Biomaterials 2020, 229, 119547. [CrossRef]

316. Kim, H.; Chung, H.; Kim, J.; Choi, D.; Shin, Y.; Kang, Y.G.; Kim, B.; Seo, S.; Chung, S.; Seok, S.H. Macrophages-Triggered Sequential Remodeling of Endothelium-Interstitial Matrix to Form Pre-Metastatic Niche in Microfluidic Tumor Microenvironment. Adv. Sci. 2019, 6, 1900195. [CrossRef] [PubMed]

317. Cui, X.; Morales, R.-T.T.; Qian, W.; Wang, H.; Gagner, J.-P.; Dolgalev, I.; Placantonakis, D.; Zagzag, D.; Cimmino, L.; Snuderl, M.; et al. Hacking macrophage-associated immunosuppression for regulating glioblastoma angiogenesis. Biomaterials 2018, 161, 164-178. [CrossRef] [PubMed]

318. Yamazoe, H.; Hagihara, Y.; Kobayashi, H. Multicomponent Coculture System of Cancer Cells and Two Types of Stromal Cells for In Vitro Evaluation of Anticancer Drugs. Tissue Eng. Part C Methods 2016, 22, 20-29. [CrossRef] [PubMed]

319. Liu, P.-F.; Cao, Y.-W.; Zhang, S.-D.; Zhao, Y.; Liu, X.-G.; Shi, H.-Q.; Hu, K.-Y.; Zhu, G.-Q.; Ma, B.; Niu, H.-T. A bladder cancer microenvironment simulation system based on a microfluidic co-culture model. Oncotarget 2015, 6, 37695-37705. [CrossRef] [PubMed]

320. Sobrino, A.; Phan, D.T.T.; Datta, R.; Wang, X.; Hachey, S.J.; Romero-López, M.; Gratton, E.; Lee, A.P.; George, S.C.; Hughes, C.C.W. 3D microtumors in vitro supported by perfused vascular networks. Sci. Rep. 2016, 6, 31589. [CrossRef]

321. Zoetemelk, M.; Rausch, M.; Colin, D.J.; Dormond, O.; Nowak-Sliwinska, P. Short-term 3D culture systems of various complexity for treatment optimization of colorectal carcinoma. Sci. Rep. 2019, 9, 7103. [CrossRef]

322. Magdeldin, T.; López-Dávila, V.; Pape, J.; Cameron, G.W.W.; Emberton, M.; Loizidou, M.; Cheema, U. Engineering a vascularised 3D in vitro model of cancer progression. Sci. Rep. 2017, 7, 44045. [CrossRef] [PubMed]

323. Aung, A.; Kumar, V.; Theprungsirikul, J.; Davey, S.K.; Varghese, S. An Engineered Tumor-on-a-Chip Device with Breast Cancer-Immune Cell Interactions for Assessing T-cell Recruitment. Cancer Res. 2020, 80, 263-275. [CrossRef] [PubMed]

324. Nii, T.; Kuwahara, T.; Makino, K.; Tabata, P.Y. A Co-Culture System of Three-Dimensional Tumor-Associated Macrophages and Three-Dimensional Cancer-Associated Fibroblasts Combined with Biomolecule Release for Cancer Cell Migration. Tissue Eng. Part A 2020, 26, 1272-1282. [CrossRef]

325. Rama-Esendagli, D.; Esendagli, G.; Yilmaz, G.; Guc, D. Spheroid formation and invasion capacity are differentially influenced by co-cultures of fibroblast and macrophage cells in breast cancer. Mol. Biol. Rep. 2014, 41, 2885-2892. [CrossRef] [PubMed]

326. Kuen, J.; Darowski, D.; Kluge, T.; Majety, M. Pancreatic cancer cell/fibroblast co-culture induces M2 like macrophages that influence therapeutic response in a 3D model. PLoS ONE 2017, 12, e0182039. [CrossRef] [PubMed]

327. Nguyen, M.; De Ninno, A.; Mencattini, A.; Mermet-Meillon, F.; Fornabaio, G.; Evans, S.S.; Cossutta, M.; Khira, Y.; Han, W.; Sirven, P.; et al. Dissecting Effects of Anti-cancer Drugs and Cancer-Associated Fibroblasts by On-Chip Reconstitution of Immunocompetent Tumor Microenvironments. Cell Rep. 2018, 25, 3884-3893.e3. [CrossRef] [PubMed]

328. Donovan, D.; Brown, N.; Bishop, E.; Lewis, C. Comparison of three in vitro human 'angiogenesis' assays with capillaries formed in vivo. Angiogenesis 2001, 4, 113-121. [CrossRef] 
329. Amann, A.; Zwierzina, M.; Koeck, S.; Gamerith, G.; Pechriggl, E.; Huber, J.M.; Lorenz, E.; Kelm, J.M.; Hilbe, W.; Zwierzina, H.; et al. Development of a 3D angiogenesis model to study tumour-Endothelial cell interactions and the effects of anti-angiogenic drugs. Sci. Rep. 2017, 7, 2963. [CrossRef]

330. Lamichhane, S.P.; Arya, N.; Kohler, E.; Xiang, S.; Christensen, J.; Shastri, V.P. Recapitulating epithelial tumor microenvironment in vitro using three dimensional tri-culture of human epithelial, endothelial, and mesenchymal cells. BMC Cancer 2016, 16, 581. [CrossRef] [PubMed]

331. Weinberg, F.; Ramnath, N.; Nagrath, D. Reactive Oxygen Species in the Tumor Microenvironment: An Overview. Cancers 2019, 11, 1191. [CrossRef]

332. Bray, L.J.; Binner, M.; Körner, Y.; Von Bonin, M.; Bornhäuser, M.; Werner, C. A three-dimensional ex vivo tri-culture model mimics cell-cell interactions between acute myeloid leukemia and the vascular niche. Haematologica 2017, 102, 1215-1226. [CrossRef]

333. Bray, L.J.; Binner, M.; Holzheu, A.; Friedrichs, J.; Freudenberg, U.; Hutmacher, D.W.; Werner, C. Multi-parametric hydrogels support 3D in vitro bioengineered microenvironment models of tumour angiogenesis. Biomaterials 2015, 53, 609-620. [CrossRef]

334. Rogers, M.; Sobolik, T.; Schaffer, D.K.; Samson, P.C.; Johnson, A.C.; Owens, P.; Codreanu, S.G.; Sherrod, S.D.; McLean, J.A.; Wikswo, J.P.; et al. Engineered microfluidic bioreactor for examining the three-dimensional breast tumor microenvironment. Biomicrofluidics 2018, 12, 034102. [CrossRef] [PubMed]

335. Herrera-Perez, R.M.; Voytik-Harbin, S.L.; Sarkaria, J.N.; Pollok, K.E.; Fishel, M.; Rickus, J.L. Presence of stromal cells in a bioengineered tumor microenvironment alters glioblastoma migration and response to STAT3 inhibition. PLoS ONE 2018, 13, e0194183. [CrossRef]

336. Kessenbrock, K.; Wang, C.-Y.; Werb, Z. Matrix metalloproteinases in stem cell regulation and cancer. Matrix Biol. 2015, 44-46, 184-190. [CrossRef] [PubMed]

337. Carmeliet, P. VEGF as a Key Mediator of Angiogenesis in Cancer. Oncology 2005, 69, 4-10. [CrossRef] [PubMed]

338. De Biasi, A.R.; Villena-Vargas, J.; Adusumilli, P.S. Cisplatin-Induced Antitumor Immunomodulation: A Review of Preclinical and Clinical Evidence. Clin. Cancer Res. 2014, 20, 5384-5391. [CrossRef]

339. Laoui, D.; Van Overmeire, E.; De Baetselier, P.; Van Ginderachter, J.; Raes, G. Functional Relationship between Tumor-Associated Macrophages and Macrophage Colony-Stimulating Factor as Contributors to Cancer Progression. Front. Immunol. $2014,5,489$. [CrossRef] [PubMed]

340. Baleia, P. 8th International conference on Tumor Microenvironment, Lisbon, Portugal June 10-14, 2018. Cancer Microenviron. 2018, 11 (Suppl. S1), 1-91. [CrossRef] [PubMed]

341. Saraiva, D.P.; Matias, A.T.; Braga, S.; Jacinto, A.; Cabral, M.G. Establishment of a 3D Co-culture With MDA-MB-231 Breast Cancer Cell Line and Patient-Derived Immune Cells for Application in the Development of Immunotherapies. Front. Oncol. 2020, 10, 1543. [CrossRef]

342. Koeck, S.; Kern, J.; Zwierzina, M.; Gamerith, G.; Lorenz, E.; Sopper, S.; Zwierzina, H.; Amann, A. The influence of stromal cells and tumor-microenvironment-derived cytokines and chemokines on CD3+CD8+ tumor infiltrating lymphocyte subpopulations. OncoImmunology 2017, 6, e1323617. [CrossRef]

343. Herter, S.; Morra, L.; Schlenker, R.; Sulcova, J.; Fahrni, L.; Waldhauer, I.; Lehmann, S.; Reisländer, T.; Agarkova, I.; Kelm, J.M.; et al. A novel three-dimensional heterotypic spheroid model for the assessment of the activity of cancer immunotherapy agents. Cancer Immunol. Immunother. 2017, 66, 129-140. [CrossRef] [PubMed]

344. Kuang, D.-M.; Zhao, Q.; Peng, C.; Xu, J.; Zhang, J.-P.; Wu, C.; Zheng, L. Activated monocytes in peritumoral stroma of hepatocellular carcinoma foster immune privilege and disease progression through PD-L1. J. Exp. Med. 2009, 206, 1327-1337. [CrossRef]

345. Mpekris, F.; Voutouri, C.; Baish, J.W.; Duda, D.G.; Munn, L.L.; Stylianopoulos, T.; Jain, R.K. Combining microenvironment normalization strategies to improve cancer immunotherapy. Proc. Natl. Acad. Sci. USA 2020, 117, 3728-3737. [CrossRef]

346. Fukumura, D.; Kloepper, J.; Amoozgar, Z.; Duda, D.G.; Jain, R.K. Enhancing cancer immunotherapy using antiangiogenics: Opportunities and challenges. Nat. Rev. Clin. Oncol. 2018, 15, 325-340. [CrossRef]

347. Tang, M.; Xie, Q.; Gimple, R.C.; Zhong, Z.; Tam, T.; Tian, J.; Kidwell, R.L.; Wu, Q.; Prager, B.C.; Qiu, Z.; et al. Three-dimensional bioprinted glioblastoma microenvironments model cellular dependencies and immune interactions. Cell Res. 2020, 30, 833-853. [CrossRef]

348. Neufeld, L.; Yeini, E.; Reisman, N.; Shtilerman, Y.; Ben-Shushan, D.; Pozzi, S.; Madi, A.; Tiram, G.; Eldar-Boock, A.; Ferber, S.; et al. Microengineered perfusable 3D-bioprinted glioblastoma model for in vivo mimicry of tumor microenvironment. Sci. Adv. 2021, 7, eabi9119. [CrossRef] [PubMed]

349. Qiao, H.; Tang, T. Engineering 3D approaches to model the dynamic microenvironments of cancer bone metastasis. Bone Res. 2018, 6, 3. [CrossRef]

350. Jeon, J.S.; Bersini, S.; Gilardi, M.; Dubini, G.; Charest, J.L.; Moretti, M.; Kamm, R.D. Human 3D vascularized organotypic microfluidic assays to study breast cancer cell extravasation. Proc. Natl. Acad. Sci. USA 2015, 112, 214-219. [CrossRef]

351. Carvalho, M.; Lima, D.; Reis, R.L.; Correlo, V.M.; Oliveira, J.M. Evaluating Biomaterial- and Microfluidic-Based 3D Tumor Models. Trends Biotechnol. 2015, 33, 667-678. [CrossRef] [PubMed]

352. Gu, L.; Mooney, D.J. Biomaterials and emerging anticancer therapeutics: Engineering the microenvironment. Nat. Rev. Cancer 2016, 16, 56-66. [CrossRef] 
353. Qiao, S.-P.; Zhao, Y.-F.; Li, C.-F.; Yin, Y.-B.; Meng, Q.-Y.; Lin, F.-H.; Liu, Y.; Hou, X.-L.; Guo, K.; Chen, X.-b.; et al. An alginate-based platform for cancer stem cell research. Acta Biomater. 2016, 37, 83-92. [CrossRef]

354. Amorim, S.; Da Costa, D.S.; Pashkuleva, I.; Reis, C.A.; Reis, R.L.; Pires, R.A. 3D hydrogel mimics of the tumor microenvironment: The interplay among hyaluronic acid, stem cells and cancer cells. Biomater. Sci. 2021, 9, 252-260. [CrossRef]

355. Egeblad, M.; Rasch, M.G.; Weaver, V.M. Dynamic interplay between the collagen scaffold and tumor evolution. Curr. Opin. Cell Biol. 2010, 22, 697-706. [CrossRef] [PubMed]

356. Benton, G.; Kleinman, H.K.; George, J.; Arnaoutova, I. Multiple uses of basement membrane-like matrix (BME/Matrigel) in vitro and in vivo with cancer cells. Int. J. Cancer 2011, 128, 1751-1757. [CrossRef] [PubMed]

357. Tsao, C.-T.; Kievit, F.M.; Wang, K.; Erickson, A.E.; Ellenbogen, R.G.; Zhang, M. Chitosan-Based Thermoreversible Hydrogel as an in Vitro Tumor Microenvironment for Testing Breast Cancer Therapies. Mol. Pharm. 2014, 11, 2134-2142. [CrossRef] [PubMed]

358. Cavo, M.; Fato, M.M.; Peñuela, L.; Beltrame, F.; Raiteri, R.; Scaglione, S. Microenvironment complexity and matrix stiffness regulate breast cancer cell activity in a 3D in vitro model. Sci. Rep. 2016, 6, 35367. [CrossRef] [PubMed]

359. Paszek, M.J.; Zahir, N.; Johnson, K.R.; Lakins, J.N.; Rozenberg, G.I.; Gefen, A.; Reinhart-King, C.; Margulies, S.S.; Dembo, M.; Boettiger, D.; et al. Tensional homeostasis and the malignant phenotype. Cancer Cell 2005, 8, 241-254. [CrossRef]

360. Rice, A.J.; Cortes, E.; Lachowski, D.; Cheung, B.C.H.; Karim, S.A.; Morton, J.; Hernández, A.D.R. Matrix stiffness induces epithelial-mesenchymal transition and promotes chemoresistance in pancreatic cancer cells. Oncogenesis 2017, 6, e352. [CrossRef]

361. Hofer, M.; Lutolf, M.P. Engineering organoids. Nat. Rev. Mater. 2021, 6, 402-420. [CrossRef]

362. Luecken, M.D.; Theis, F.J. Current best practices in single-cell RNA-seq analysis: A tutorial. Mol. Syst. Biol. 2019, 15, e8746. [CrossRef] [PubMed]

363. Wu, H.; Zhu, J.; Huang, Y.; Wu, D.; Sun, J. Microfluidic-Based Single-Cell Study: Current Status and Future Perspective. Molecules 2018, 23, 2347. [CrossRef] [PubMed]

364. Vargo-Gogola, T.; Rosen, J.M. Modelling breast cancer: One size does not fit all. Nat. Rev. Cancer 2007, 7, 659-672. [CrossRef]

365. Holliday, D.L.; Speirs, V. Choosing the right cell line for breast cancer research. Breast Cancer Res. 2011, 13, 215. [CrossRef] [PubMed]

366. Prasad, V.V.; Gopalan, R.O. Continued use of MDA-MB-435, a melanoma cell line, as a model for human breast cancer, even in year, 2014. NPJ Breast Cancer 2015, 1, 15002. [CrossRef]

367. Pauli, C.; Hopkins, B.D.; Prandi, D.; Shaw, R.; Fedrizzi, T.; Sboner, A.; Sailer, V.; Augello, M.; Puca, L.; Rosati, R.; et al. Personalized In Vitro and In Vivo Cancer Models to Guide Precision Medicine. Cancer Discov. 2017, 7, 462-477. [CrossRef]

368. Weeber, F.; Ooft, S.; Dijkstra, K.; Voest, E.E. Tumor Organoids as a Pre-clinical Cancer Model for Drug Discovery. Cell Chem. Biol. 2017, 24, 1092-1100. [CrossRef]

369. Neal, J.T.; Kuo, C.J. Organoids as Models for Neoplastic Transformation. Annu. Rev. Pathol. Mech. Dis. 2016, 11, 199-220. [CrossRef]

370. Wörsdörfer, P.; Dalda, N.; Kern, A.; Krüger, S.; Wagner, N.; Kwok, C.K.; Henke, E.; Ergün, S. Generation of complex human organoid models including vascular networks by incorporation of mesodermal progenitor cells. Sci. Rep. 2019, 9, 15663. [CrossRef] [PubMed]

371. Fong, E.L.; Wan, X.; Yang, J.; Morgado, M.; Mikos, A.G.; Harrington, D.A.; Navone, N.M.; Farach-Carson, M.C. A 3D in vitro model of patient-derived prostate cancer xenograft for controlled interrogation of in vivo tumor-stromal interactions. Biomaterials 2016, 77, 164-172. [CrossRef]

372. Majumder, B.; Baraneedharan, U.; Thiyagarajan, S.; Radhakrishnan, P.; Narasimhan, H.; Dhandapani, M.; Brijwani, N.; Pinto, D.D.; Prasath, A.; Shanthappa, B.U.; et al. Predicting clinical response to anticancer drugs using an ex vivo platform that captures tumour heterogeneity. Nat. Commun. 2015, 6, 6169. [CrossRef]

373. Muraro, M.G.; Muenst, S.; Mele, V.; Quagliata, L.; Iezzi, G.; Tzankov, A.; Weber, W.P.; Spagnoli, G.C.; Soysal, S.D. Ex-vivo assessment of drug response on breast cancer primary tissue with preserved microenvironments. OncoImmunology 2017, 6, e1331798. [CrossRef]

374. Jeppesen, M.; Hagel, G.; Glenthoj, A.; Vainer, B.; Ibsen, P.; Harling, H.; Thastrup, O.; Jorgensen, L.N.; Thastrup, J. Short-term spheroid culture of primary colorectal cancer cells as an in vitro model for personalizing cancer medicine. PLoS ONE 2017, 12, e0183074. [CrossRef] [PubMed]

375. Liao, D.; Johnson, R.S. Hypoxia: A key regulator of angiogenesis in cancer. Cancer Metastasis Rev. 2007, 26, 281-290. [CrossRef] [PubMed]

376. Park, J.E.; Tan, H.S.; Datta, A.; Lai, R.C.; Zhang, H.; Meng, W.; Lim, S.K.; Sze, S.K. Hypoxic Tumor Cell Modulates Its Microenvironment to Enhance Angiogenic and Metastatic Potential by Secretion of Proteins and Exosomes. Mol. Cell. Proteom. 2010, 9, 1085-1099. [CrossRef] [PubMed]

377. Laoui, D.; Van Overmeire, E.; Di Conza, G.; Aldeni, C.; Keirsse, J.; Morias, Y.; Movahedi, K.; Houbracken, I.; Schouppe, E.; Elkrim, Y.; et al. Tumor Hypoxia Does Not Drive Differentiation of Tumor-Associated Macrophages but Rather Fine-Tunes the M2-like Macrophage Population. Cancer Res. 2014, 74, 24-30. [CrossRef]

378. Onozuka, H.; Tsuchihara, K.; Esumi, H. Hypoglycemic/hypoxic condition in vitro mimicking the tumor microenvironment markedly reduced the efficacy of anticancer drugs. Cancer Sci. 2011, 102, 975-982. [CrossRef]

379. Fischer, K.; Hoffmann, P.; Voelkl, S.; Meidenbauer, N.; Ammer, J.; Edinger, M.; Gottfried, E.; Schwarz, S.; Rothe, G.; Hoves, S.; et al. Inhibitory effect of tumor cell-derived lactic acid on human T cells. Blood 2007, 109, 3812-3819. [CrossRef] 
380. Goetze, K.; Walenta, S.; Ksiazkiewicz, M.; Kunz-Schughart, L.; Mueller-Klieser, W. Lactate enhances motility of tumor cells and inhibits monocyte migration and cytokine release. Int. J. Oncol. 2011, 39, 453-463. [CrossRef]

381. Radhakrishnan, J.; Varadaraj, S.; Dash, S.K.; Sharma, A.; Verma, R.S. Organotypic cancer tissue models for drug screening: 3D constructs, bioprinting and microfluidic chips. Drug Discov. Today 2020, 25, 879-890. [CrossRef]

382. Miller, C.P.; Shin, W.; Ahn, E.H.; Kim, H.J.; Kim, D.-H. Engineering Microphysiological Immune System Responses on Chips. Trends Biotechnol. 2020, 38, 857-872. [CrossRef] [PubMed]

383. Perego, P.; On behalf of the EORTC PAMM Group; Hempel, G.; Linder, S.; Bradshaw, T.D.; Larsen, A.K.; Peters, G.J.; Phillips, R.M. Cellular pharmacology studies of anticancer agents: Recommendations from the EORTC-PAMM group. Cancer Chemother. Pharmacol. 2018, 81, 427-441. [CrossRef] [PubMed]

384. Wennerberg, K. Cancer Cell Drug Response Transcriptomes in 3D. Cell Chem. Biol. 2016, 23, 1323-1324. [CrossRef] [PubMed]

385. Langhans, S.A. Three-Dimensional in Vitro Cell Culture Models in Drug Discovery and Drug Repositioning. Front. Pharmacol. 2018, 9, 6. [CrossRef] [PubMed]

386. Sampson, J.H.; Gunn, M.D.; Fecci, P.E.; Ashley, D.M. Brain immunology and immunotherapy in brain tumours. Nat. Rev. Cancer 2020, 20, 12-25. [CrossRef]

387. Ma, S.; Li, X.; Wang, X.; Cheng, L.; Li, Z.; Zhang, C.; Ye, Z.; Qian, Q. Current Progress in CAR-T Cell Therapy for Solid Tumors. Int. J. Biol. Sci. 2019, 15, 2548-2560. [CrossRef]

388. Salmon, H.; Franciszkiewicz, K.; Damotte, D.; Dieu-Nosjean, M.-C.; Validire, P.; Trautmann, A.; Mami-Chouaib, F.; Donnadieu, E. Matrix architecture defines the preferential localization and migration of T cells into the stroma of human lung tumors. J. Clin. Investig. 2012, 122, 899-910. [CrossRef] [PubMed]

389. Kuczek, D.E.; Larsen, A.M.H.; Thorseth, M.-L.; Carretta, M.; Kalvisa, A.; Siersbæk, M.S.; Simões, A.M.C.; Roslind, A.; Engelholm, L.H.; Noessner, E.; et al. Collagen density regulates the activity of tumor-infiltrating T cells. J. Immunother. Cancer $2019,7,68$. [CrossRef]

390. Carragher, N.; Piccinini, F.; Tesei, A.; Trask Jr, O.J.; Bickle, M.; Horvath, P. Concerns, challenges and promises of high-content analysis of 3D cellular models. Nat. Rev. Drug Discov. 2018, 17, 606. [CrossRef] [PubMed] 